\title{
Transition Metal Catalyzed Azidation Reactions
}

\author{
Roberto Sala $₫$, Camilla Loro $₫$, Francesca Foschi $₫$ and Gianluigi Broggini * \\ Dipartimento di Scienza e Alta Tecnologia, Università degli Studi dell'Insubria, Via Valleggio 9, \\ 22100 Como, Italy; rsala@uninsubria.it (R.S.); cloro@uninsubria.it (C.L.); francesca.foschi@uninsubria.it (F.F.) \\ * Correspondence: gianluigi.broggini@uninsubria.it
}

Received: 17 September 2020; Accepted: 11 October 2020; Published: 12 October 2020

\begin{abstract}
A wide range of methodologies for the preparation of organic azides has been reported in the literature for many decades, due to their interest as building blocks for different transformations and their applications in biology as well as in materials science. More recently, with the spread of the use of transition metal-catalyzed reactions, new perspectives have also materialized in azidation processes, especially concerning the azidation of $\mathrm{C}-\mathrm{H}$ bonds and direct difunctionalization of multiple carbon-carbon bonds. In this review, special emphasis will be placed on reactions involving substrates bearing a leaving group, hydroazidation reactions and azidation reactions that proceed with the formation of more than one bond. Further reactions for the preparation of allyl and vinyl azides as well as for azidations involving the opening of a ring complete the classification of the material.
\end{abstract}

Keywords: azide; transition metal catalysis; C-H functionalization; difunctionalization reactions; hydroazidation; homogeneous catalysis

\section{Introduction}

Organic azides show a multifaceted interest in various scientific fields such as chemistry, medicinal chemistry, biology, and material science. In organic synthesis, the azido group is a precursor of amines, amides, or imines and often found application as key functional group in heterocyclic chemistry and peptide chemistry [1,2]. Its crucial role in a variety of reactions such as isocyanate or azo-compounds synthesis, Staudinger reduction, or C-H bond amination has long been known [3-6]. Azides can lose dinitrogen providing electron-deficient nitrenes, which are intermediates in various reactions and whose reactivity can be controlled by coordination with transition metal catalysts [7]. An example is given by the aziridination of olefins usually catalyzed by copper, rhodium, ruthenium, iron, or silver complexes, which is the methodology of choice for the preparation of this nitrogen-containing heterocycles [8,9]. The azides are exploited in heterocyclic synthesis as 1,3-dipoles with alkynes, alkenes, and nitriles in [3+2] dipolar cycloadditions to easily obtain 1,2,3-triazole and tetrazole derivatives, also according to the principle of the "click chemistry" [10-14].

Relatively stable azides are an important structural part of pharmaceuticals endowed with anti-inflammatory [15] and anti-myeloma [16] activities. The azido functional group is used in biological chemistry to investigate the cellular metabolism of synthetic azidosugars [17], among which the azido nucleoside AZT is a well-known example of anti-HIV drug [18,19]. Moreover, biologically active peptides bearing azide moieties have been prepared under Mitsunobu conditions [20].

Because of the wide interest for the azido group, there is an ongoing need for the development of synthetic protocols to access organoazides avoiding the use of hazardous reagents or reaction conditions. In principle, azides are accessible through a large number of methodologies [21,22], most of which, however, are not applicable on a large scale for safety problems related, above all, to the high energy of the reagents or reaction intermediates. Aryl azides are usually prepared following classic procedures of the aromatic chemistry (i.e., using diazonium compounds [23-27] or by nucleophilic 
aromatic substitution [28-30]), whereas nucleophilic substitution of the azide ion on alkyl halides is the method of choice to access aliphatic azides [31-33]. Typically, the drawbacks of these procedures lie both in the need for pre-functionalized starting materials and in the formation of hazardous waste.

Great improvements in the synthesis of organic azides have been achieved with the development of procedures based on the direct $\mathrm{C}-\mathrm{H}$ functionalization [34-36]. Synthetic approaches based on the functionalization of ubiquitous and easily available $\mathrm{C}-\mathrm{H}$ bonds have proven to be highly efficient for the preparation of many organic compounds. Both carbon-carbon and carbon-heteroatom bonds are achievable by avoiding the synthetic steps necessary for the pre-functionalization of the starting materials, considerably reducing the amount of waste materials [37-46]. The interest toward these strategies has grown with the development of transition metal studies in organic synthesis since their use in catalytic quantities is often essential to promote reactions of this type.

This review focuses on the new transition metal catalyzed procedures to install the azido group on organic reagent, highlighting applicability, substrate scopes, and mechanisms of the reaction conditions. The reactions have been organized on the basis of the type of procedures involved to access the azide compounds. The first two sections deal with reactions that use substrates bearing a leaving group or that occur on $\mathrm{C}-\mathrm{H}$ bonds. Different types of reactions that occur with the formation of more than one bond have been grouped according to the combination of the generated bonds. Procedures to perform allylic azide, hydroazidation processes, and azidations involving ring opening complete the review.

\section{Azidation of Substrates Bearing a Leaving Group}

In the perspective of azidation reactions, nucleophilic substitution of good leaving groups with azido anion is a valid methodology for the preparation of azido compounds. This approach can be facilitated by transition metals, allowing the use of unconventional leaving groups.

Palladium catalysis was found to be efficient to prepare azido derivatives from substrates having -OR as leaving groups. The first $\mathrm{Pd}(0)$-catalyzed azidation to convert allyl acetates and phosphates 1 into the corresponding allyl azides was developed by Taniguchi and co-workers in 1986. As shown in Scheme 1, this synthetic protocol is based on the use of $\mathrm{Pd}\left(\mathrm{PPh}_{3}\right)_{4}$ as the catalyst and $\mathrm{NaN}_{3}$ as the azide source. These conditions were applied to a wide range of allyl derivatives for the selective synthesis of allyl azides, as a way to access allylamines $[47,48]$. The plausible mechanism started with the oxidative addition of the substrate to $\mathrm{Pd}(0)$-species, which gave the ( $\pi$-allyl)-complex intermediate I-1. The latter reacted with the azide ion, allowed to obtain the azide-substituted product after inversion of configuration.

The reactivity of allyl phosphates was proven to be greater than for acetates. It is worth noting the behavior of the (Z)-4-acetoxy-2-buten-1-yl diethyl phosphate 2, which provides a variety of differently substituted allyl azides through an amination or alkylation/azidation sequence (Scheme 2). After few years, Salaün and co-workers reported a similar procedure for the azidation of 1-alkenylcyclopropyl esters to give alkenylcyclopropyl azides as intermediates to achieve cyclopropylaminoacids [49].

In 1990, the Sinou's group reported an alternative method for azidation of allyl esters using trimethylsilyl azide (TMS-N 3 ) as the nucleophile source (Scheme 3) [50]. The reaction requires anhydrous conditions and undergoes different $\operatorname{Pd}(0)$-catalysts on different substrates in good yields. Also, in this case, the mechanism of the reaction involves a ( $\pi$-allyl)-complex, which in turn reacts with the azide ion as previously shown in Scheme 1. 


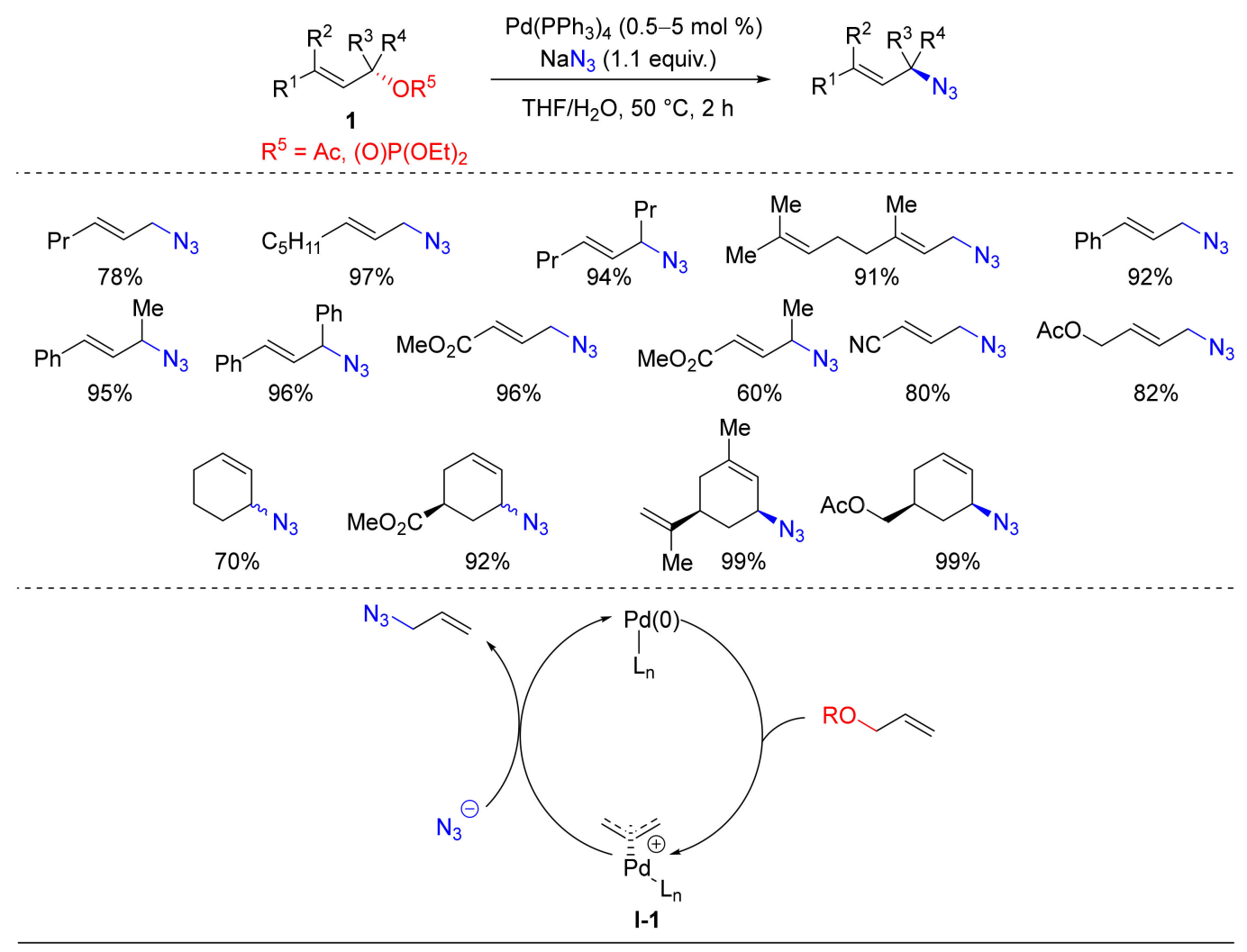

Scheme 1. $\operatorname{Pd}(0)$-catalyzed azidation.

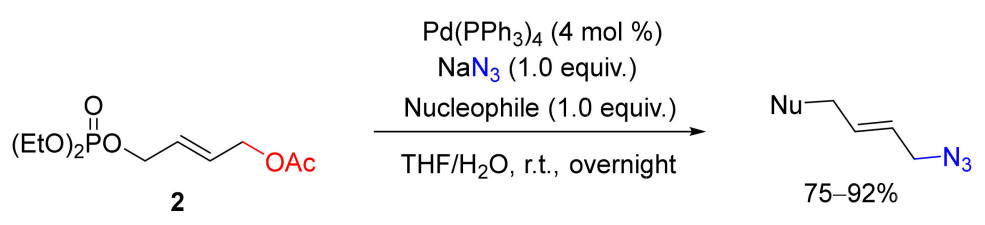

Nucleophiles:
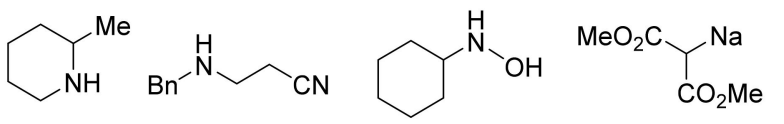

${ }_{\mathrm{CO}_{2} \mathrm{Me}}^{\mathrm{PhO}_{2} \mathrm{~S}} \stackrel{\mathrm{Na}}{\mathrm{Na}} \mathrm{\textrm {CO } _ { 2 } \mathrm { Et }}$

Scheme 2. $\operatorname{Pd}(0)$-catalyzed azidation of allyl phosphates.

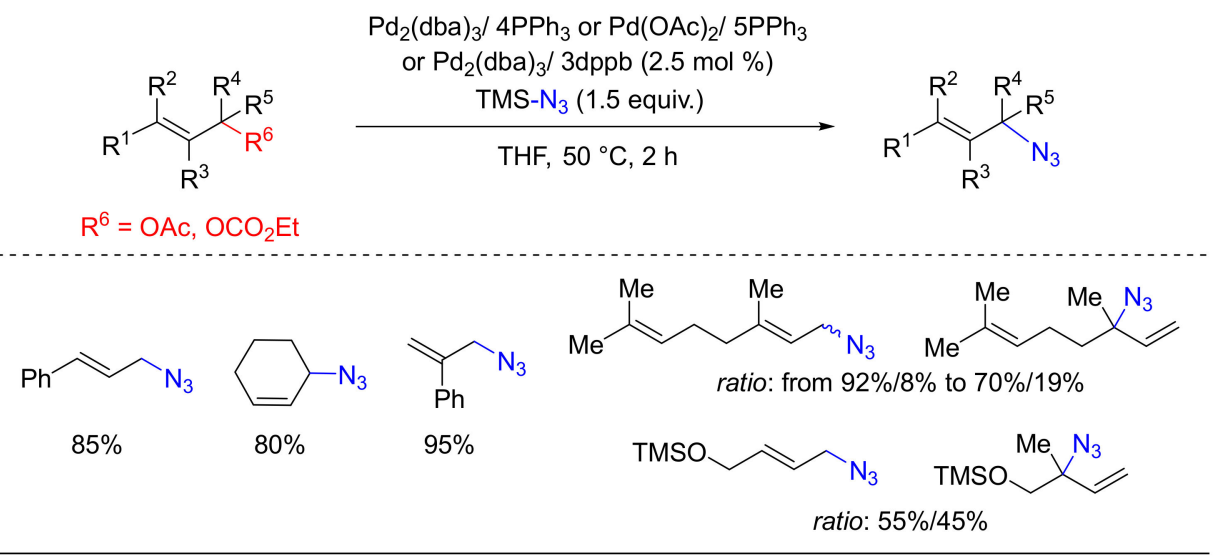

Scheme 3. Azidation of allyl compounds under anhydrous conditions. 
A stereoselective azidation was used by Pulley and Trost in 1995 as one of the key-step in the total synthesis of the (+)-pancratistatin (Scheme 4) [51]. The $\pi$-allylpalladium chloride combined with the $(1 R, 2 R)-N, N^{\prime}$-bis[2-(diphenylphosphino)benzyl]cyclohexane-1,2-diamine (4) allowed the desymmetrization of the dicarbonate 3 to form the desired product with satisfactory ee.

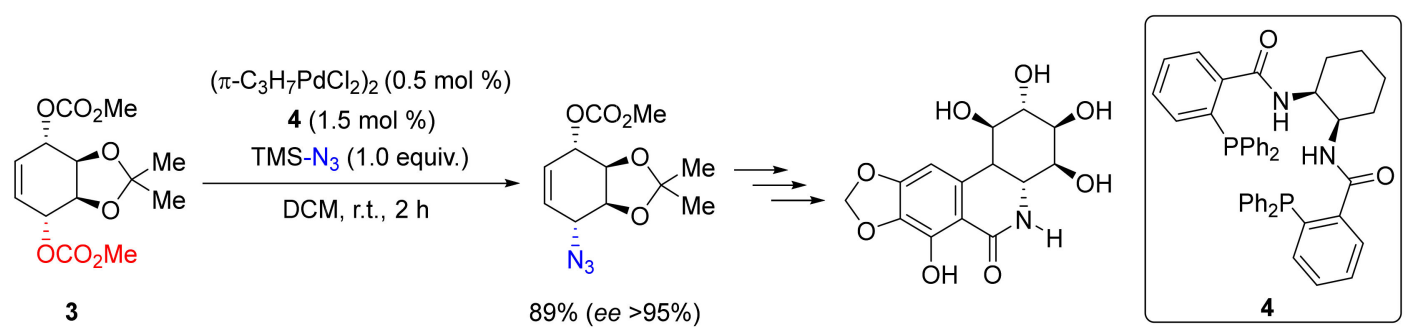

Scheme 4. First step of the total synthesis of (+)-pancratistatin.

In 2012, Uria and co-workers reported the direct azidation of the allyl alcohols $\mathbf{5}$ as a route for the preparation of allyl azides [52]. The displacement of the $\mathrm{OH}$ group with $\mathrm{N}_{3}$ was realized in good yields employing AgOTf as the catalyst and TMS- $\mathrm{N}_{3}$ as the azide source at room temperature (Scheme 5). The regioselectivity of the reaction in term of $E / Z$ isomers is over 20:1. Authors suggest that the in situ formation of triflic acid generated from the $[\mathrm{Ag}]^{+}$counterion plays as a determinant path to warrant a Brønsted acid catalysis.<smiles>[R]C([R])=C([R])C(O)C([R])[R]</smiles>

$$
\begin{aligned}
\mathrm{R}^{1}= & \mathrm{H}, \mathrm{Me}, \mathrm{Et}, \mathrm{Ph} \\
\mathrm{R}^{2}= & \mathrm{Ph}, 2-\mathrm{Me}-\mathrm{C}_{6} \mathrm{H}_{4}, 4-\mathrm{Me}-\mathrm{C}_{6} \mathrm{H}_{4}, 4-\mathrm{F}_{-} \mathrm{C}_{6} \mathrm{H}_{4} \text {, anthranyl } \\
& \text { 2-Ac-5-Br-C } \mathrm{C}_{6}, 2-\mathrm{Ac}-4,5-\mathrm{Cl}_{-} \mathrm{C}_{6} \mathrm{H}_{2}, \text { cinnamyl } \\
\mathrm{R}^{3}= & \mathrm{H}, \mathrm{Ph}, \text { cyclohexenyl } \\
\mathrm{R}^{4}= & \mathrm{H}, \mathrm{Me} \\
\mathrm{R}^{5}= & \mathrm{H}, \mathrm{Me}, i-\mathrm{Pr}, \mathrm{Ph}
\end{aligned}
$$

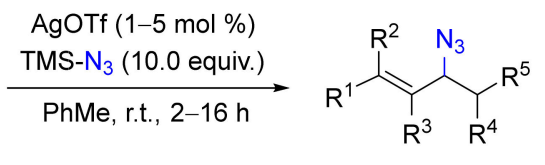

24 examples $42-96 \%$ $E / Z:>20: 1$

Scheme 5. Silver catalyzed azidation of allyl alcohols.

The azidation process by substitution of unconventional leaving groups can be achieved working in the presence of iron catalysts.

In 2011, Kim and co-workers published a Fe(III)-catalyzed azidation of benzylic acetates using of TMS-N $\mathrm{N}_{3}$ as source (Scheme 6) [53]. A co-catalytic amount of AgOTf used in combination with $\mathrm{FeCl}_{3}$ increases the speed of the reaction. Studies carried out by the authors provide evidence of the in situ formation of $\mathrm{Fe}(\mathrm{OTf})_{3}$ as the active species for the catalytic process.

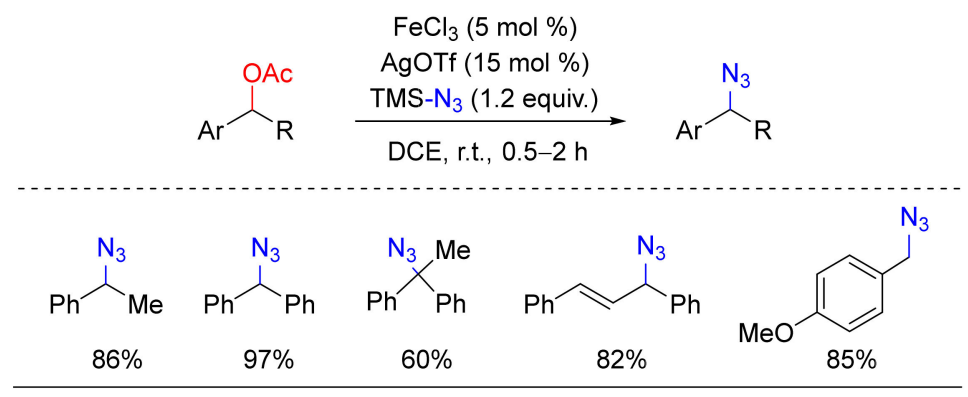

Scheme 6. Azidation via nucleophilic substitution of benzylic acetates. 
The couple $\mathrm{FeCl}_{3} / \mathrm{TMS}-\mathrm{N}_{3}$ has been successfully used also for the azido glycosylation of glycosyl peracetates to afford 1,2-trans glycosyl azides as single isomers [54]. When copper powder was added to the reaction, 1,3-dipolar cycloadditions of azido glycosides with terminal alkynes were proven to be feasible.

An analogous strategy based on the use of Fe(III) salts for the direct formation of benzyl azides was proposed by Sawama and Sajiki in two separate articles. In the first one, azidation of the benzylic silyl ethers 6 was realized employing either $\mathrm{FeCl}_{3}$ or $\mathrm{FeBr}_{3}$ as Lewis acid [55]. As reported in the left side of Scheme 7, a possible reaction mechanism is based on the formation of the trimeric adduct I-7 arising from 6, the catalyst, and the azide source. (TMS) ${ }_{2} \mathrm{O}$ is eliminated from I-7 with generation of ionic species II-7, which evolves to form the final product 7.

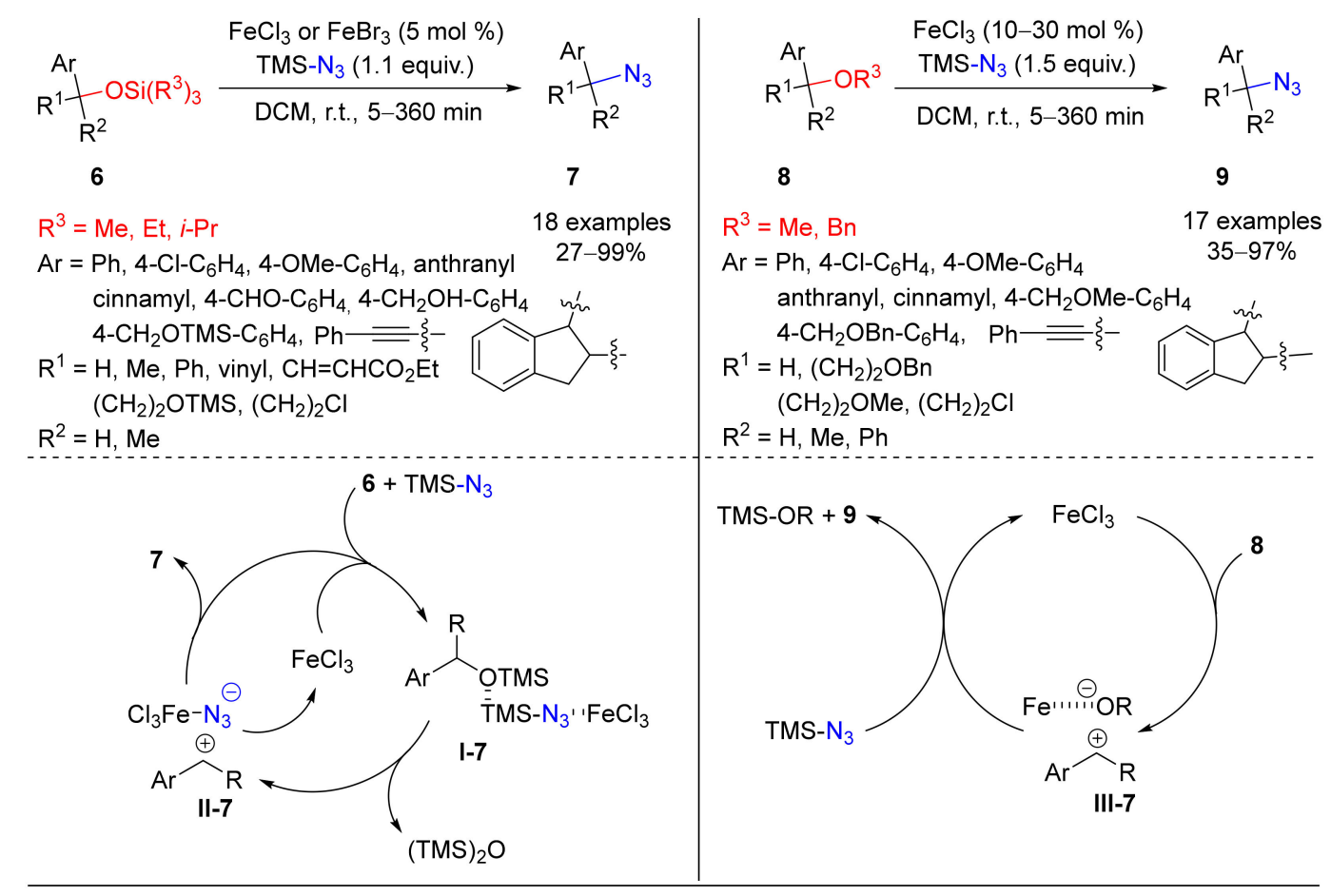

Scheme 7. Silyl ethers as leaving groups for the iron catalyzed azidation of benzylic carbon.

On the other hand, the same methodology was proven to be valuable also for the azidation of ethyl benzyl ethers or unsymmetrical dibenzyl and cinnamyl ethers 8 (Scheme 7 right side) [56]. The advantages concern about the minor number of synthetic steps, avoiding protection/deprotection reactions. In this case, the catalytic cycle starts from the interaction between the Lewis acid $\mathrm{FeCl}_{3}$ and the alkoxy group, with formation of the carbocationic intermediate III-7. The subsequent nucleophilic addition of the azide ion gives rise to the final product 9.

In the perspective of the selective $\mathrm{C}-\mathrm{N}_{3}$ bond formation, decarboxylative azidation is an emerging strategy for the high stability and easy handling of carboxylic acids. Recently, this strategy has been applied for the preparation of alkyl azides using silver salts with $\mathrm{K}_{2} \mathrm{~S}_{2} \mathrm{O}_{8}$ as oxidizing agent. Li's group applied this strategy for the preparation of alkyl azides from primary, secondary, or tertiary carboxylic acids with $\mathrm{TsN}_{3}$ or 3-PySO${ }_{2} \mathrm{~N}_{3}$ as possible azide sources (Scheme 8) [57]. The mechanism proposed by authors is based on a radical decarboxylation step, promoted by a $\mathrm{Ag}$ (II) intermediate, in turn generated by in situ oxidation of $\mathrm{AgNO}_{3}$. The unstable radical species thus formed immediately reacts with the nucleophile source providing the final azido product. 


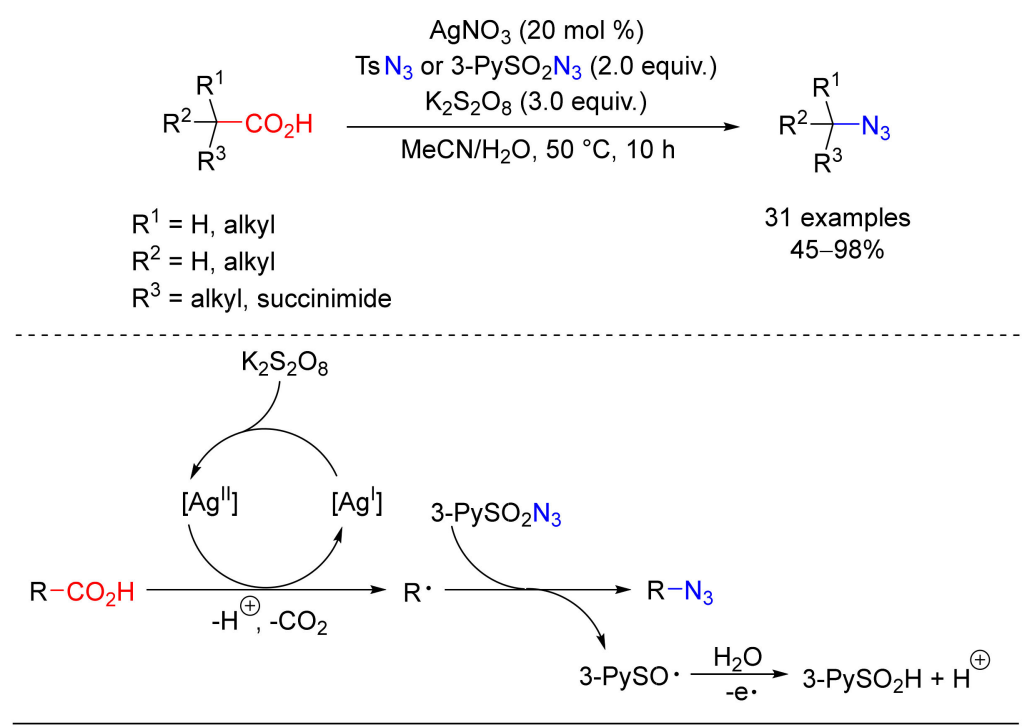

Scheme 8. Radical decarboxylation for alkyl azides synthesis.

Jiao, Song, and co-workers confirmed and improved the theory of Li group about silver catalyzed radical decarboxylation [58]. From the synthetic point of view, the azidation process was carried out in the presence of $\mathrm{AgF}$ and $\mathrm{PhSO}_{2} \mathrm{~N}_{3}$, as shown in Scheme 9. Density Functional Theory (DFT) computational studies agree with the initial oxidation of $\mathrm{AgF}$ to an $\mathrm{Ag}$ (II)-species by $\mathrm{K}_{2} \mathrm{~S}_{2} \mathrm{O}_{8}$ to give an alkyl radical that reacts with $\mathrm{PhSO}_{2} \mathrm{~N}_{3}$ to provide the intermediate I-9, which finally evolves to the final product.

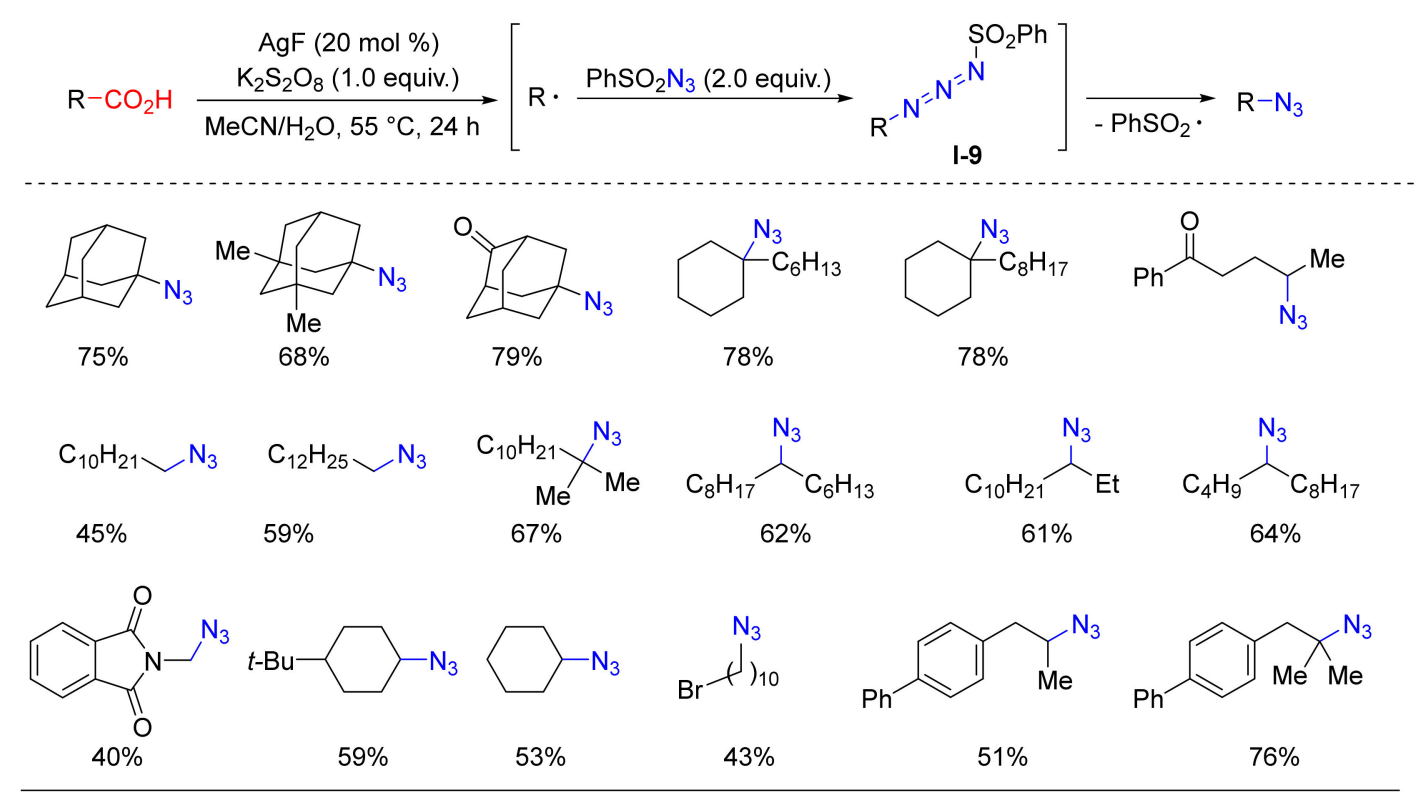

Scheme 9. Synthesis of aliphatic azides via radical dercarboxylative process.

A direct azidation using $\mathrm{Cu}(\mathrm{OTf})_{2}$ as the catalyst and $\mathrm{TMS}-\mathrm{N}_{3}$ as the azide source was reported by Kumar and co-workers as a mild route to convert benzylic alcohols into the corresponding azides (Scheme 10) [59]. 


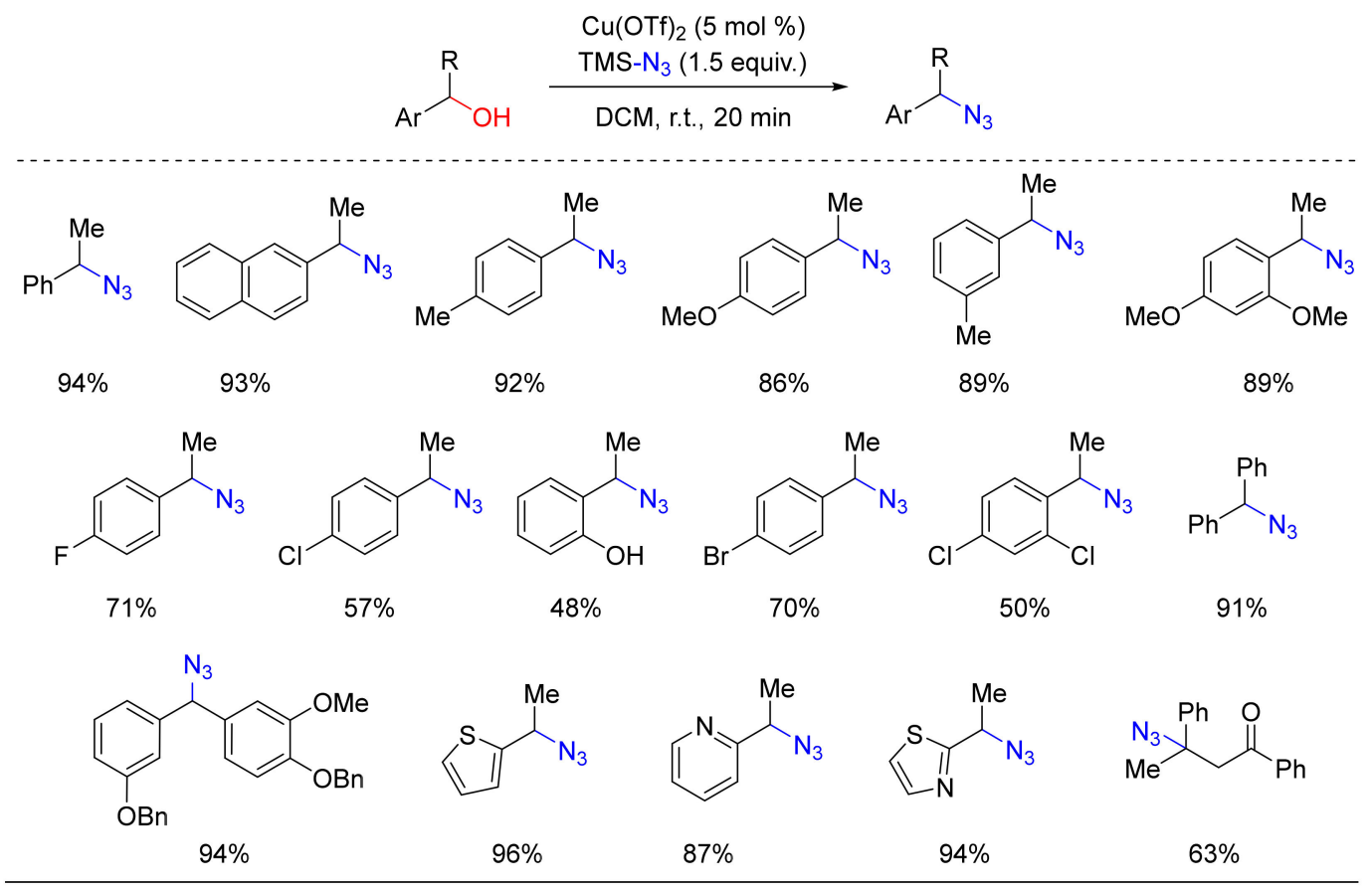

Scheme 10. Copper catalyzed conversion of benzyl alcohols into the corresponding azides.

Copper catalysis was largely employed for azidation of $\mathrm{C}\left(s p^{2}\right)$ atoms. One of the first examples was reported by Zhu and Ma via copper catalyzed coupling of aryl or vinyl iodides or bromides and $\mathrm{NaN}_{3}$ (Scheme 11) [60]. The reaction was realized with CuI salt as catalyst and L-proline as the ligand.

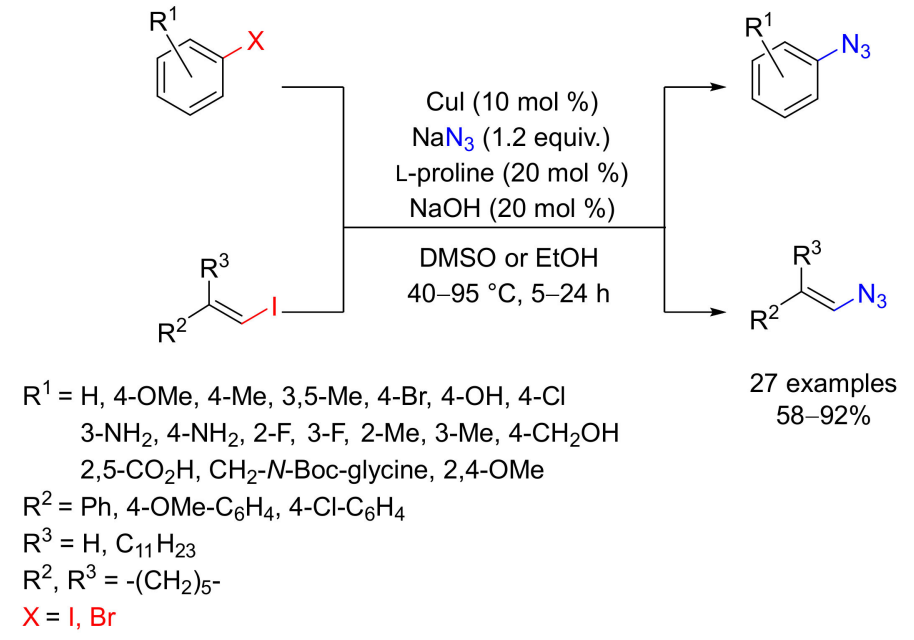

Scheme 11. Copper catalyzed coupling between $\mathrm{NaN}_{3}$ and aryl halides.

In 2007, Liu and Guo published the synthesis of aryl azides exploiting a copper catalyst and boronic acids as aryl partner [61]. As shown in Scheme 12, reaction conditions are mild and $\mathrm{CuSO}_{4}$ was proven to be the best copper salt to obtain high yields. 


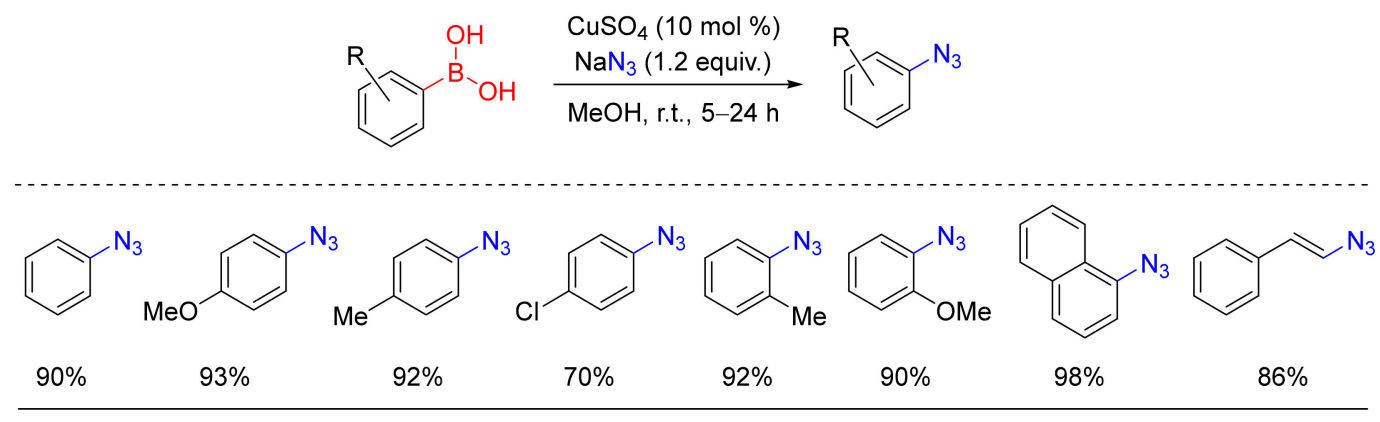

Scheme 12. Synthesis of aryl azides with boronic acids.

Three years later, Han's group extended the same strategy with the aryl boronic acids $\mathbf{1 0}$ or esters 11 and copper salts in the presence of TMS-N3 instead of $\mathrm{NaN}_{3}$ [62]. Tetrabutylammonium fluoride (TBAF) was essential for the cleavage of $\mathrm{Si}-\mathrm{N}_{3}$ bond from TMS- $\mathrm{N}_{3}$ (Scheme 13).

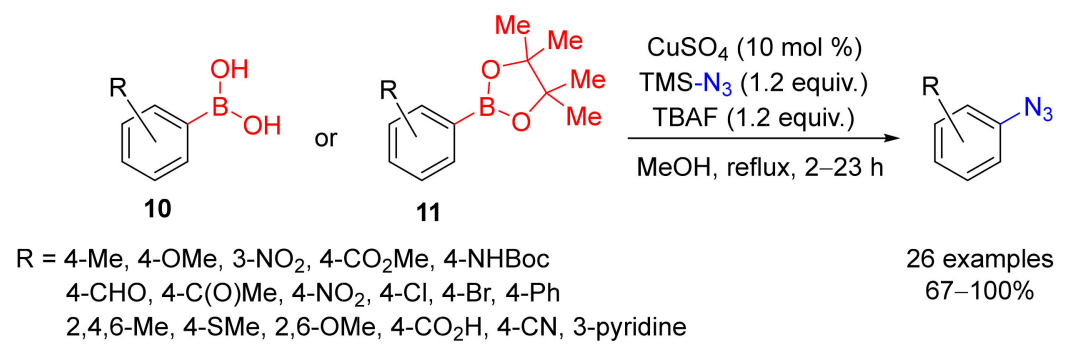

Scheme 13. Copper catalyzed azidation of aryl boronic acids/esters.

Recently, the conversion of (hetero)aryl and vinyl boronic acids into the corresponding azides was proven to be feasible in heterogeneous catalysis conditions using the recyclable zeolite $\mathrm{Cu}(\mathrm{I})$-USY catalyst [63].

The conversion of sulfonamides into sulfonyl azides is achievable working in the presence of $\mathrm{CuSO}_{4}$ as the catalyst, triflyl azide, and $\mathrm{NaHCO}_{3}$ as the base (Scheme 14) [64]. This procedure is a valuable alternative for the synthesis of sulfonyl azides avoiding the use of sulfonyl chlorides, which generate hydrochloric and sulfonic acids by contact with water as well as hydrazoic acid in the azidation step. No hypotheses about the mechanism of the reaction were provided by the authors.

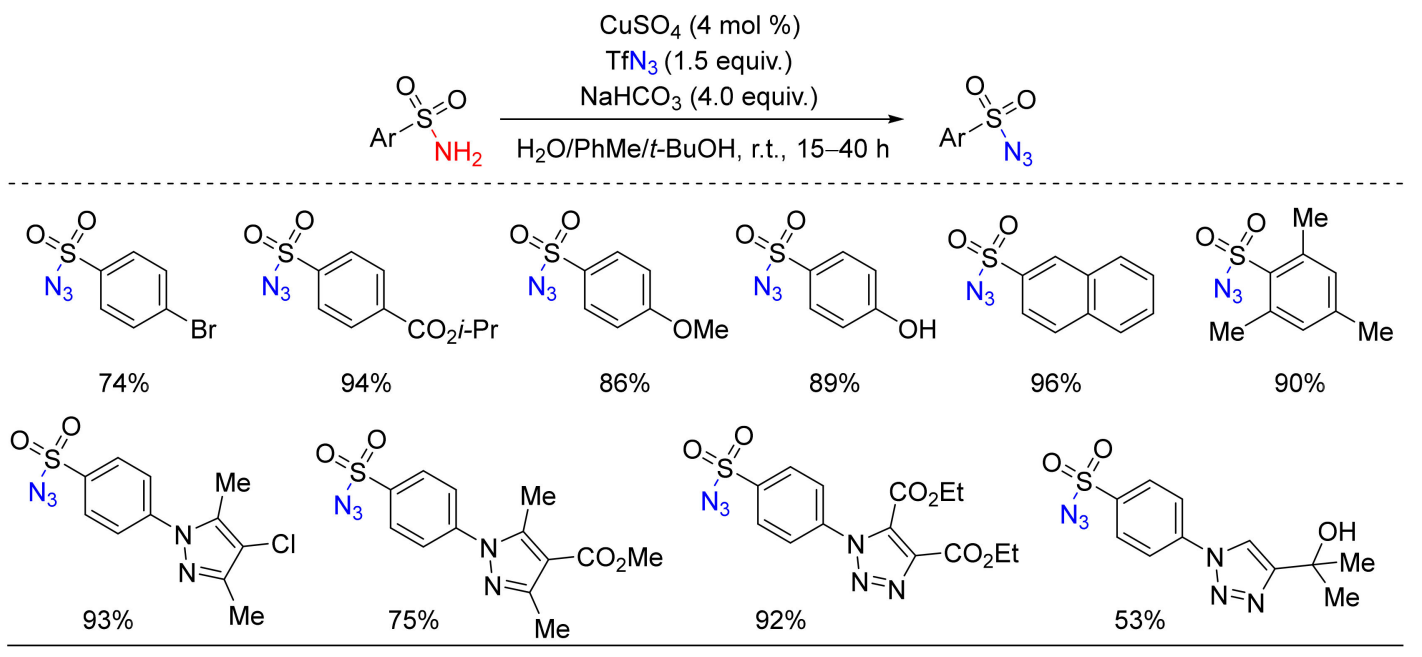

Scheme 14. Copper catalyzed azidation of sulfonamide with triphlyl azide. 


\section{Azidation of C-H Bonds}

The functionalization of unactivated $\mathrm{C}-\mathrm{H}$ bonds represents one of the most challenging perspectives also for the introduction of an azide group.

In 2012, Jiao proposed the direct azidation of the aryl systems 12 exploiting a primary amine as the directing group [65]. The reaction conditions (i.e., catalytic $\mathrm{CuBr}, \mathrm{TMS}-\mathrm{N}_{3}$ as azide source, and $t$-butylhydroperoxide (TBHP) as the oxidizing agent at room temperature) and the mechanism are reported in Scheme 15. The process starts with the coordination of the copper salt to 12, generating intermediate I-15, followed by the intervention of the azido anion to generate the intermediate II-15, which evolves to the III-15 species via SET (single electron transfer). The transfer of the azido group is favored by $\mathrm{HBr}$, generated in the first step, to form the intermediate IV-15, which leads to the final product 13 by another SET. Reasonably, the diazidation compound 14 arises from $\mathbf{1 3}$ through an analogous reaction path, which involves the unoccupied o-position of the amino group.

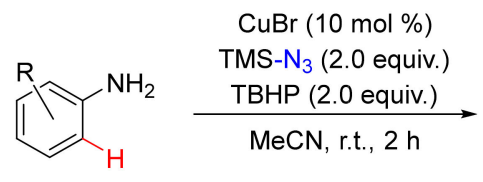

12

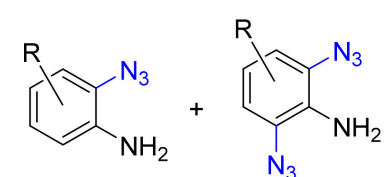

13
14

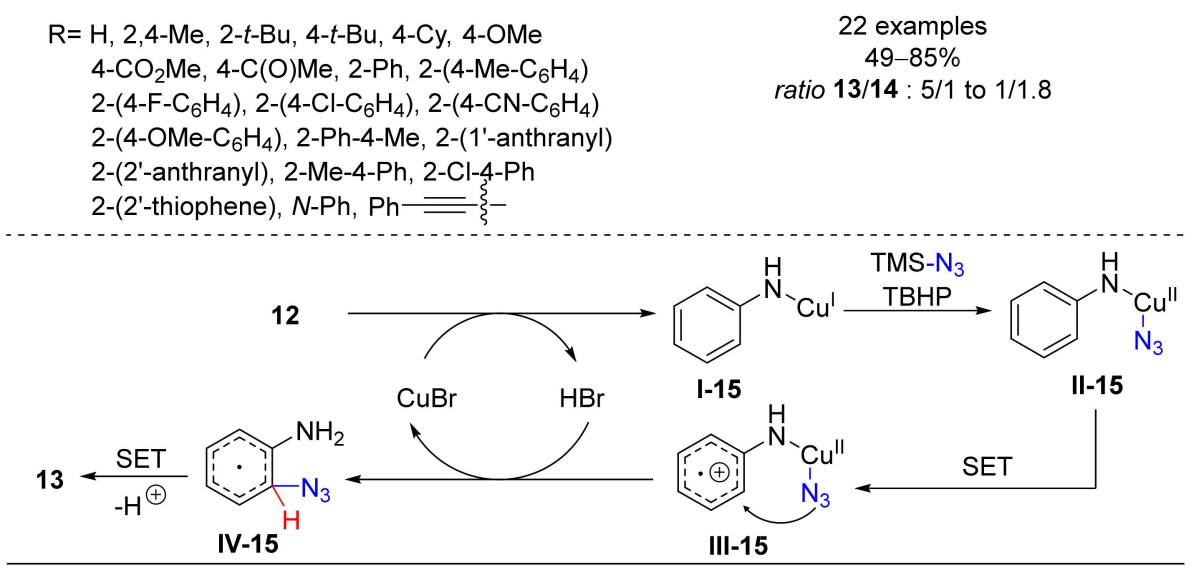

Scheme 15. Primary amine as directing group for azidation of aryls.

Some years later, the same approach was exploited for a direct and regioselective azidation of anilines by use of a $\mathrm{Cu}(\mathrm{OAc})_{2}$ catalyst, $\mathrm{NaN}_{3}$, and $\mathrm{H}_{2} \mathrm{O}_{2}$ as the oxidant (Scheme 16) [66]. The reaction runs in mild conditions in water as solvent through a mechanism analogous to that previously reported in Scheme 15.

1-Azido-1,2-benziodoxol-3(1H)-one (known as Zhdankin's reagent or ABX) can be used instead of $\mathrm{NaN}_{3}$ combined with a $\mathrm{Cu}(\mathrm{II})$-catalyst to accomplish the azidation of the $o$-position of anilines [67]. This source of the azide circumvents the need of an external oxidant, even if its waste is formed by higher weight side-products.

Azad and Narula reported the azidation of the 2-aryl-pyridines 15, in which the aza-group also acts as directing group [68]. Beside catalytic $\mathrm{CuI}$, the azidating reagent is the benzotriazole sulphonyl azide $\left(\mathrm{BtSO}_{2} \mathrm{~N}_{3}\right)$, whereas $\mathrm{K}_{2} \mathrm{~S}_{2} \mathrm{O}_{8}$ is the oxidant in a reaction mixture carried out at high temperature (Scheme 17). From the mechanistic point of view, after the coordination of pyridine to copper catalyst, $\mathrm{BtSO}_{2} \mathrm{~N}_{3}$ leads to the generation of the intermediate I-17. After a step of SET, the delocalization of the radical on the aromatic ring and the shift of the azido group to the arene to generate intermediate II-17. Consequently, a second SET allows the leaving of $\mathrm{BtH}$ and $\mathrm{SO}_{2}$ with formation of intermediate III-17, which gives the final product $\mathbf{1 6}$ after release of CuI. 


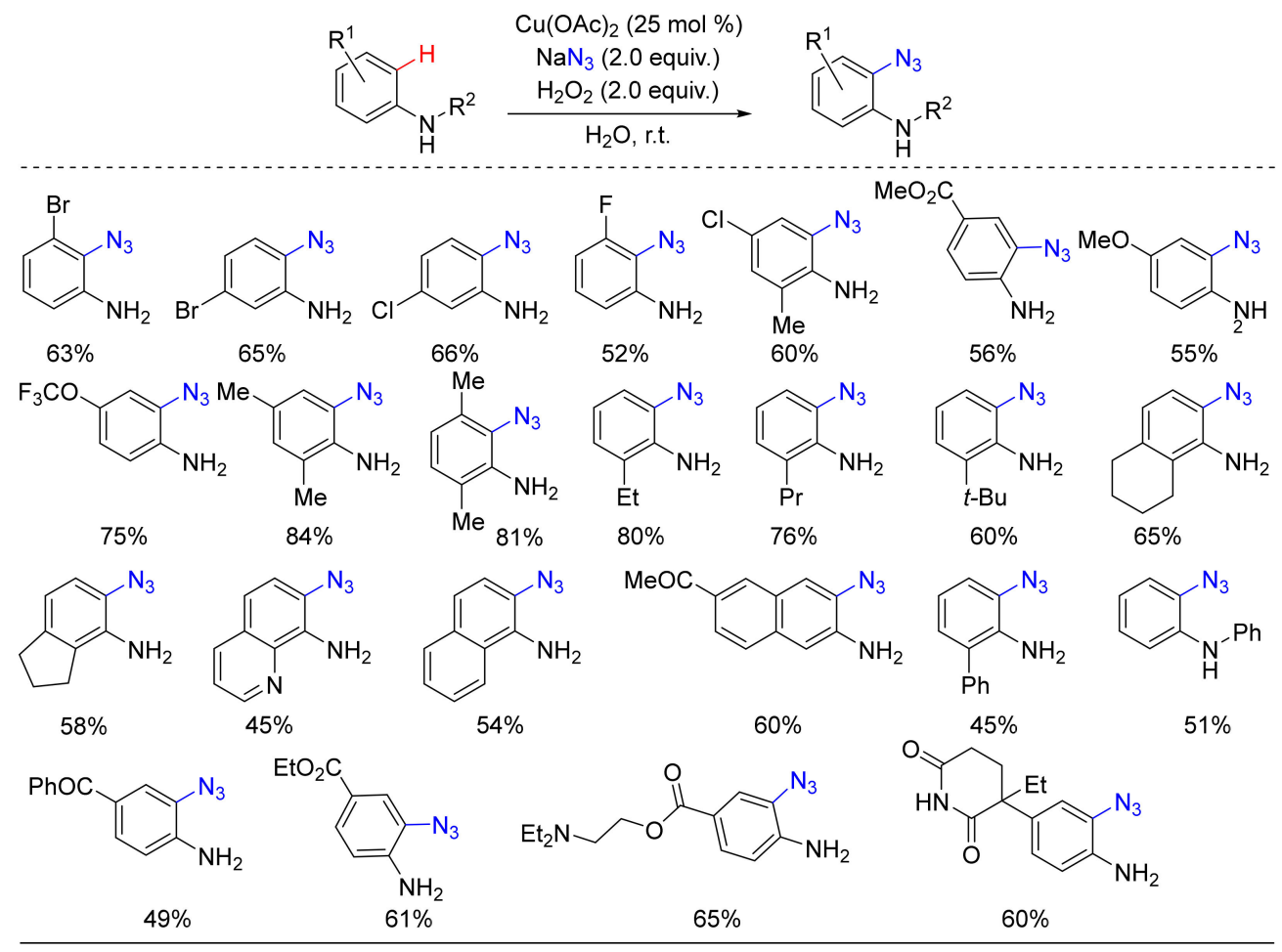

Scheme 16. Copper catalyzed C-H azidation of anilines.

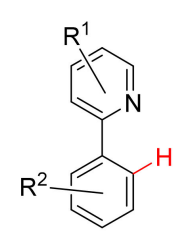

15

$\mathrm{R}^{1}=\mathrm{H}, 3-\mathrm{Me}, 4-\mathrm{Me}, 4-\mathrm{Cl}$

$\mathrm{R}^{2}=\mathrm{H}, 2-\mathrm{OBn}, 2-\mathrm{Me}, 2-\mathrm{Cl}, 4-\mathrm{Me}$

4-OMe, 4- $\mathrm{CN}, 4-\mathrm{CHO}, 4-\mathrm{CO}_{2} \mathrm{Me}$

2,5-Me, 3-Br, 2-thiophene

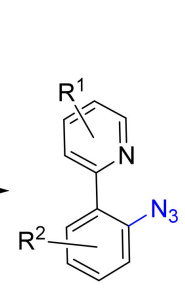

16

16 examples $32-92 \%$

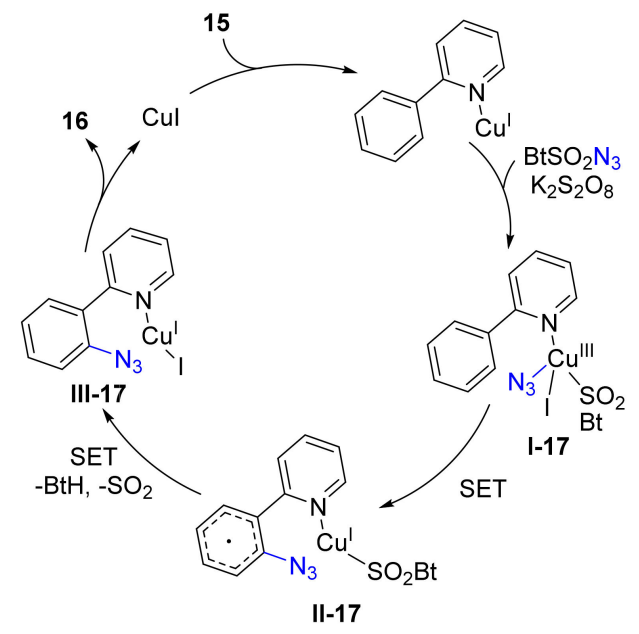

Scheme 17. Pyridine as directing group for the $\mathrm{C}-\mathrm{H}$ azidation of arenes.

The regioselective control in azidation of heteroarenes was also investigated by Zhu and co-workers [69]. In the presence of $\mathrm{Cu}(\mathrm{OAc})_{2}, \mathrm{~K}_{2} \mathrm{~S}_{2} \mathrm{O}_{8}$, tetrabutyl ammonium bromide (TBAB), $\mathrm{DBU}$, and $\mathrm{NaN}_{3}$ as the azide source, the 8-quinolinyl carboxamides $\mathbf{1 7}$ were converted into the corresponding 5-azido derivatives 18 (Scheme 18). The proposed mechanism involves the intermediate I-18, arising from the coordination of the quinoline derivative to the $\mathrm{Cu}(\mathrm{OAc})_{2}$, that undergoes addition of an azido radical via SET giving the intermediate II-18. An oxidative step by atmospheric oxygen gives the intermediate III-18, that evolves by metal-decomplexation into the intermediate IV-18 and then into the final quinoline $\mathbf{1 8}$ product by losing of proton.

An interesting example of oxidative copper catalyzed catalytic cycle for azidation of arenes was reported by Wang's group in 2014 [70]. The reaction allows the conversion of the azacalix[3]arene[3]pyridines 19 into the corresponding azido derivatives 20 occurring by a catalytic cycle 
that involves an unprecedented $\mathrm{Cu}(\mathrm{II})-\mathrm{ArCu}(\mathrm{II})-\mathrm{ArCu}(\mathrm{III})-\mathrm{Cu}(\mathrm{I})$ sequence (Scheme 19). The process starts with the coordination between 19 and the $\mathrm{Cu}$ (II)-catalyst to generate the arylcopper(II) intermediate I-19, which is oxidized to the intermediates II-19 by free copper(II) ions. The arylcopper(III) complex II-19 undergoes cross-coupling reaction with nucleophilic azide to produce the aryl azide $\mathbf{2 0}$. $\mathrm{Cu}(\mathrm{I})$ separately generated in two different steps of the sequence is oxidized again into $\mathrm{Cu}$ (II) by air.

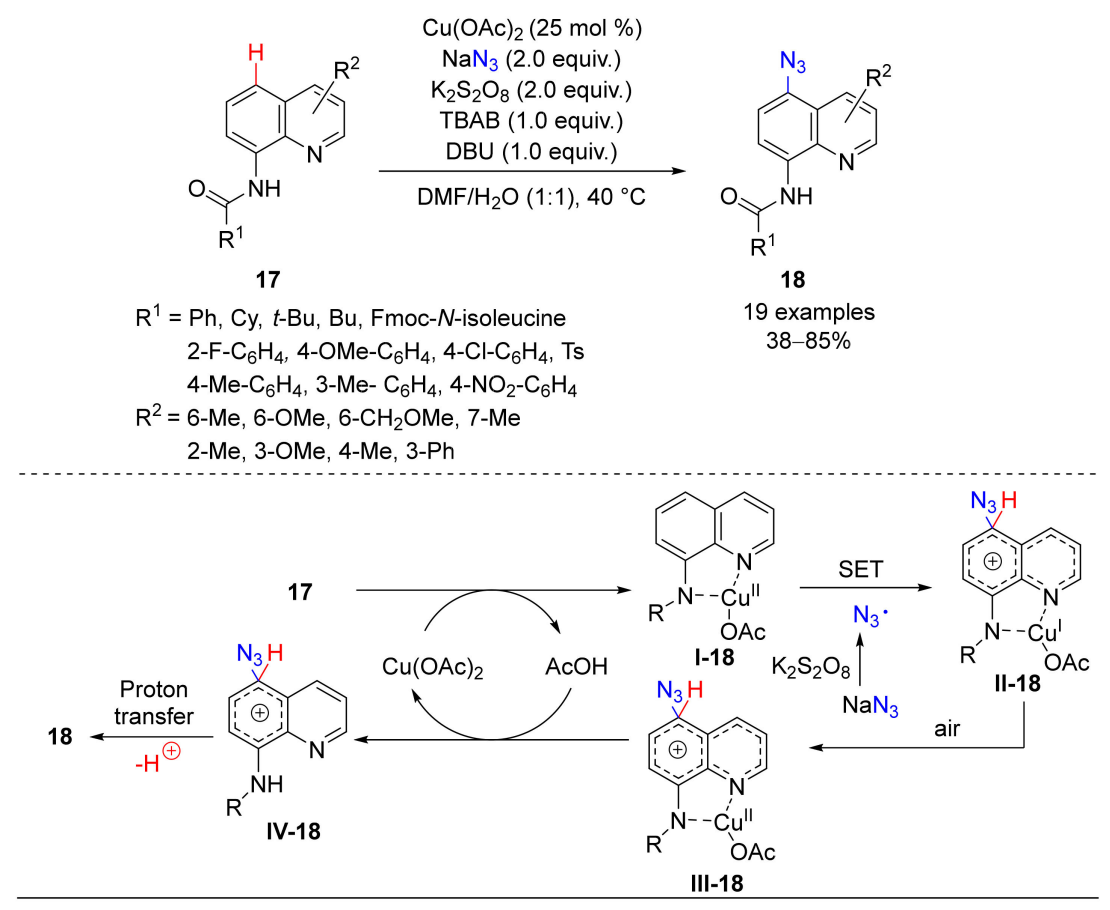

Scheme 18. C-H azidation of quinolines by $\mathrm{Cu}(\mathrm{OAc})_{2}$ catalysis.
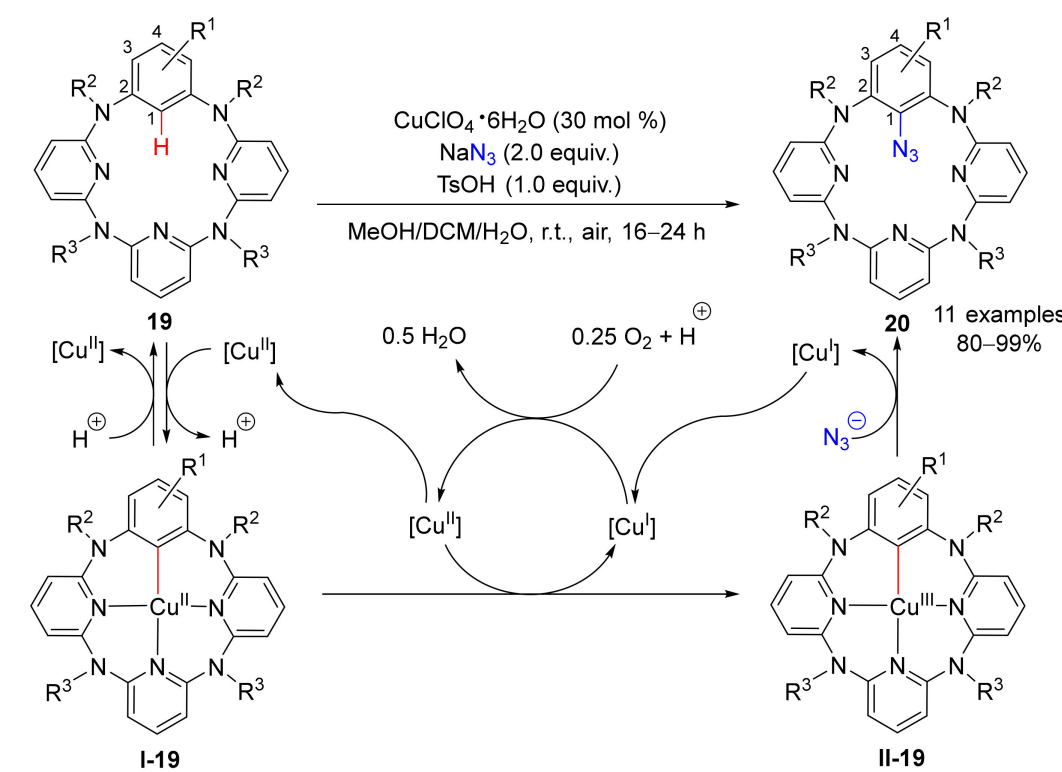

$\mathrm{R}^{1}=\mathrm{H}, 3-\mathrm{Me}, 4-\mathrm{Me}, 3-\mathrm{Cl}, 4-\mathrm{Cl}, 3-\mathrm{Br}$

$\mathrm{R}^{2}=\mathrm{H}, \mathrm{Me}, \mathrm{Bn}$

$\mathrm{R}^{3}=\mathrm{Me}, \mathrm{Bn}, \mathrm{Boc}$

Scheme 19. Oxidative copper catalyzed azidation via $\mathrm{ArCu}(\mathrm{III})$-complex.

In 2020, Stahl and co-workers reported a site-selective copper catalyzed benzylic C-H azidation [71]. As shown in Scheme 20, the conditions are based on the presence of $\mathrm{Cu}(\mathrm{OAc})_{2}$ as the catalyst, TMS- $\mathrm{N}_{3}$ as 
the azide source, the 2,2'-bis[(4S)-4-benzyl-2-oxazoline] (21) as the ligand, $N$-fluorobenzenesulfonamide (NFSI) as the additive, and $\mathrm{MeNO}_{2}$ as the solvent. The reaction proceeds through a hydrogen atom transfer to give a benzylic radical species that reacts with a $\mathrm{Cu}(\mathrm{II})$-azide intermediate.

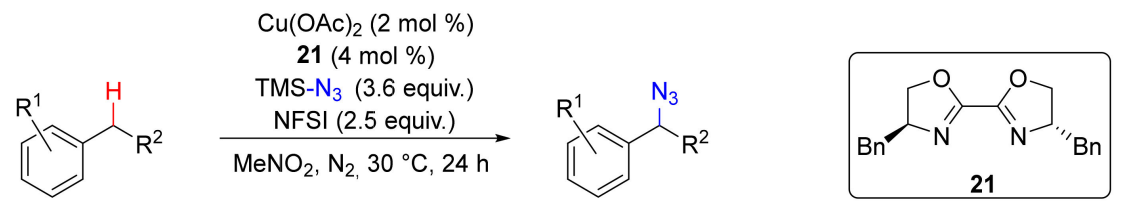

32 examples
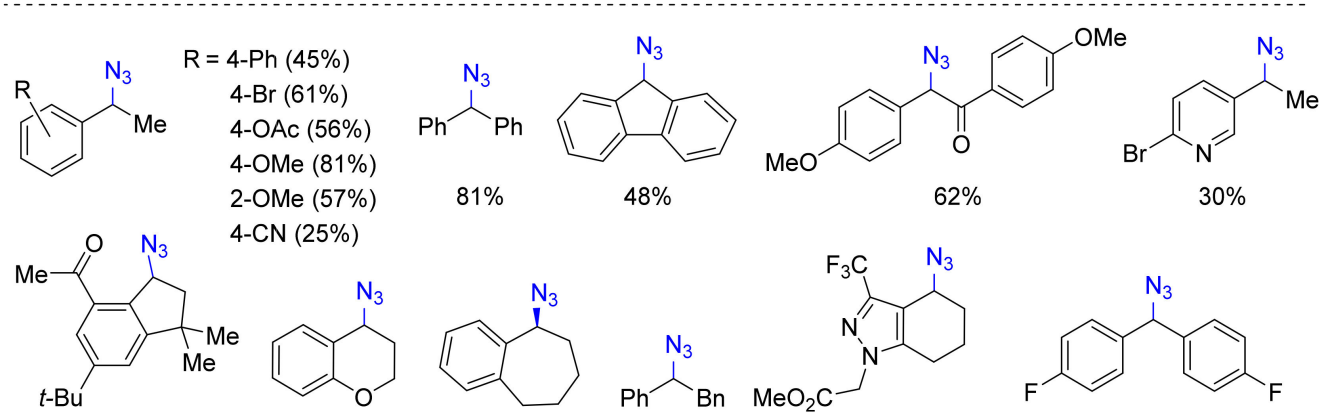

$92 \%$

$85 \%$

$72 \%$

$65 \%$

$60 \%$<smiles>COc1ccc(C(N)c2cc(C3O[C@H](COC(C)=O)[C@@H](OC(C)=O)[C@H](OC(C)=O)[C@H]3OC(C)=O)ccc2Cl)cc1</smiles><smiles>CC(C)c1ccc2c(c1)[C@@H](C)CC1[C@@](C)(CNC=[In])CCC[C@@]21C</smiles>

$63 \%$

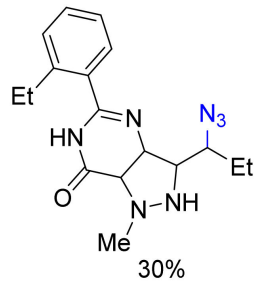

Scheme 20. Oxidative copper catalyzed $\mathrm{C}\left(s p^{3}\right)-\mathrm{H}$ azidation.

An innovative strategy for azidation of (hetero)arenes, involving copper catalysis combined with a site-selective C-H zincation, was reported in 2017 by Wang and co-workers (Scheme 21) [72]. Reaction was successful on electron-poor (hetero)arenes employing $\mathrm{Zn}(\mathrm{TMP}) \mathrm{Cl} \cdot \mathrm{LiCl}$ or on both electron-poor and electron-rich (hetero)arenes using $\mathrm{LiTMP}_{0.1} \mathrm{Li}\left[\mathrm{ZnEt}_{2}(\mathrm{TMP})\right]$ for the $\mathrm{C}-\mathrm{H}$ zincation step.

$$
\text { 2) Base } \mathrm{Zn}(\mathrm{TMP}) \mathrm{X} \text { (1.5 equiv.) }
$$
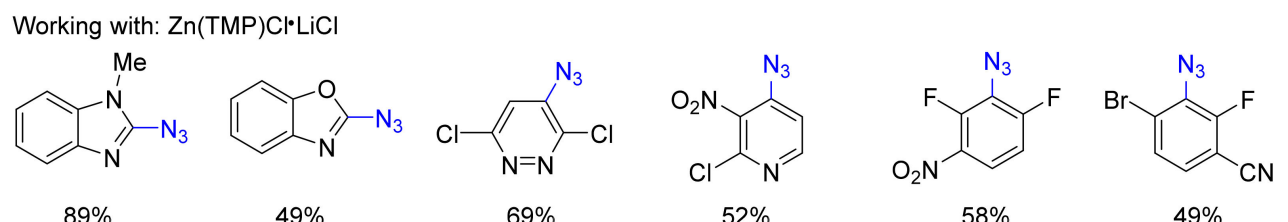

$49 \%$

$69 \%$

$52 \%$

$58 \%$

$49 \%$

Working with: LiTMP $\left._{0.1} \mathrm{Li}_{\left[\mathrm{ZnEt}_{2}\right.}(\mathrm{TMP})\right]$<smiles>Nc1ccccc1C(=O)Nc1ccccc1</smiles><smiles>N#Cc1c(N)cccc1Br</smiles><smiles>COc1cccc(OC)c1N</smiles><smiles>Nc1cccc(Cl)c1Cl</smiles><smiles>C=Cc1ccc(F)c(N)c1</smiles>

Scheme 21. Zinc-based assisted copper catalyzed azidation of arenes. 
In the last years, stable $\left[\mathrm{Cp}^{*} \mathrm{Rh}^{\mathrm{III}}\right]$ complexes were proven to be useful catalysts for $\mathrm{C}-\mathrm{H}$ activation/coupling reactions. In this context, $\mathrm{Li}$ and co-workers developed a new $\mathrm{Rh}$ (III)-catalyzed $\mathrm{C}-\mathrm{H}$ azidation procedure for arenes bearing chelating groups [73]. As shown in Scheme 22, the 2-phenylpyridines differently substituted both on pyridine and on the phenyl ring have been converted into the corresponding azide derivatives with good yields. The most plausible mechanism involves an initial interaction between the $\mathrm{Rh}(\mathrm{III})$-catalyst and the substrate to give the $\mathrm{Rh}$ (III)-intermediate I-22, which in turn leads to the intermediate II-22. The active species of azidation is $\mathrm{PhI}\left(\mathrm{N}_{3}\right) \mathrm{OTs}$, generated in situ by reaction between $\mathrm{PhI}(\mathrm{OH}) \mathrm{Ts}$ and $\mathrm{NaN}_{3}$. II-22 evolves towards the azido intermediate III-22, which is the precursor of the final product.

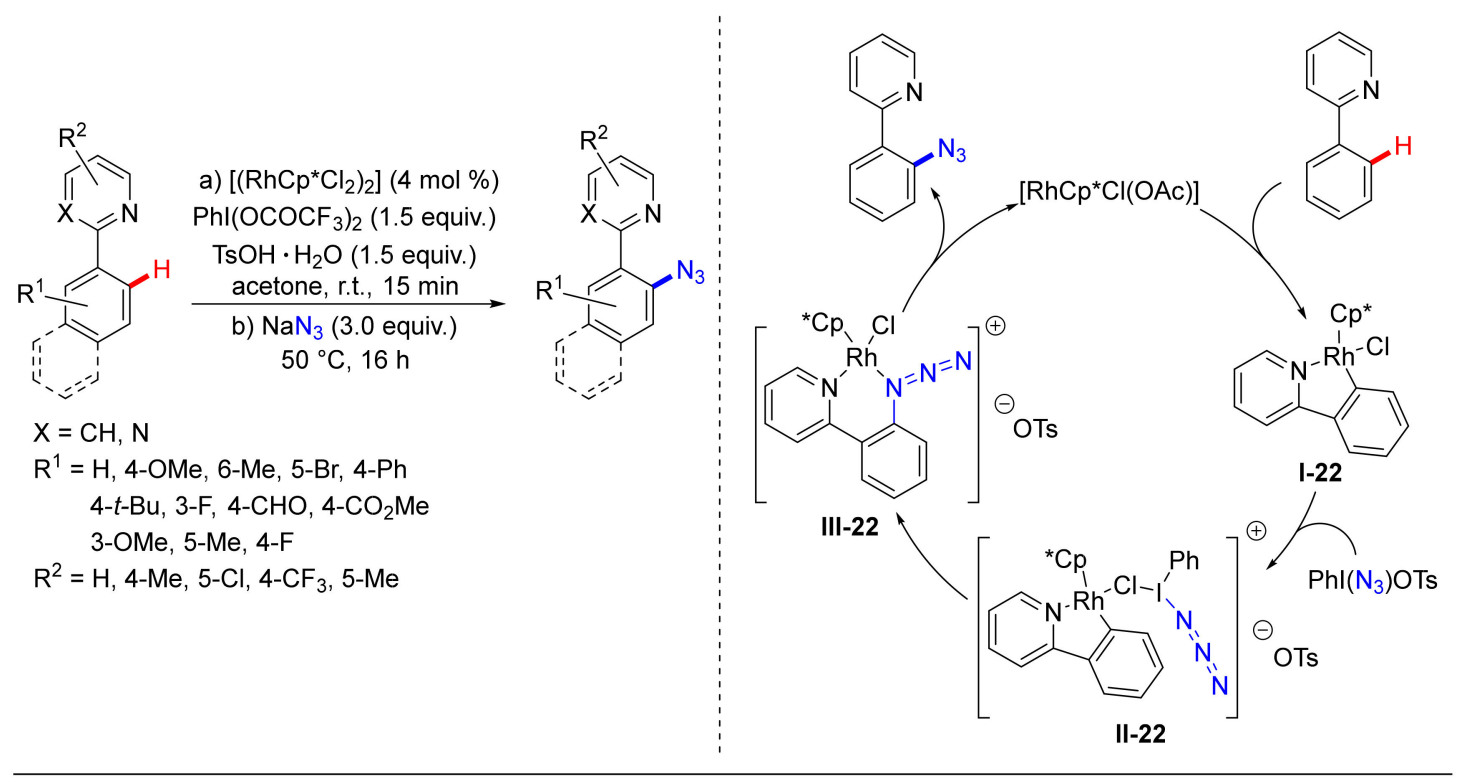

Scheme 22. $\mathrm{Rh}(\mathrm{III})$-catalyzed $\mathrm{C}-\mathrm{H}$ azidation of arenes.

Five years later, Wang and co-workers developed a chemo- and regioselective azidation of the arenes 22 using $\mathrm{Rh}_{2}(\mathrm{esp})_{2}$-bis[rhodium(tetramethyl-1,3-benzenedipropionic acid)]-as a dirhodium catalyst and the Zhdankin's reagent as the azide source (Scheme 23) [74]. This type of procedure is more effective on electron-rich arenes. The plausible mechanism started with the generation of the species $\mathrm{Rh}_{2}(\mathrm{esp})_{2} \mathrm{~N}_{3} \mathbf{I}-23$ beside the 2-iodobenzoxyl radical II-23. The I-23 species reacts with the substrate forming the carbon-nitrogen bond leading the azidated radical III-23 regenerating the $\mathrm{Rh}_{2}(\mathrm{esp})_{2}$ catalyst. The azido radical III-23 undergoes hydrogen abstraction by the radical II-23 providing the desired products 23.

Recently, an analogous catalytic system was employed to prepare azide-substituted aromatic aldehydes [75]. Working with a dirhodium catalyst in the presence of TMS- $\mathrm{N}_{3}$ and diacetoxyiodo benzene (PIDA) as the oxidizing agent, direct and regioselective $\mathrm{C}-\mathrm{H}$ azidation was achieved avoiding the need of protected aldehydes or prefunctionalized arenes (Scheme 24). 
<smiles>[R]c1ccccc1</smiles>

22

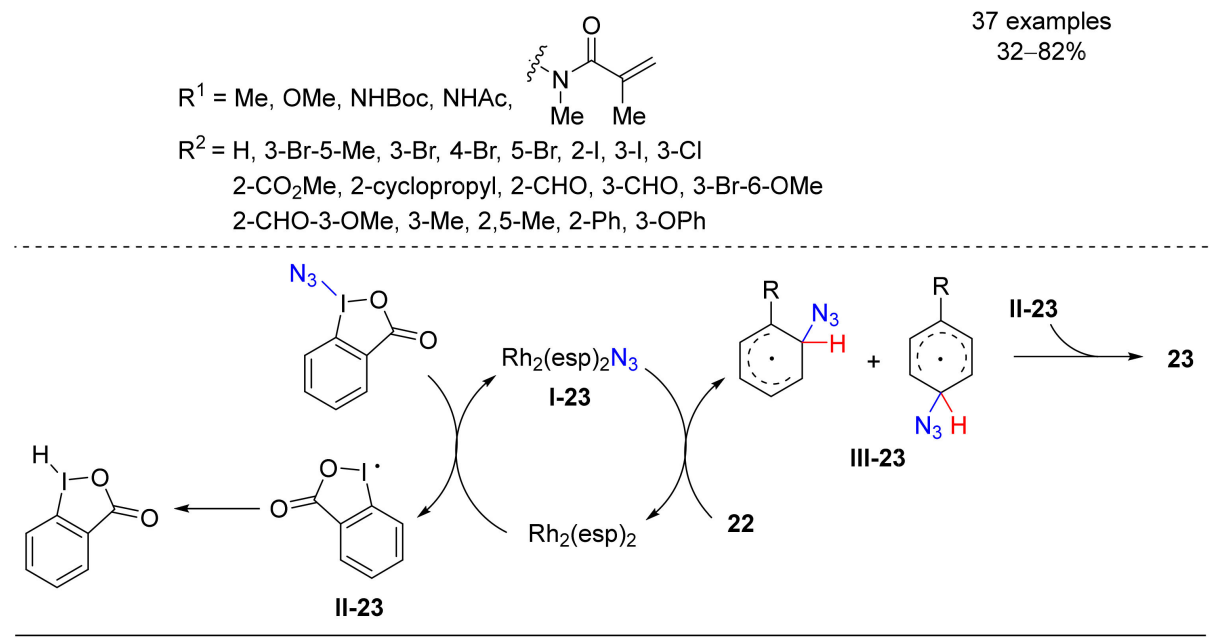

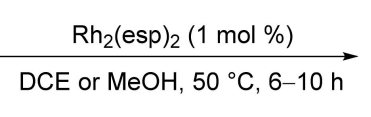<smiles>[Y]c1ccc([R])c([R])c1</smiles>

23

Scheme 23. Dirhodium(II)-catalyzed C-H azidation of arenes.

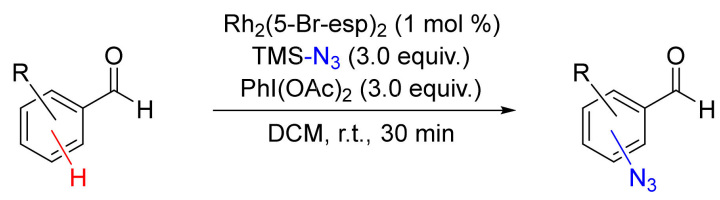

31 examples<smiles>Cc1ccccc1Oc1ccc(N)cc1</smiles>

O-allyl (47\%)

$\mathrm{O}\left(\mathrm{CH}_{2}\right)_{2} \mathrm{Br}(63 \%)$<smiles>COc1cc(C=O)c(N)cc1OC1CCCC1</smiles><smiles>COc1ccc(N)cc1/C=C/C=O</smiles>

$55 \%$

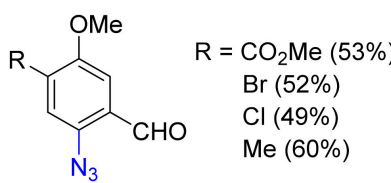<smiles>COc1cc(C=O)c(N)cc1Cl</smiles>

$52 \%$

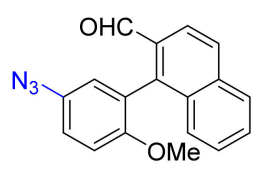

$57 \%$

Scheme 24. Dirhodium(II) direct azidation of aromatic aldehydes.

In 2015, Groves and co-workers developed a Mn-catalyzed aliphatic C-H azidation procedure (Scheme 25) [76]. $\mathrm{Mn}(\mathrm{TMP}) \mathrm{Cl}$ (manganese tetramethylololpropane chloride) and $\mathrm{Mn}(\mathrm{salen}) \mathrm{Cl}$ were investigated as catalysts and the optimized conditions were compatible for the azidation of secondary, tertiary, and benzylic $\mathrm{C}-\mathrm{H}$ bonds. This method was also effective for the azidation of bioactive molecules, in particular the use of chiral $\mathrm{Mn}(\mathrm{salen}) \mathrm{Cl}$ provided an enantioselective azidation reaction for celestolide $(70 \% e e)$. In the proposed radical mechanism, the $\mathrm{Mn}(\mathrm{III})$-catalyst reacts with sodium azide and undergoes oxidation by iodosobenzene to the oxoMn(V) intermediate (I-25). The following hydrogen abstraction step from the substrate is regioselectively dependent on the catalyst ligand 
architecture. Then, the substrate radical evolves by interaction with the $\mathrm{Mn}(\mathrm{IV})-\mathrm{N}_{3}$ intermediate (II-25) to form the $\mathrm{C}-\mathrm{N}_{3}$ bond and allowing the regeneration of the catalyst.

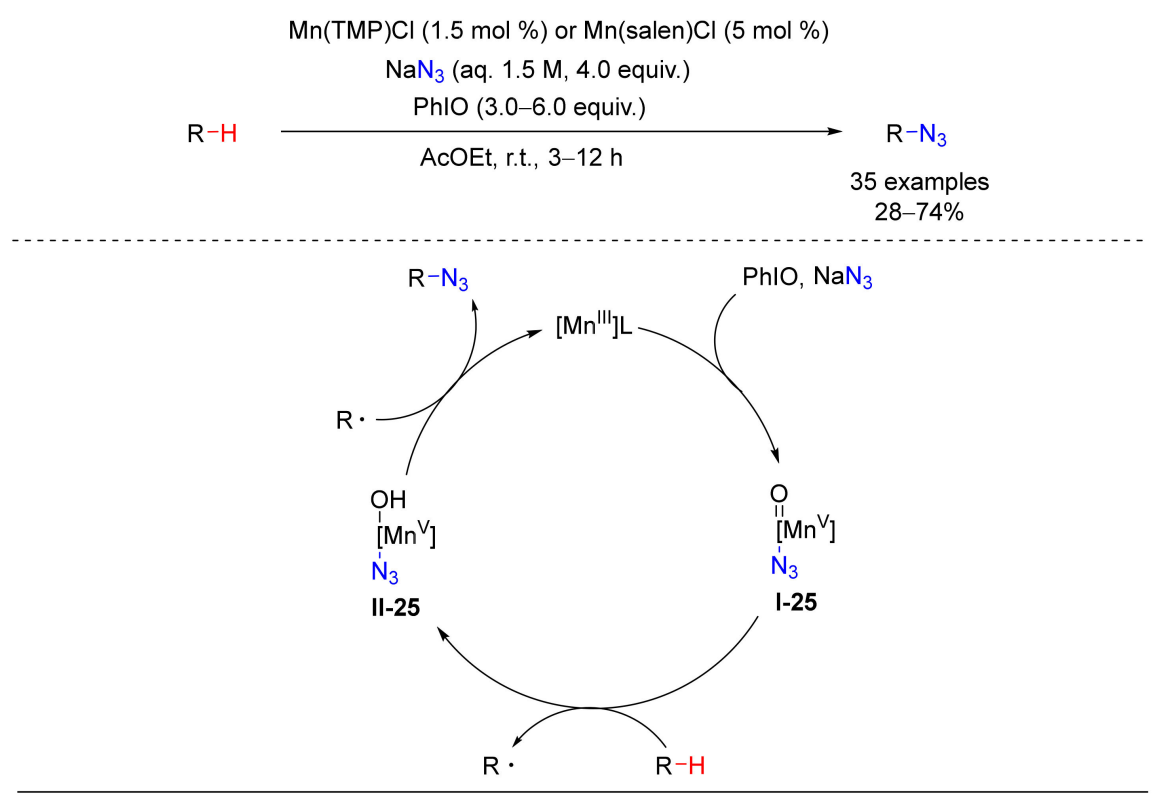

Scheme 25. Aliphatic $\mathrm{C}-\mathrm{H}$ azidation procedure.

In 2013, Gade's group exploited an iron/silver co-catalytic system for the azidation of the $\beta$-keto esters 24 (Scheme 26) [77]. An iodine(III) compound was used as an azido-transfer reagent, iron(II) propionate was found as the best catalyst, and silver arylcarboxylates in diethyl ether as solvent gave better $e e$ values. The silver salt furnishes the counteranion for the iron catalyst, which is coordinated by the enantiopure pincer ligand 26. The reaction outputs are excellent in terms of yields and enantioselectivity. This type of reactivity was successfully applied also for the azidation of oxindoles 25. In this case, the active catalyst species was generated in situ between ligand $\mathbf{2 6}$ and $\mathrm{Fe}(\mathrm{OOCEt})_{2}$ salt. In this case, the reaction was performed in the absence of silver salts due to the negative effect of their counteranion on the enantioselectivity of the outcome.

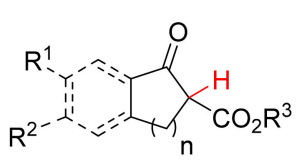

24<smiles>CN1OC(C)(C)c2ccccc21</smiles>

( 1.5 equiv.)

$\mathrm{n}=1,2$

$\mathrm{R}^{1}=\mathrm{H}, \mathrm{OMe}, \mathrm{MeS}, 1,3$-dioxolane

$\mathrm{R}^{2}=\mathrm{H}$, OMe, $\mathrm{Br}, \mathrm{Me}, 1,3-$ dioxolane

$\mathrm{R}^{3}=\mathrm{Bn}, t-\mathrm{Bu}$<smiles>[R]c1ccc2c(c1)C([R])C(=O)N2C(=O)OC(C)(C)C</smiles>

25<smiles>CC1(C)ONc2ccccc21</smiles>

(1.5 equiv.)

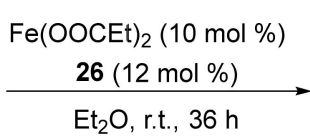

$\mathrm{Et}_{2} \mathrm{O}$, r.t., $36 \mathrm{~h}$

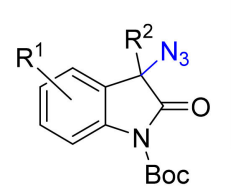

Boc

ee: $87-94 \%$

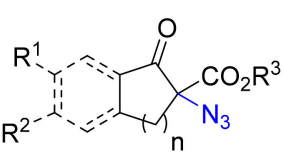

15 examples $84-90 \%$ ee: $67-93 \%$

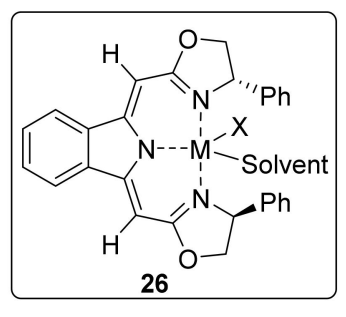

$\mathrm{R}^{1}=\mathrm{H}, 5-\mathrm{OMe}, 5-\mathrm{Me}, 5-\mathrm{F}, 7-\mathrm{F}$ $\mathrm{R}^{2}=\mathrm{Ph}, 4-\mathrm{F}-\mathrm{C}_{6} \mathrm{H}_{4}, 4-\mathrm{Me}-\mathrm{C}_{6} \mathrm{H}_{4}$

Scheme 26. Iron(II) catalysis for azidation reaction. 
In 2015, Sharma and Hartwig applied the same strategy for the azidation of unactivated tertiary $\mathrm{C}-\mathrm{H}$ bonds (Scheme 27) [78]. ABX compound was the azide-transfer reagent, while the enantioselectivity was achieved with the 2,6-bis[(4S)-(-)-isopropyl-2-oxazolin-2-yl]pyridine ligand (27). When the substrate bears more than one functionalizable positions, the reaction occurs with a regioselectivity degree depending on the distance of the electron-withdrawing group from the proximal $\mathrm{C}-\mathrm{H}$ bond. The key-step of the mechanism supposed by authors is given by the generation of a tertiary alkyl radical intermediate.

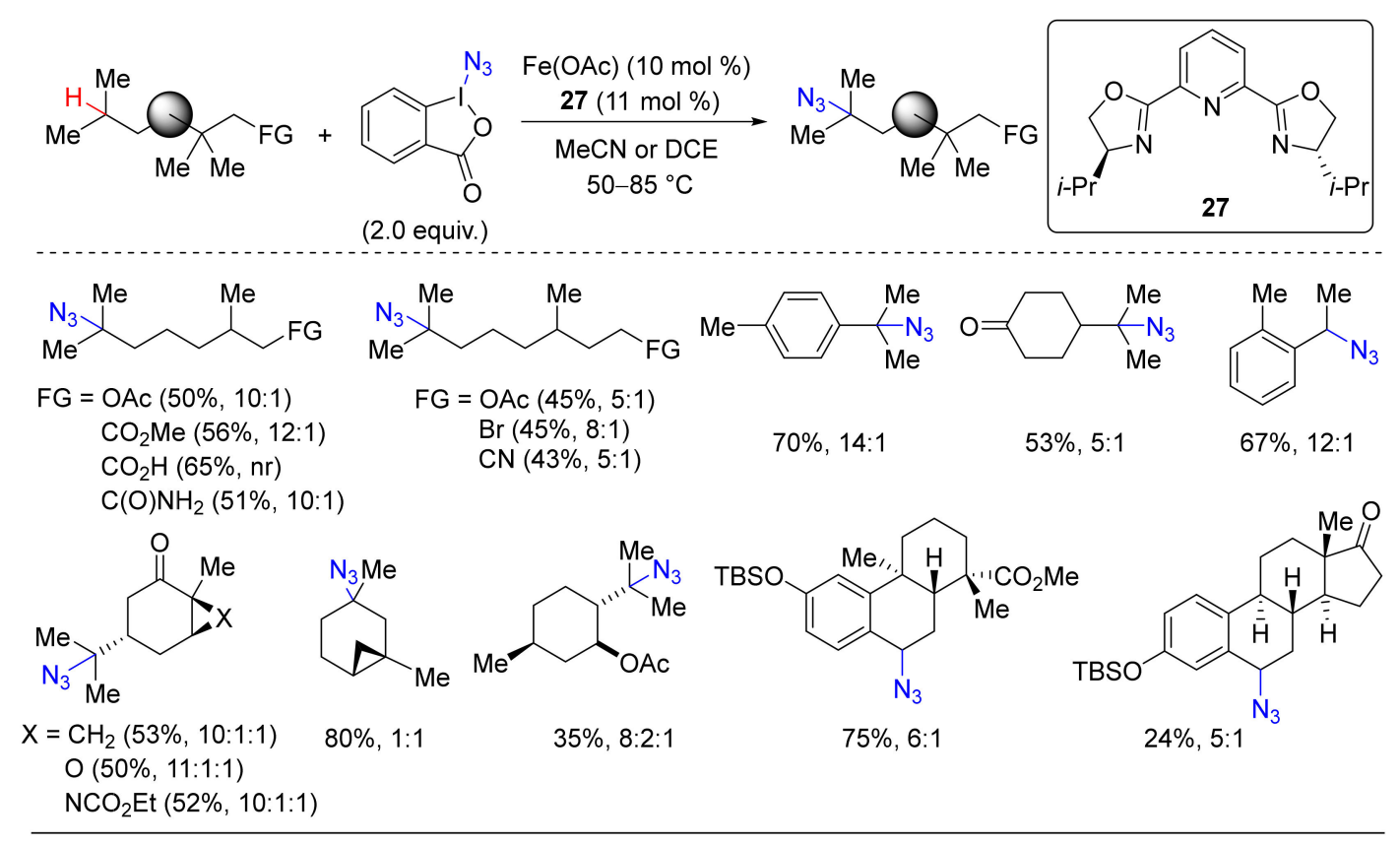

Scheme 27. Iron catalyzed azidation of unactivated tertiary $\mathrm{C}-\mathrm{H}$ bond.

One year later, Sharma and Hartwig extended the enantioselective azidation catalyzed by Fe(II) to natural compounds of biological interest with complex structures [79]. In this case, authors focused their attention on the activation of benzylic and heterobenzylic $\mathrm{C}-\mathrm{H}$ bond (Scheme 28). Authors investigated the azidation of high functionalized $\mathrm{C}-\mathrm{H}$ bonds in aliphatic chains and cycles, of allylic position as well as the enantioselective azidotrifluoromethylation of substituted alkenes.

Analogous iron catalyzed reaction conditions have been recently used for the $\mathrm{C}-\mathrm{H}$ benzylic azidation using TMS- $\mathrm{N}_{3}$ instead of azido-periodinanes as the azide source [80].

A similar radical-mediated reaction for the azidation of tertiary aliphatic $\mathrm{C}-\mathrm{H}$ bonds was reported by Chen and co-workers [81]. The procedure is based on the use of Zhdankin azidoiodinane reagent, $\mathrm{Ru}(\mathrm{bpy})_{3} \mathrm{Cl}_{2}$ as the catalyst, and visible-light irradiation at room temperature. This $\mathrm{C}\left(s p^{3}\right)-\mathrm{H}$ functionalization provides a potentially useful tool for selectively labeling of organic and biomolecules being compatible with complex structures.

$\beta$-Ketoesters 28 and silyl enol ethers 29 can undergo azidation reaction with $\mathrm{Zn}(\mathrm{OTf})_{2}$ as the catalyst (Scheme 29) [82]. The use of this cheap and non-toxic reagent in presence of hypervalent iodine azido-species (IBX-N 3 ) permits to obtain the desired azido products in moderate to good yields when starting substrates are acyclic keto esters or less reactive silyl enol ether. The reaction can also be applied in the preparation of tertiary azides, also bearing heteroaromatic rings. 

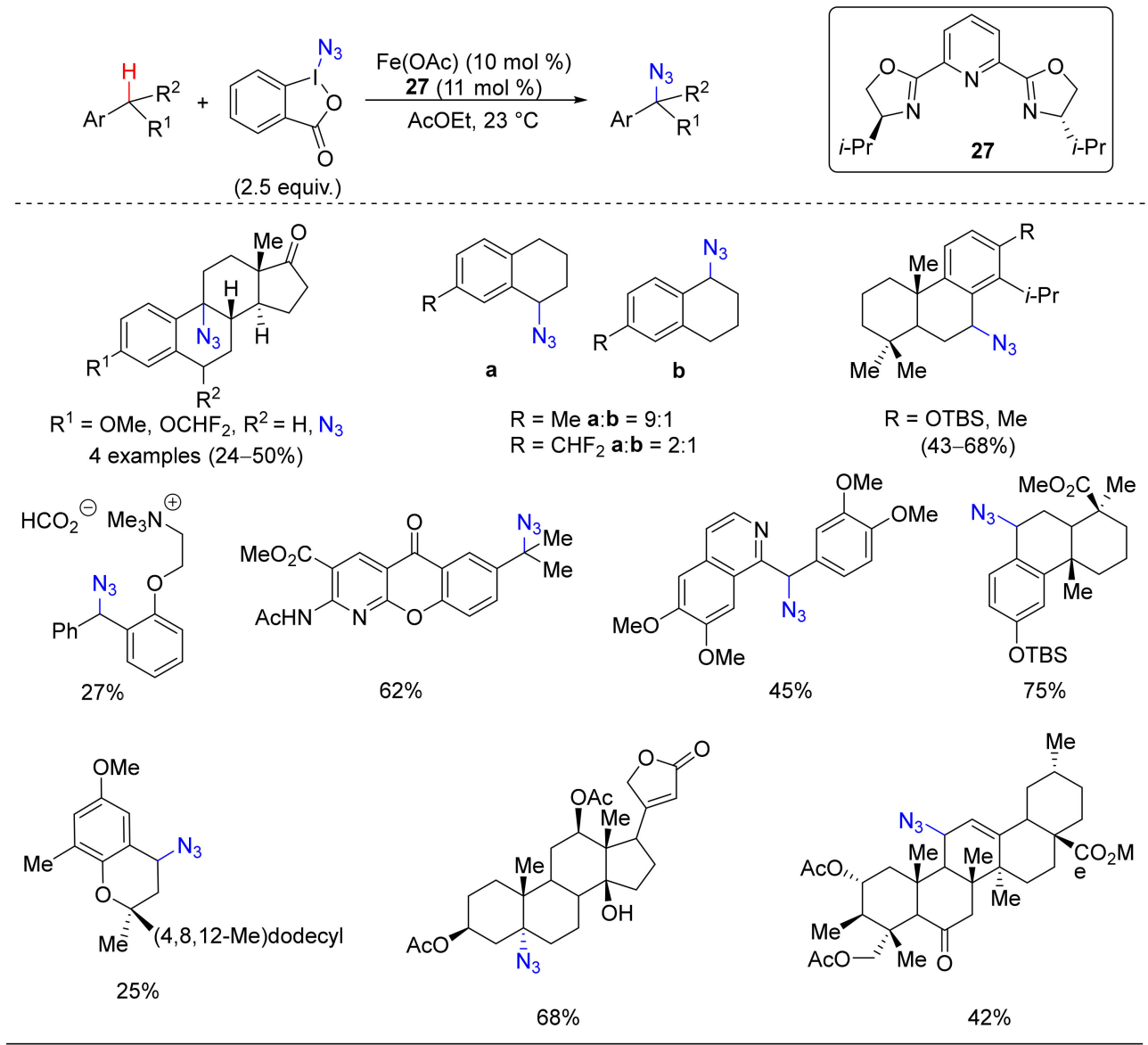

Scheme 28. Azidation of natural complex molecules via iron catalysis.

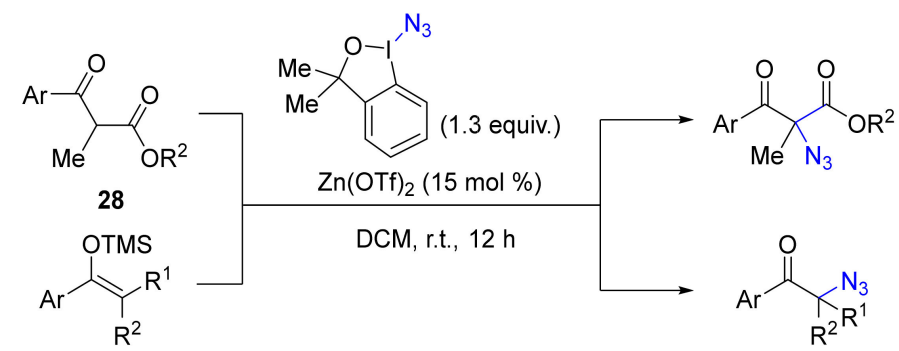

29
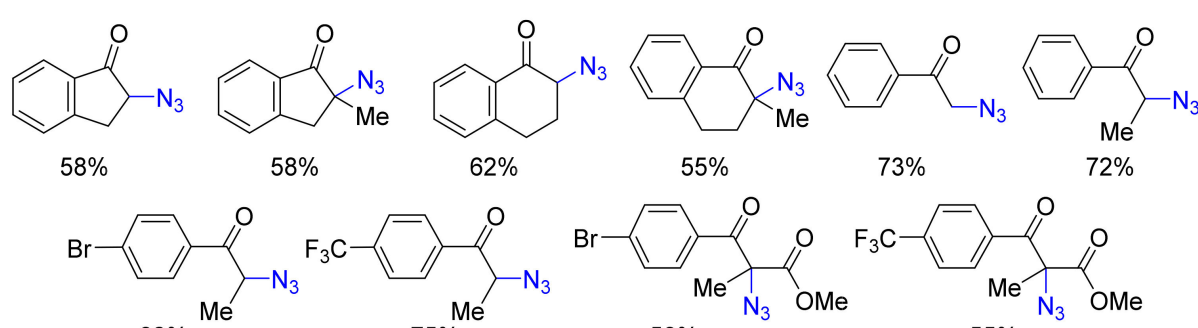

$82 \%$

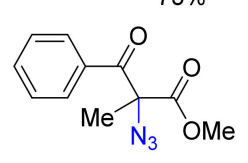

$58 \%$

$55 \%$

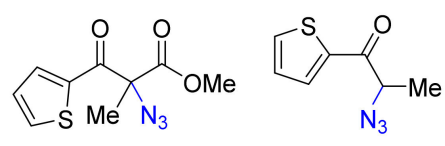

$73 \%$

$64 \%$

$81 \%$

Scheme 29. $\mathrm{Zn}$ (II) Lewis acid for the azidation of $\beta$-keto esters and silyl enol ethers. 
The azidation of benzylic compounds using visible light photochemistry in the presence of $\left[\mathrm{Cu}(\text { dap })_{2}\right] \mathrm{Cl}$ as catalyst and Zhdankin reagent was reported by Greaney in 2016 [83]. As shown in Scheme 30, authors propose a radical mechanism which initiates with the homolytic cleavage of the $\mathrm{I}-\mathrm{N}_{3}$ bond by generating azide radicals. After abstraction of a benzylic hydrogen atom from the substrate $\mathbf{3 0}$ with generation of I-30, the propagation continues involving iodane radicals II-30, which in turn removes a hydrogen atom from the benzyl substrate providing the final product 31.

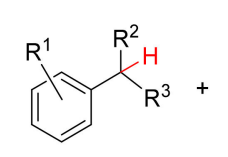

30

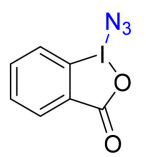

(1.0 equiv.)

$\mathrm{Cu}(\mathrm{dap})_{2} \mathrm{Cl}(0.5 \mathrm{~mol} \%)$ $\underset{\mathrm{MeCN} \text {, r.t., } 16 \mathrm{~h}}{\stackrel{\text { visible light }(30 \mathrm{~W})}{\longrightarrow}}$

$\mathrm{R}^{1}=\mathrm{H}$, Et, 2-Me, 3-Me, 4-Me, 2-Br, 3-Br, 2-I 2-Ph, 3-F, 4-F, 3-Cl, 4-Cl, 4-NO $\mathrm{N}_{2}$, 4-OMe 4-CN, 4-C(O)Me, 4- $\mathrm{CO}_{2} \mathrm{Me}, 3-\mathrm{Br}-5-\mathrm{Me}$, 2,4,5-Me, 3,5-Me, 4-i-Pr, 3,5-i-Pr, 2,6-F $\mathrm{N}$-Boc-indole, benzotiophene $\mathrm{R}^{2}=\mathrm{H}, \mathrm{Ph}, \mathrm{Me}$ $\mathrm{R}^{3}=\mathrm{H}, \mathrm{Me}$

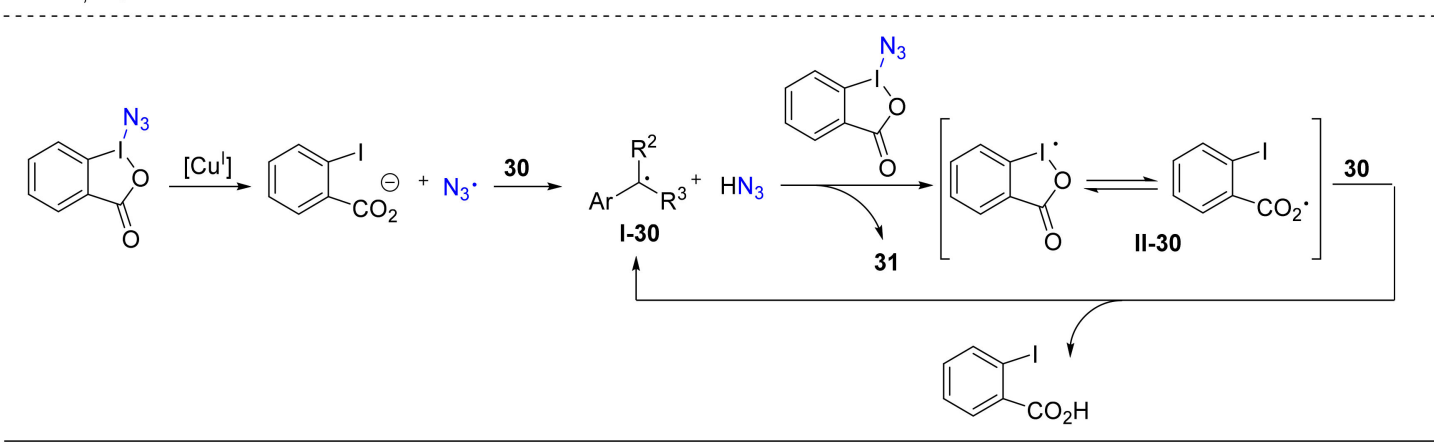

Scheme 30. Azidation of benzylic compound with photoredox-copper catalysis.

Tertiary azide in naphthalenone derivatives can be prepared by dearomative $\mathrm{C}-\mathrm{H}$ azidation of $\beta$-naphthols in the presence of catalytic $\mathrm{CuBr}, \mathrm{TMS}-\mathrm{N}_{3}$, and aqueous TBHP in acetonitrile at room temperature (Scheme 31) [84]. Using the same reaction conditions, the same group obtained the $\mathrm{C}-\mathrm{H}$ azidation of the $\mathrm{C} 2$ position of indolyl compounds [85]. These substrates give rise to dearomative azidation of the $\mathrm{C} 3$ position working with $\mathrm{I}_{2}$ as the catalyst instead of $\mathrm{CuBr}$.

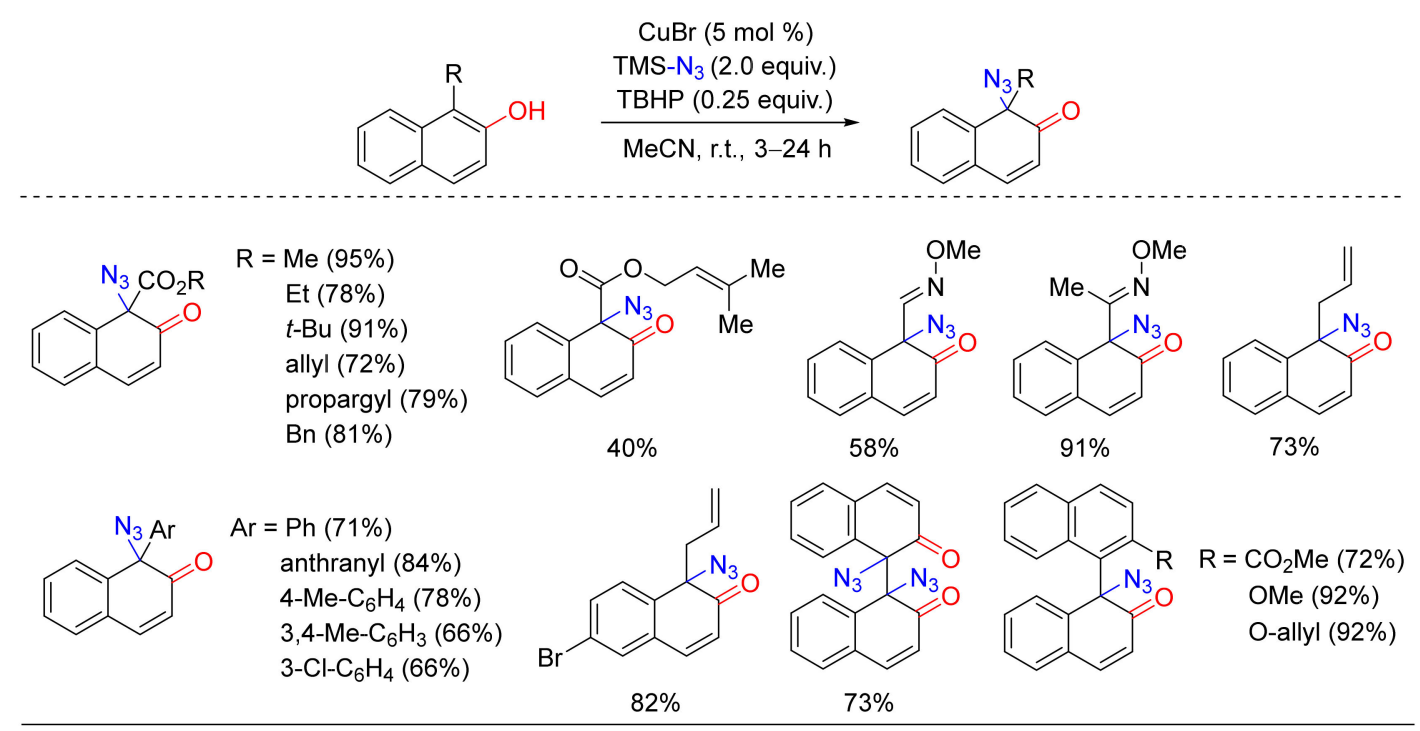

Scheme 31. $\mathrm{Cu}(\mathrm{I})$-catalyzed azidation of $\beta$-naphthols. 
In 2018, Reiser and co-workers used the same copper catalyst and TMS- $\mathrm{N}_{3}$ as azide source for the regio- and chemoselective oxyazidation of the vinyl arenes 32 providing the $\alpha$-azidoketones 33 [86]. Scheme 32 shows that after the oxidation from $\mathrm{Cu}(\mathrm{I})$ to $\mathrm{Cu}(\mathrm{II})$, the copper species reacted with TMS- $\mathrm{N}_{3}$ to generate an azide-bridged dimer, which gave an azide radical and a $\mathrm{Cu}(\mathrm{I})$ species through a homolytic dissociation. The azide radical reacted with the olefin to obtain the intermediate I-32 that trapped $\mathrm{O}_{2}$. In the end, the desired product was obtained from the I-32 specie through a homolytic dissociation.

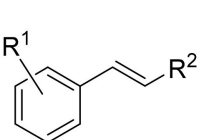

32

$\mathrm{R}^{1}=\mathrm{H}, 2-\mathrm{Me}, 4-\mathrm{Me}, 4-t-\mathrm{Bu}, 2-\mathrm{OMe}, 3-\mathrm{OMe}$

4-OMe, 4-OAc, 4- $\mathrm{F}, 3-\mathrm{Cl}, 4-\mathrm{Br}, 4-\mathrm{NH}_{2}$

4-NHAc, 2-NO 2 , 4-NO 2 , 4-CN, 3,5-OMe

$3,4,5-\mathrm{OMe}, 2-\mathrm{CF}_{3}$, anthranyl, 2,3-OBn

$2,6-\mathrm{Cl}, 4-\mathrm{CH}_{2} \mathrm{Cl}, 4$-allyl

$\mathrm{R}^{2}=\mathrm{H}, \mathrm{Me}$
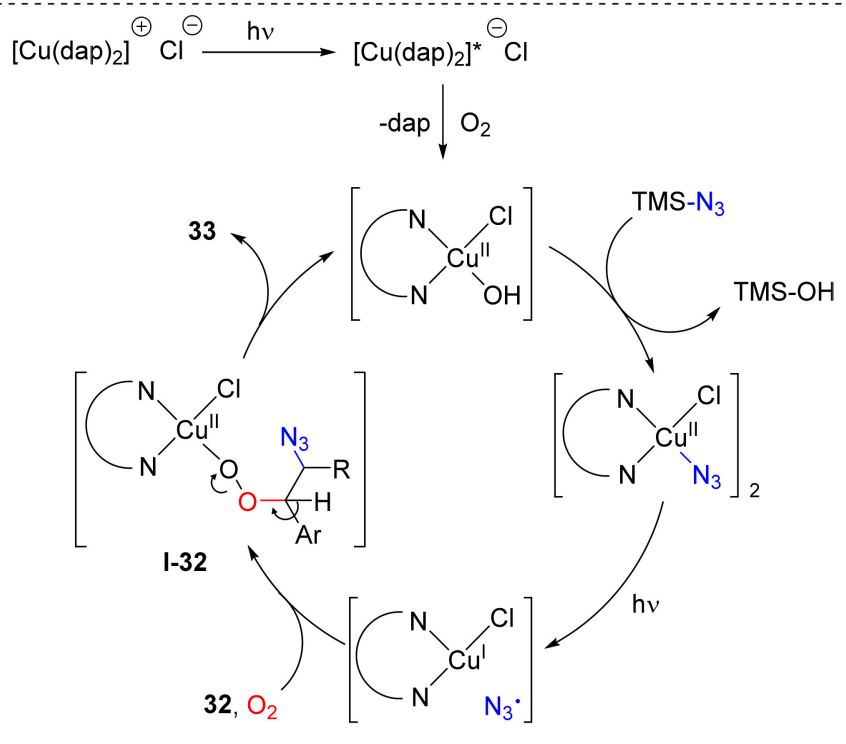

Scheme 32. Regio- and chemoselective oxyazidation of vinyl arenes.

\section{Azidation Involving the Formation of More Than One Bond}

\subsection{Amination/Azidation}

Copper catalyzed reactions are among the most used to obtain vicinal difunctionalized products. In a pioneering work on intra-/intermolecular diamination of amino alkenes promoted by copper complexes, Chemler and co-workers described few examples of aminoazidation reaction using stoichiometric amount of copper species [87].

A Cu-catalyzed aminoazidation of the unactivated alkenes 34 was performed under neutral conditions by $\mathrm{Fu}$ and co-workers using $\mathrm{N}$-halodialkylamine with $\mathrm{AgN}_{3}$ or $\mathrm{NaN}_{3}$ as azide sources furnishing the products $\mathbf{3 5}$ (Scheme 33) [88]. Reactions were successfully carried out with a wide range of $N$-halodialkylamines bearing acetals, unprotected alcohols, or thienyl moieties. The presence of the bidentate 8-aminoquinoline group tethered on the alkenyl substrate is essential for the outcome of the reaction. After the generation of the $\pi$-olefin intermediate I-33, a single electron transfer process which involves the $\mathrm{N}$-halodialkylamine affords the $\mathrm{Cu}$ (II)-complex II-33 and the aminyl radical III-33. 
The latter coordinates with the $\mathrm{Cu}$ (II) complex to give the electrophilic aminyl $\mathrm{Cu}$ (II) radical intermediate IV-33. The following step is the migratory insertion of the olefin into the radical IV-33 supported by chelation of the bidentate auxiliary with the copper center providing the $\mathrm{Cu}(\mathrm{III})$-intermediate $\mathrm{V}-33$. The addition of the azide anion to V-33 gives rise to ligand exchange providing VI-33, which evolves into the aminoazidation product by a reductive elimination process.
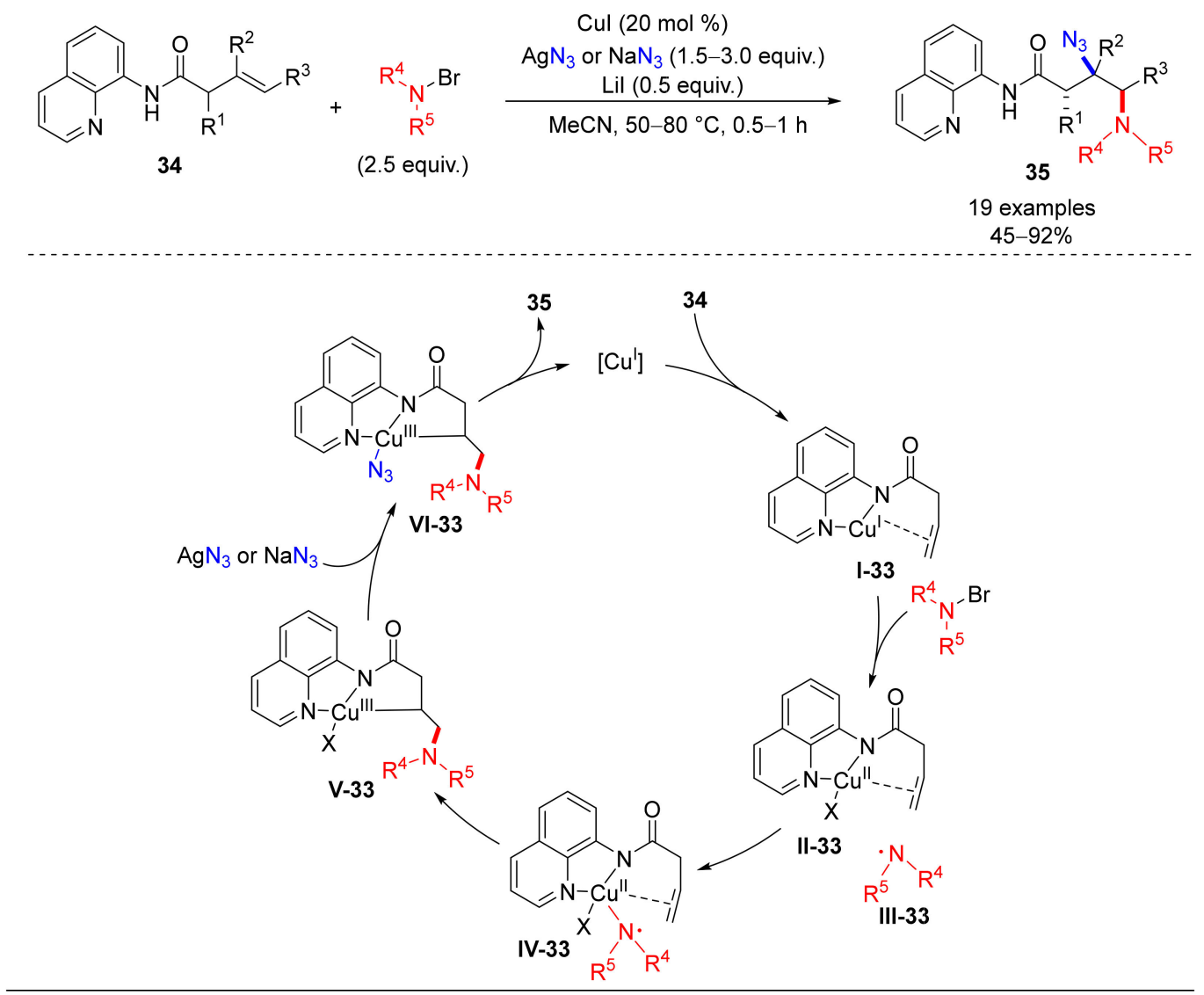

Scheme 33. Cu-catalyzed amination/azidation reaction.

In 2014, Studer and Zhang developed a new aminoazidation of alkenes using NFSI as nitrogen-radical precursor and $\mathrm{TMS}-\mathrm{N}_{3}$ as azide source with 1,10-phenantroline as ligand (Scheme 34) $[89,90]$. These conditions allow the difunctionalization of different styrene derivatives in moderate to high yields and the reaction on internal alkenes occurs with high diastereoseletivity.

The mechanism plausibly involves an initial NFSI reduction by the $\mathrm{Cu}(\mathrm{I})$-catalyst to afford two possible $\mathrm{Cu}$ (III)-species (I-34 and II-34), which are both sources of bis-sulfonylamidyl radical. These latter add to the alkene generating the radical III-34 beside the $\mathrm{Cu}$ (II)-species IV-34. The aminoazidation product can arise either from the reductive elimination of azido- $\mathrm{Cu}(\mathrm{III})$ intermediate $\mathbf{V}-\mathbf{3 4}$ or from the attack of the azide ion on the cationic intermediate VI-34. 


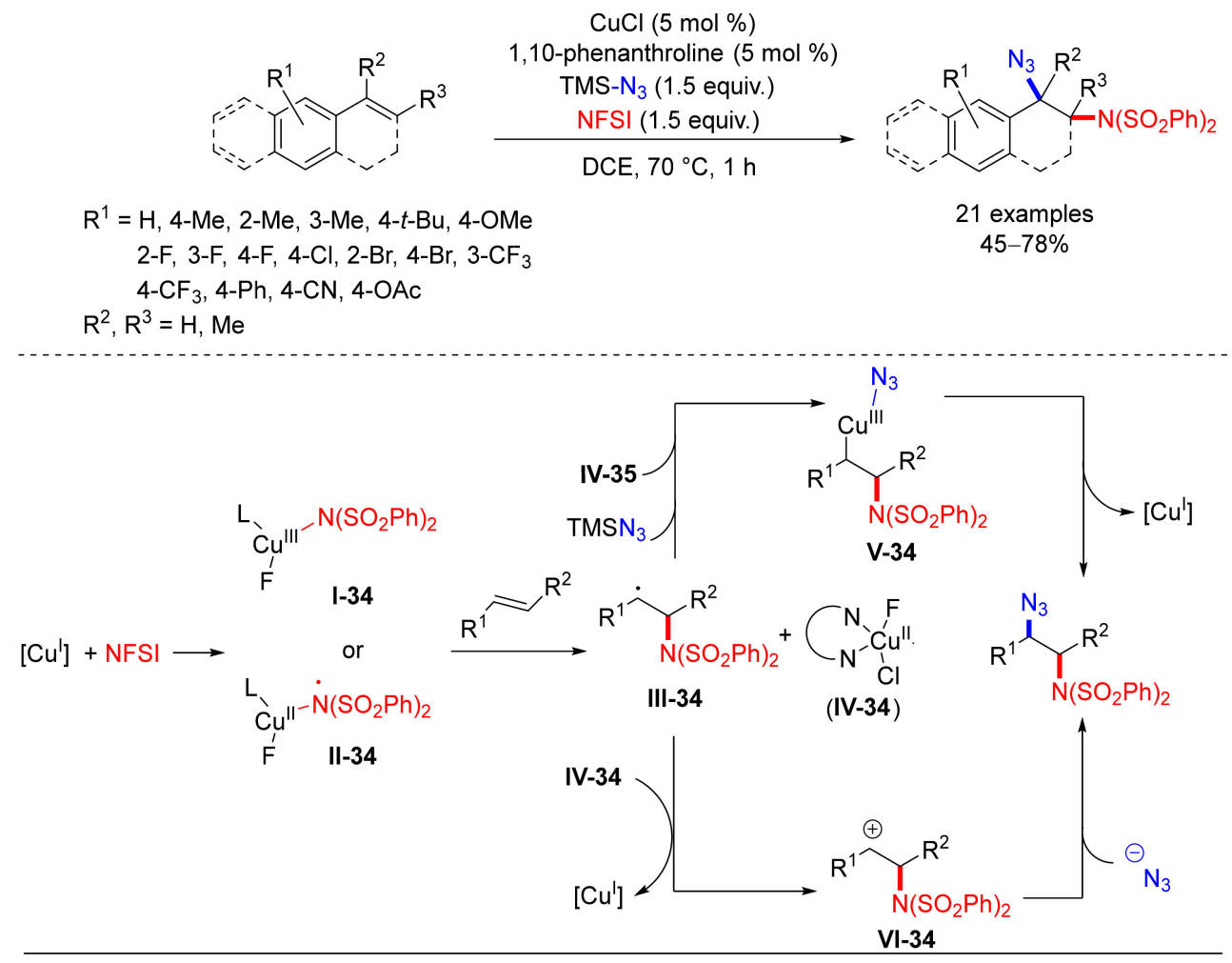

Scheme 34. Aminoazidation of olefins with $N$-fluorobenzenesulfonamide (NFSI).

Five years later, Zhang and co-workers extended this aminoazidation procedure to arylcyclopropanes as a route to obtain 1,3-aminoazidation products using bathocuproine $\mathbf{3 6}$ as the ligand (Scheme 35) [91].
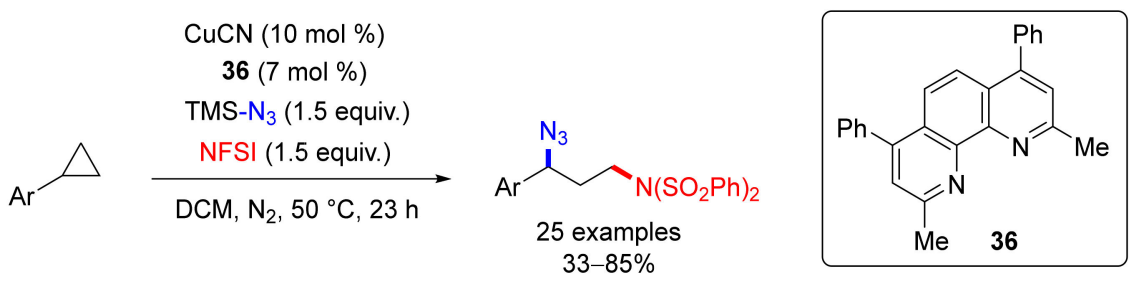

Scheme 35. Aminoazidation of arylcyclopropanes with NFSI.

In the field of aminoazidation, $\mathrm{Li}$ and co-workers studied an iron catalysis methodology for the addition of NFSI to olefins in the presence of $\mathrm{FeCl}_{2}$ as catalyst and TMS- $\mathrm{N}_{3}$ as azide source (Scheme 36) [92]. The reaction proceeds following a radical mechanism and styrene derivatives have proved to be the best substrates for the process among the non-activated alkenes.

In 2017, Wang and Shen reported a copper catalyzed cyclization/azidation of $N$-methoxy alkenyl amides providing an efficient strategy for the synthesis of azido-substituted azaheterocycles (Scheme 37) [93,94]. Azidoiodinanes were selected as highly electrophilic azide source to overcome the competition with protonation and $\beta$-hydride elimination processes. The reaction could start either by activation of the alkene by a $\mathrm{Cu}(\mathrm{II})$-catalyst (through the intermediate I-37) or by a $\mathrm{Cu}$ (III)-intermediate II-37, which was generated from the interaction between $\mathrm{Cu}(\mathrm{I})$ and $\mathrm{ABX}$. In both cases, the subsequent step involves an exo or endo cyclization that allows the formation of the final products. 


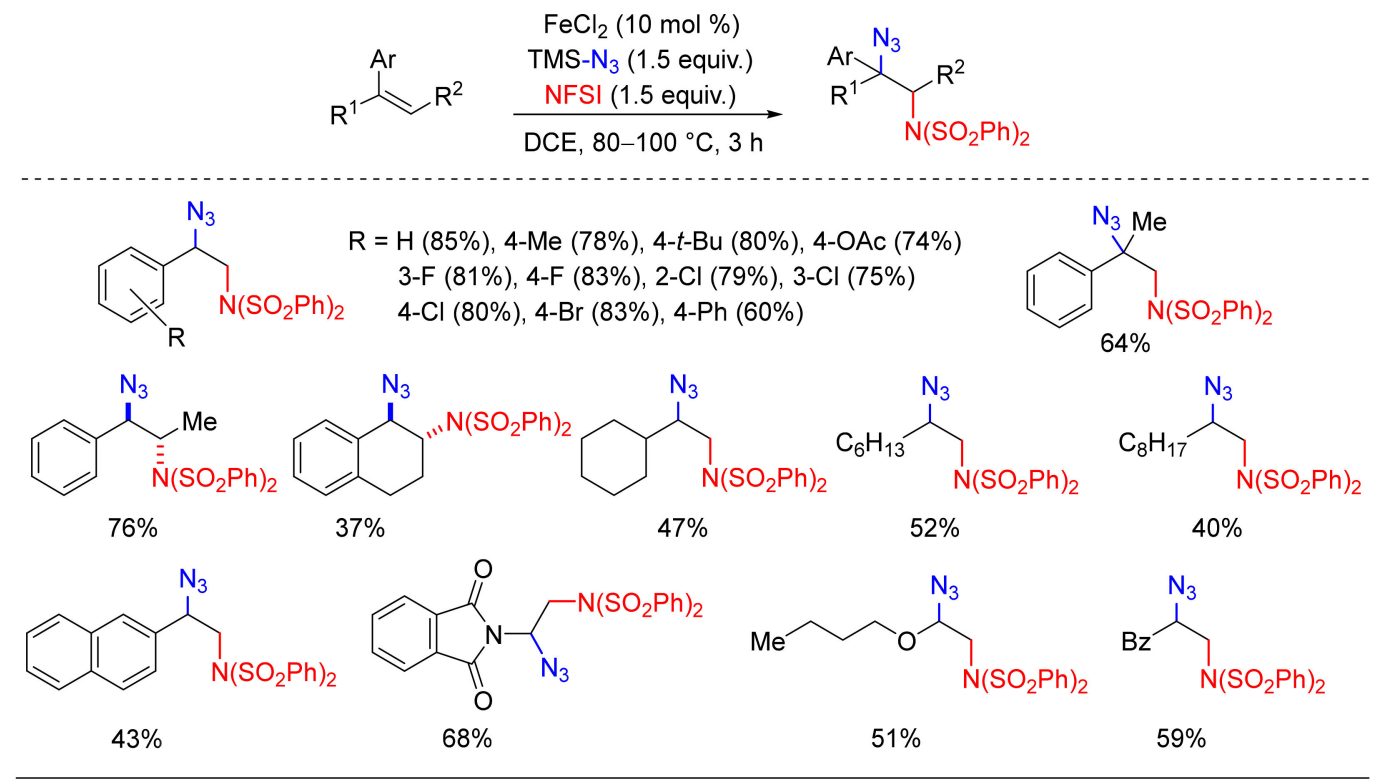

Scheme 36. Iron catalyzed aminoazidation with NFSI reagents.
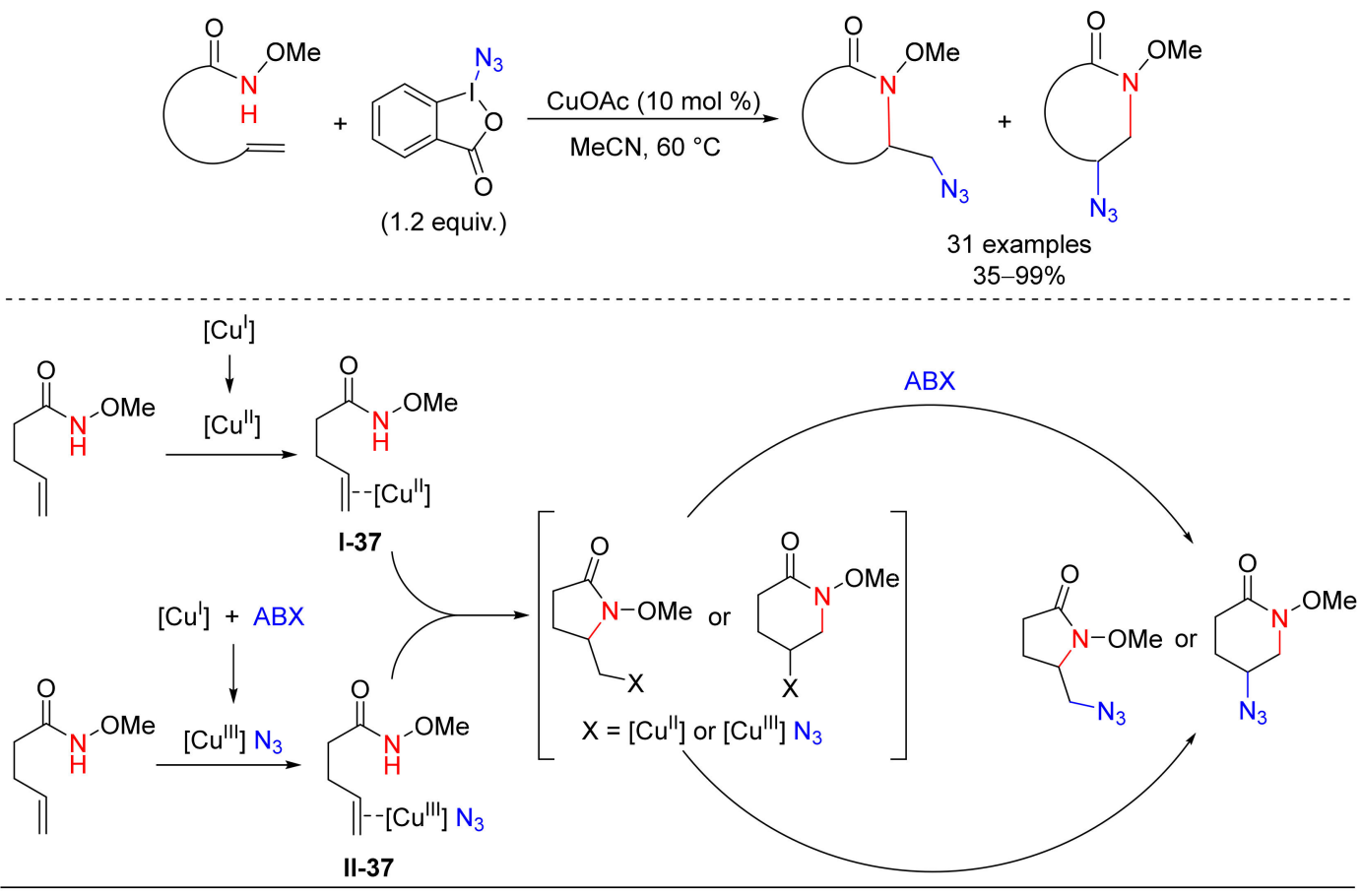

Scheme 37. Copper catalyzed aminoazidation of alkenes.

An iron catalyzed intramolecular amination/intermolecular azidation of the unactivated alkenes 37 has been recently reported by Prestat's group for the aminoazidation of allyl acetoxy carbamates, ureas, and amides [95]. As reported in Scheme 38, imidazoles, oxazoles, or pyrrolidinones 38 have been achieved with losing of the OAc protecting group and attack of the nitrogen on the alkenyl moiety.

Recently, an intramolecular palladium catalyzed aminoazidation of unactivated terminal alkenes in oxidative conditions was developed [96]. The reaction occurs in mild conditions in the presence of a $\mathrm{Pd}(\mathrm{II})$-catalyst and $\mathrm{H}_{2} \mathrm{O}_{2}$ as oxidant agent allowing to obtain five-, six-, and seven-membered heterocyclic rings through a selective exo-cyclization (Scheme 39). The possible mechanism starts with the coordination of the Pd(II)-catalyst to the alkenyl double bond giving the $\pi$-olefin complex I-39, followed by the generation of the $\sigma$-alkyl-complex II-39. The latter was oxidized to the 
Pd(IV)-intermediate III-39 by $\mathrm{H}_{2} \mathrm{O}_{2}$ and, finally, intervention of the azide ion provided the desired aminoazidation product with regeneration of the $\mathrm{Pd}(\mathrm{II})$-species.

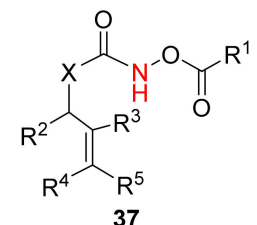

$\mathrm{X}=\mathrm{NBn}, \mathrm{NMe}, \mathrm{O}, \mathrm{CH}_{2}$

$\mathrm{R}^{1}=\mathrm{Me}, \mathrm{Ph}, 2,4-\mathrm{Cl}-\mathrm{C}_{6} \mathrm{H}_{3}, 2,4-\mathrm{CF}_{3}-\mathrm{C}_{6} \mathrm{H}_{3}$

$\mathrm{R}^{2}=\mathrm{H}, \mathrm{Me}$, cyclohexenyl

$\mathrm{R}^{3}=\mathrm{H}, \mathrm{Me}$

$\mathrm{R}^{4}=\mathrm{H}, \mathrm{Me}, 4-\mathrm{NO}_{2}-\mathrm{C}_{6} \mathrm{H}_{4}, 4-\mathrm{Cl}-\mathrm{C}_{6} \mathrm{H}_{4}$

$\mathrm{R}^{5}=\mathrm{H}, \mathrm{Me}, \mathrm{Ph}, 2-\mathrm{OMe}-\mathrm{C}_{6} \mathrm{H}_{4}, 4-\mathrm{OMe}-\mathrm{C}_{6} \mathrm{H}_{4}$

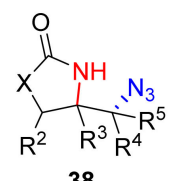

38

26 examples $27-87 \%$

Scheme 38. Aminoazidation of amides, ureas, and carbamates derivatives.

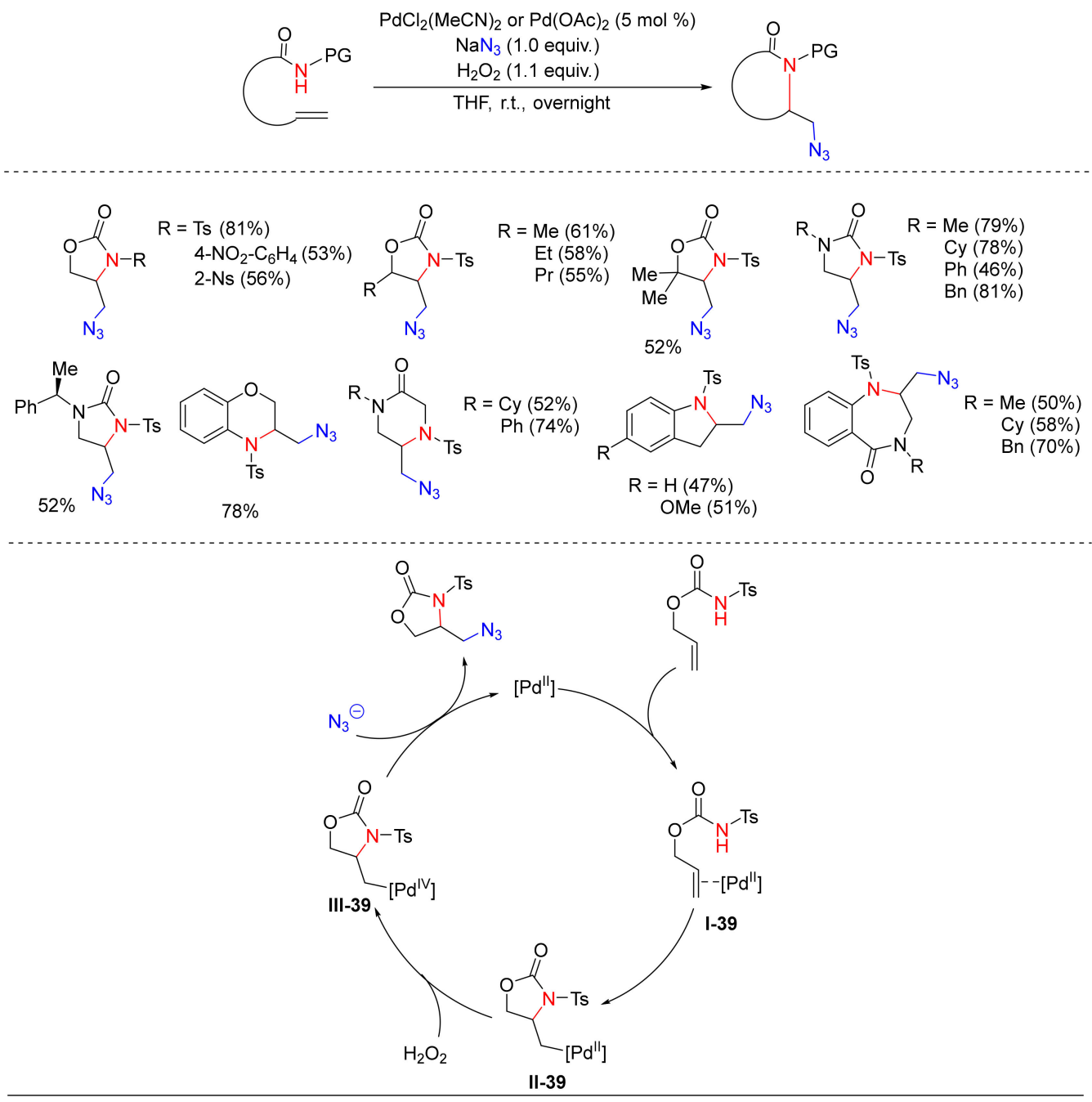

Scheme 39. Aminoazidation of unactivated terminal alkenes in oxidative conditions.

In 2020, an enantioselective Pd-catalyzed azidation of unactivated alkenes in oxidative conditions has been reported by Liu and co-workers [97]. This procedure was proven to be efficient for the synthesis of 3-azido-substituted piperidines, achieved by treatment of 5-aminoalkenes with catalytic $\mathrm{Pd}(\mathrm{OAc})_{2}, \mathrm{ABX}$ as the azide source and oxidizing agent, and the (4R,5S)-2-(6-benzhydrylpyridin-2-yl)-4,5-diphenyl-4,5-dihydrooxazole (39) ligand (Scheme 40). 
An electrophilic azidating reagent and a sterically bulky chiral Pyox ligand are essential for the outcome of the reaction.

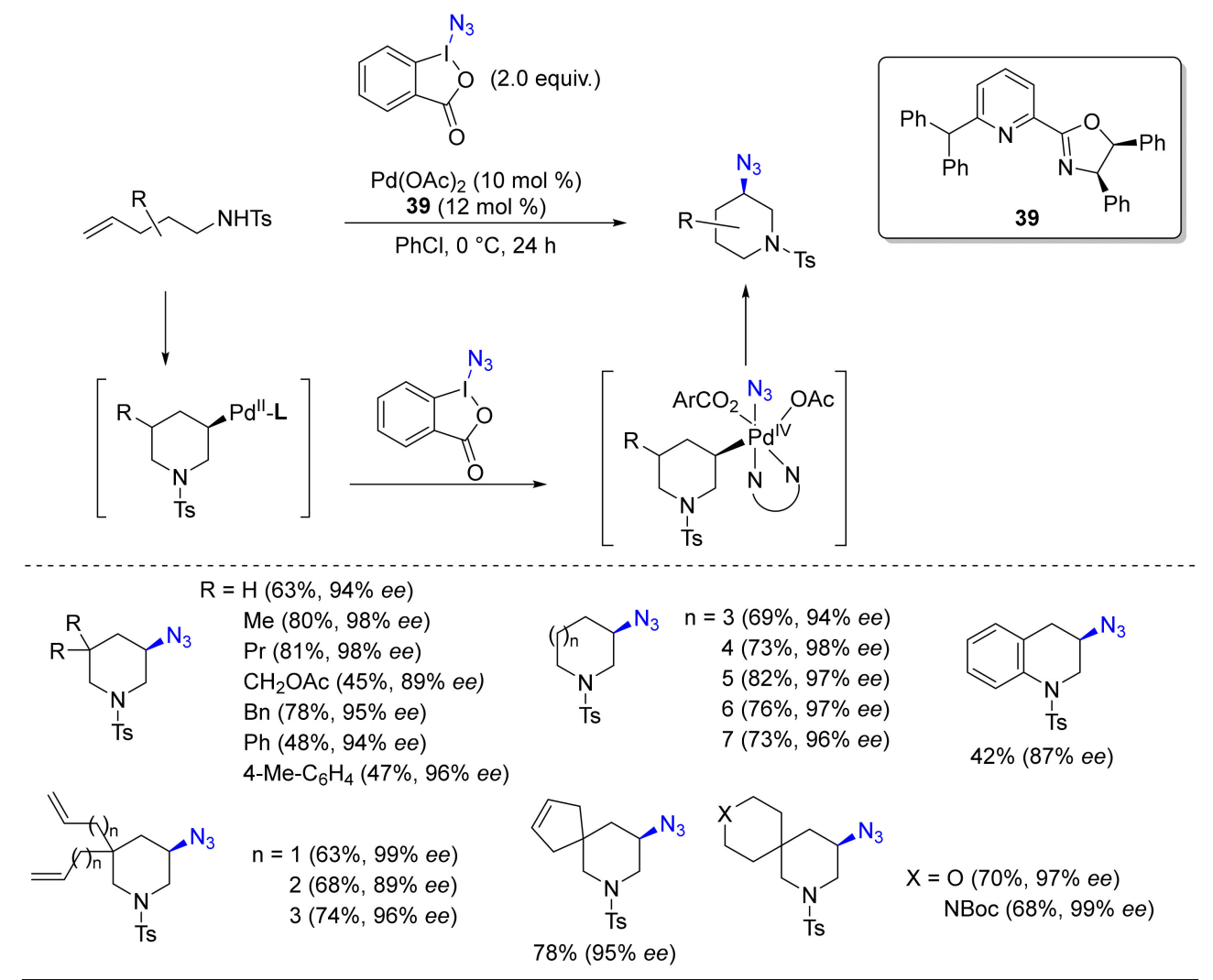

Scheme 40. Enantioselective oxidative Pd-catalyzed azidation of unactivated alkenes.

A procedure for the imination/azidation of $C$-alkenyl $O$-benzoyl oximes was reported by $Y u$ and co-workers in 2015 [98]. The reaction, operative in the presence of $\mathrm{Cu}(\mathrm{I})$-catalyst, TMS- $\mathrm{N}_{3}$, and the 1,3-dicarbonyl compound 40 as copper ligand, occurs through a reductive $\mathrm{N}-\mathrm{O}$ bond cleavage and subsequent $\mathrm{C}-\mathrm{N}$ bond formation (Scheme 41 ). Two possible mechanisms are proposed by authors. The first one starts with a SET between the substrate and $\mathrm{Cu}(\mathrm{I})$ with generation of the iminyl radical I-41. Its cyclization forms the intermediate II-41 that evolves into the product through oxidation by the $\mathrm{Cu}(\mathrm{II}) \mathrm{N}_{3}$ species arising from $\mathrm{Cu}(\mathrm{II})$ and $\mathrm{TMS}-\mathrm{N}_{3}$. Alternatively, an initial oxidative addition of the $\mathrm{Cu}(\mathrm{I})$-species to the $\mathrm{N}-\mathrm{O}$ bond of the substrates results in the intermediate III-41, which undergoes a ligand exchange between $\mathrm{PhCO}_{2}{ }^{-}$and $\mathrm{N}_{3}{ }^{-}$anions giving the cyclization step. The so-formed intermediate $\mathbf{I V - 4 1}$ gives reductive elimination affording the imination/azidation product.

In 2016, Wan and co-workers developed the diastereoselective azidation of the 1,7-enynes 41, where transition metals and ligands play a crucial role on the control of the diastereoselectivity [99]. As shown in Scheme 42, trans-products 42 were obtained working with $\mathrm{Mn}(\mathrm{OAc})_{3}$, otherwise cis-ones 43 were achieved using the system $\mathrm{Cu}(\mathrm{II})$ as catalyst and 2,2' -bipyridine as ligand. From the mechanistic point of view, the radical intermediate $\mathbf{I}-\mathbf{4 2}$, possibly generated by a free azidiyl radical addition or an azide transfer oxidation, undergoes a 6-exo-dig cyclization giving the vinyl radical II-42. This radical can be trapped by the azido group with releasing of one molecule of nitrogen in the second cyclization step to afford aminyl radical III-42. Its alkyl radical tautomer IV-42 undergoes an azide transfer oxidation process giving the final products. The stereodivergent effect could be ascribable to the different effect of coordination given by the transition metal complex that was used. NFSI and $t$-butyl perbenzoate (TBPB) regenerate the catalysts by oxidation of the low-valent metals $\mathrm{Mn}(\mathrm{II})$ and $\mathrm{Cu}(\mathrm{I})$. 

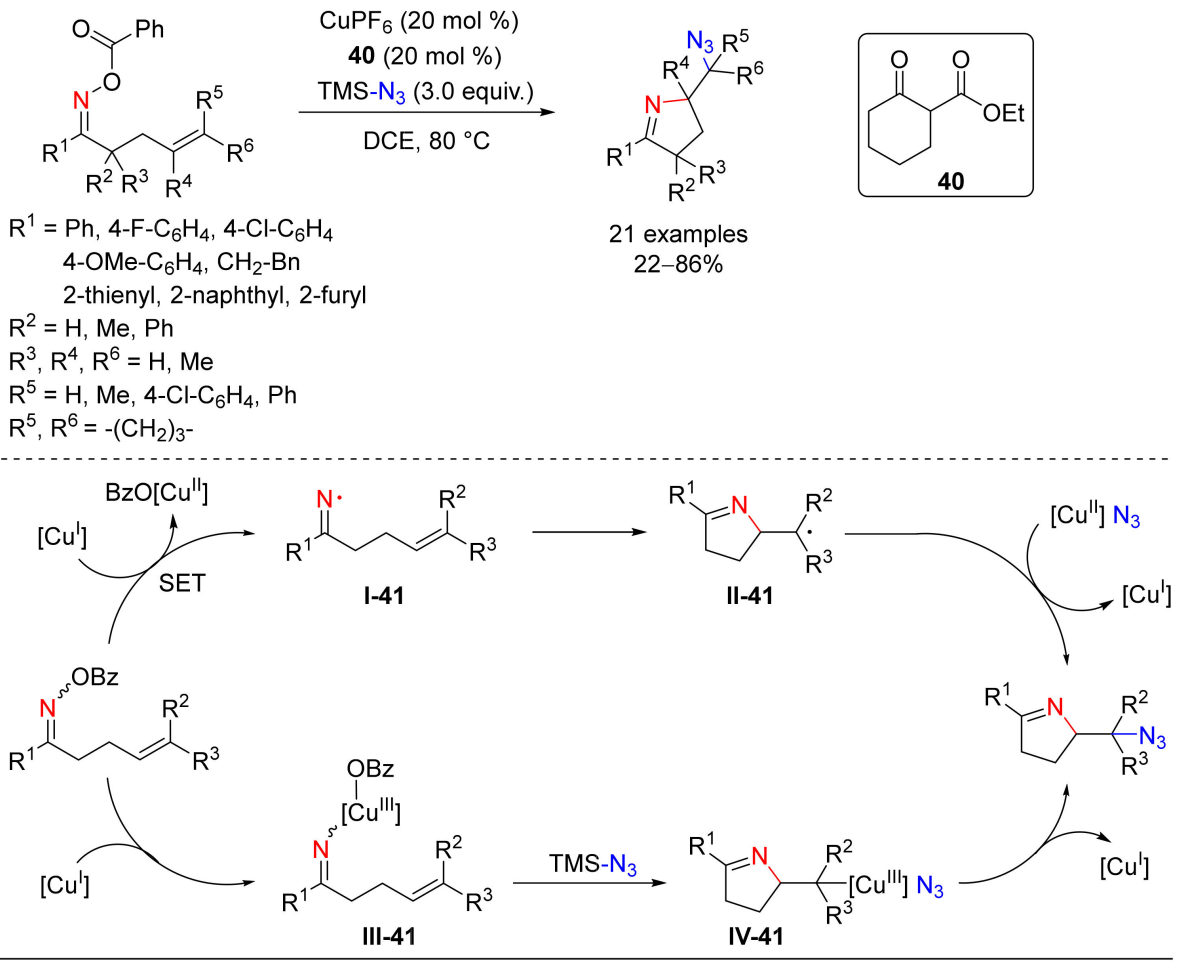

Scheme 41. Imination/azidation procedure.

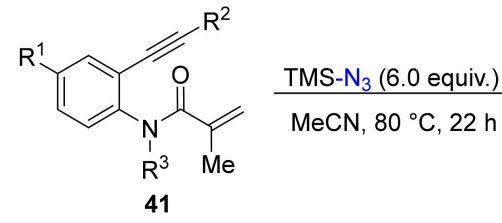

$\mathrm{R}^{1}=\mathrm{H}, \mathrm{Me}, \mathrm{Cl}$

$\mathrm{R}^{2}=\mathrm{Ph}, 2-\mathrm{Me}-\mathrm{C}_{6} \mathrm{H}_{4}, 3-\mathrm{F}-\mathrm{C}_{6} \mathrm{H}_{4}, 4-\mathrm{Me}-\mathrm{C}_{6} \mathrm{H}_{4}$ $4-\mathrm{F}-\mathrm{C}_{6} \mathrm{H}_{4}, 4-\mathrm{Cl}-\mathrm{C}_{6} \mathrm{H}_{4}, 4-\mathrm{Br}-\mathrm{C}_{6} \mathrm{H}_{4}$

$\mathrm{R}^{3}=\mathrm{Ts}, \mathrm{Ms}, \mathrm{Me}, \mathrm{Bn}$

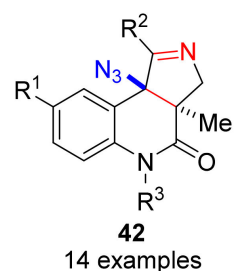

$19-72 \%$

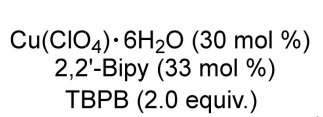

14 examples

$46-86 \%$

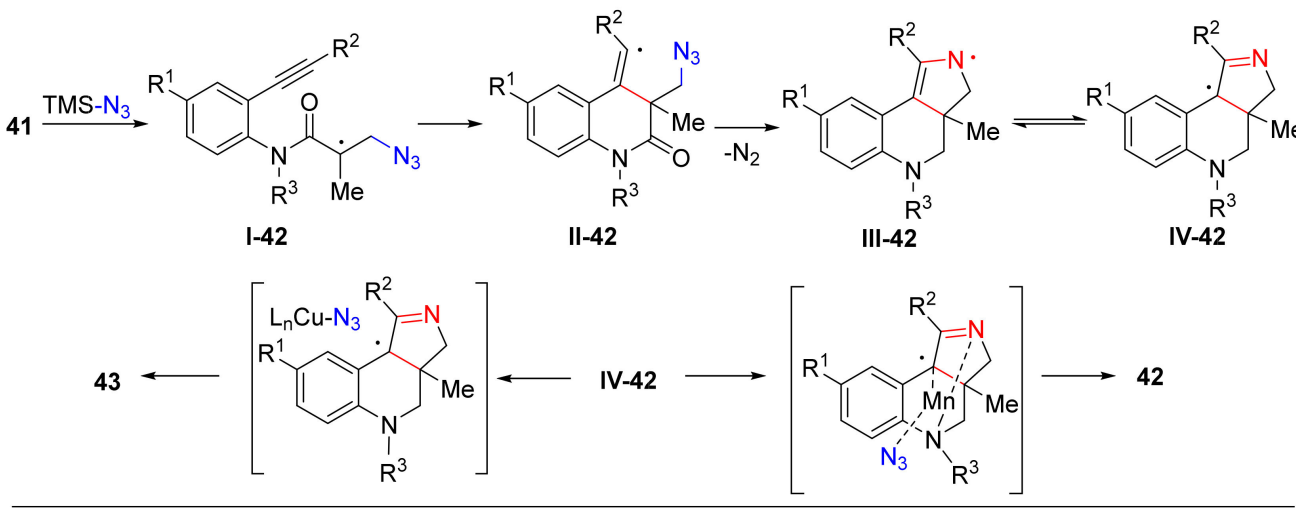

Scheme 42. Copper catalyzed azidation/cyclization of 1,7-enynes. 
Analogous conditions based on the copper catalysis for the conversion of $1, n$-enynes into fused pyrroline compounds were reported by Song and Li (Scheme 43) [100].

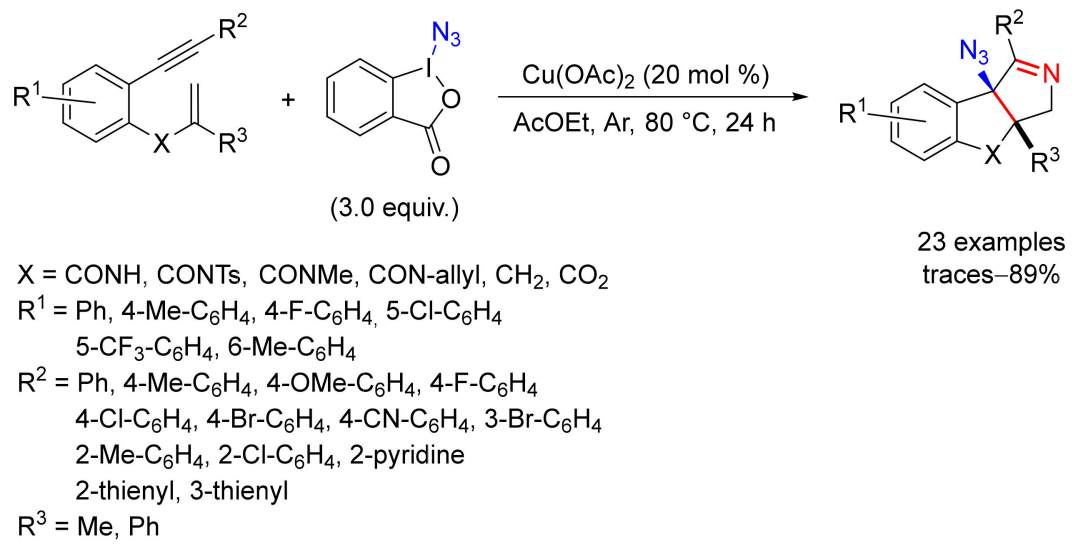

Scheme 43. Cu-catalyzed azidation of 1,6- or 1,7-enynes.

\subsection{Diazidation}

In 2015, Loh and co-workers investigated the vicinal diazidation of styrenes by copper catalysis and found that the use of $\mathrm{CuI}$ as catalyst combined with the $\mathrm{ABX}$ reagent was effective to obtain 1,2-diazide derivatives [101]. The change of copper salt and solvent led to the formation of the oxyazidation products starting from substrates bearing electron-withdrawing as well as electron-donating substituents on the aromatic ring (Scheme 44).

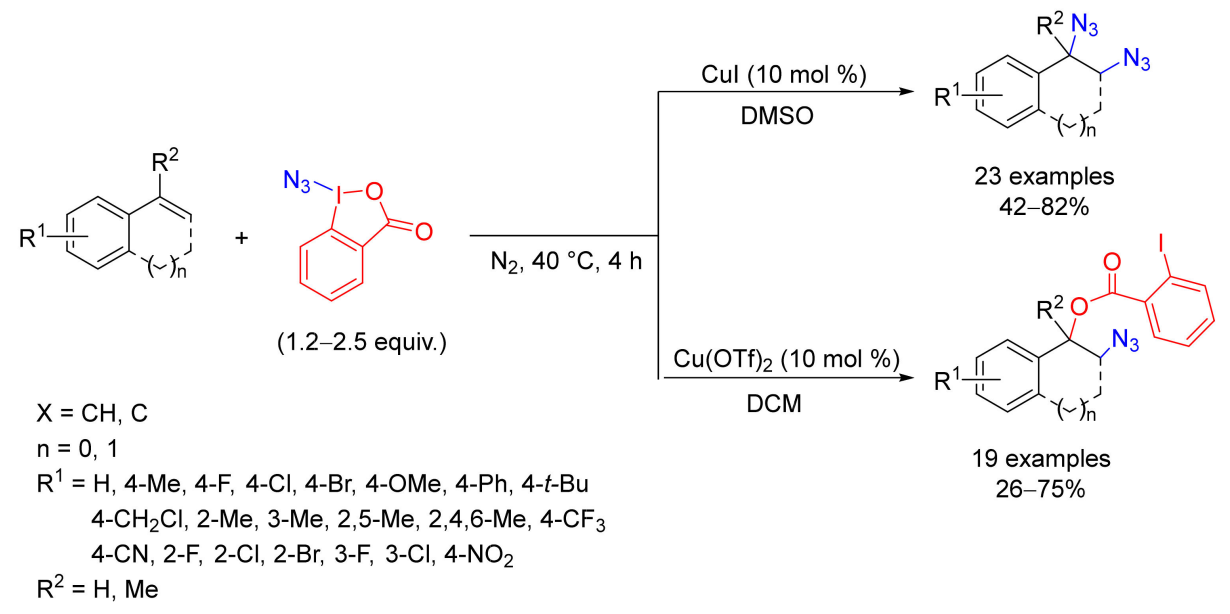

Scheme 44. Cu-catalyzed diazidation vs. oxyazidation of styrenes.

An alternative $\mathrm{Cu}$-catalyzed olefin diazidation operative with $\mathrm{TMS}-\mathrm{N}_{3}$ as the azide transfer combined with TBPB as the oxidant was reported by Bao and co-workers (Scheme 45) [102]. These conditions, which can be used in water as solvent, worked on both 1,1- and 1,2-disubstituted olefins. TBPB is assumed to generate the $\mathrm{Cu}(\mathrm{II})$-species $\mathbf{I}-45$ and the $t$-butoxyl radical. The latter converts TMS- $N_{3}$ into the azido radical that adds to the olefin affording the radical intermediate II-45. Ligand exchange generates the $\mathrm{Cu}(\mathrm{II}) \mathrm{N}_{3}$ species, which gave the final product after interaction with II-45.

A few decades ago, in a pioneering work Minisci and Galli reported the diazidation and alkoxyazidation of alkenes by a radical $\mathrm{Fe}(\mathrm{II}) / \mathrm{Fe}(\mathrm{III})$ process in presence of $\mathrm{H}_{2} \mathrm{O}_{2}$ as oxidant reagent $[103,104]$. 


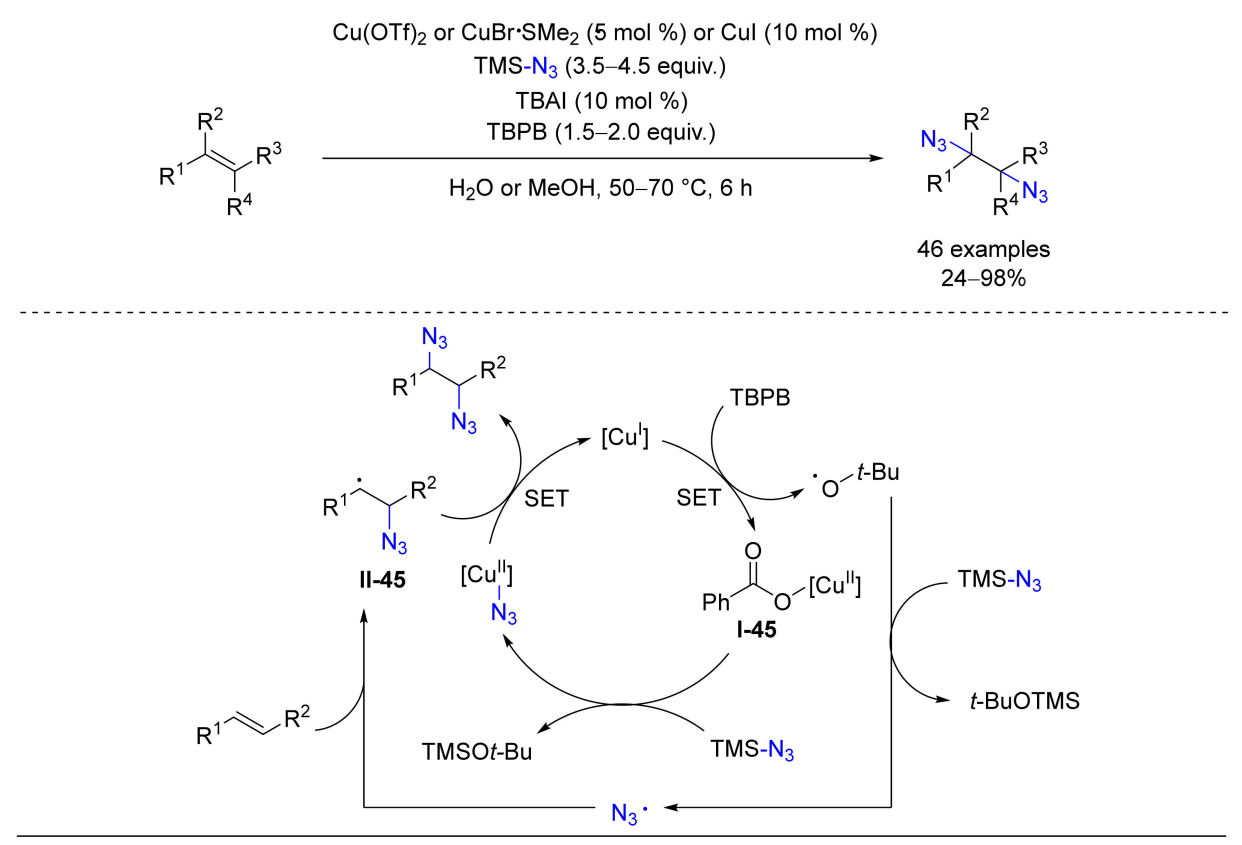

Scheme 45. Cu-catalyzed diazidation.

More recently, $\mathrm{Xu}$ and co-workers focused their attention on iron catalyzed diazidation of the alkenes 44 with the in situ generated azido-benziodioxole and a $\mathrm{Fe}(\mathrm{II})$ salt with the 2,6-bis(4,4-dimethyl-4,5-dihydrooxazol-2-yl)pyridine ligand (46), developing the trans diazidation of a wide range of olefins [105]. As proposed by Minisci and Galli work, the reaction mechanism is based on a radical process, involving an $\mathrm{Fe}$ (III) species. The intermediate I-46, generated from $\mathrm{TMS}^{-\mathrm{N}_{3}}$ and benziodioxole, in the presence of the iron catalyst is converted into the complex II-46, which finally evolves in the product 45 (Scheme 46).
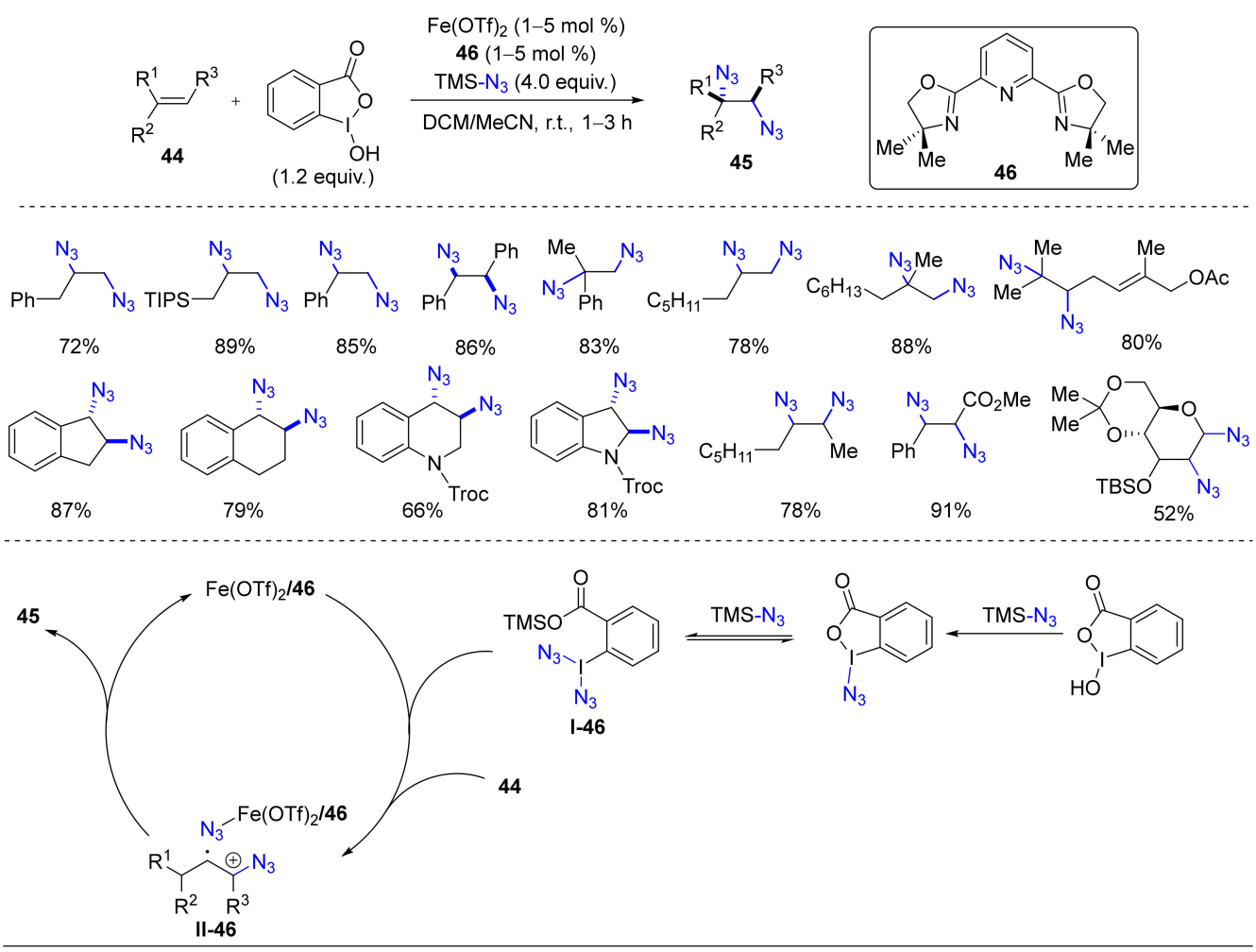

Scheme 46. Iron catalyzed diazidation of olefins. 
In 2018, the same authors investigated a diazidation process using the alkenes 47 and exploiting peroxide agents for the generation of the azido radical to yield products 48 (Scheme 47) [106]. The activation of peroxide by $\mathrm{Fe}(\mathrm{II})$ precatalyst may be facilitated by the formation of an iron-azido-ligand complex I-47 generated in situ, which speeds up the rate-determining C- $\mathrm{N}_{3}$ bond formation.
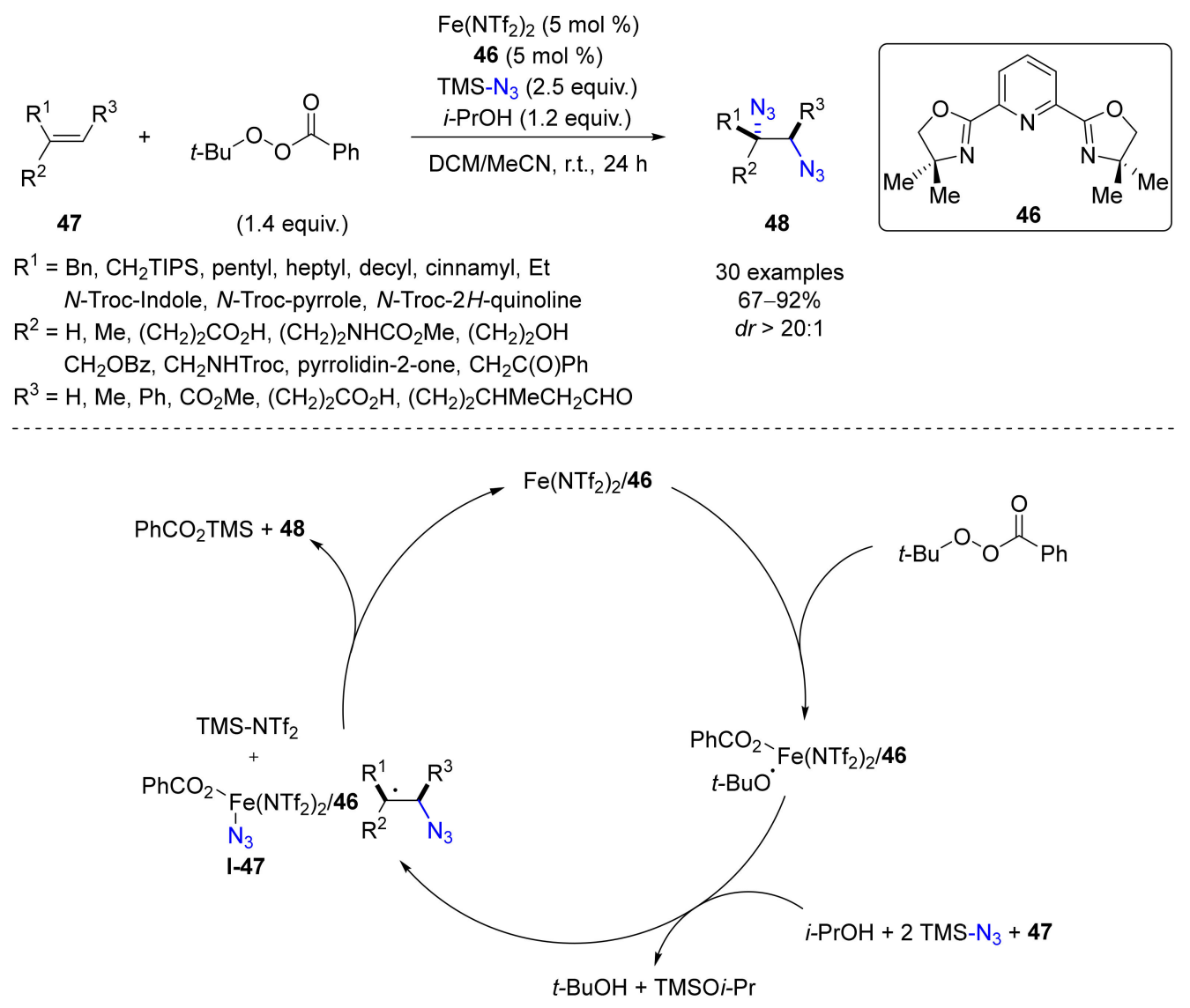

Scheme 47. Diazidation of alkenes by iron complexes and peroxide agents.

In 2017, Liu and co-workers developed a Pd(II)-catalyzed diazidation of olefins in oxidative conditions [107]. The optimal results were obtained working with $\operatorname{Pd}(\mathrm{TFA})_{2}$ as a catalyst, TMS- $\mathrm{N}_{3}$ as azide source, and NFSI as oxidant in the presence of the bidentate nitrogen ligand 4,7-di(4-bromophenyl)-1,10-phenanthroline 49. This reaction is compatible with a wide range of functional groups as well as with internal alkenes, whereas cyclic alkenes show high diastereoselectivity when water was used as co-solvent (Scheme 48). A plausible mechanism starts with the oxidation of the catalyst by NSFI to generate the intermediate I-48, which in turn oxidizes TMS- $\mathrm{N}_{3}$ through a SET process giving a Pd(III)-species II-48 and an azido radical. The latter reacted with the alkene providing a carbon radical, which in turn interacts with $\mathrm{TMS}^{-\mathrm{N}_{3}}$ yields the $\mathrm{Pd}(\mathrm{IV})$-species III-48 Ligand exchange and reductive elimination afforded the diazidation product. Alternatively, the $\mathrm{Pd}(\mathrm{III})-\mathrm{N}_{3}$ complex IV-48, arising from II-48 and TMS-N ${ }_{3}$, could be involved, followed by reaction with the carbon radical V-48 at the external nitrogen atom giving the product beside the regenerated $\mathrm{Pd}(\mathrm{II})$-species. 

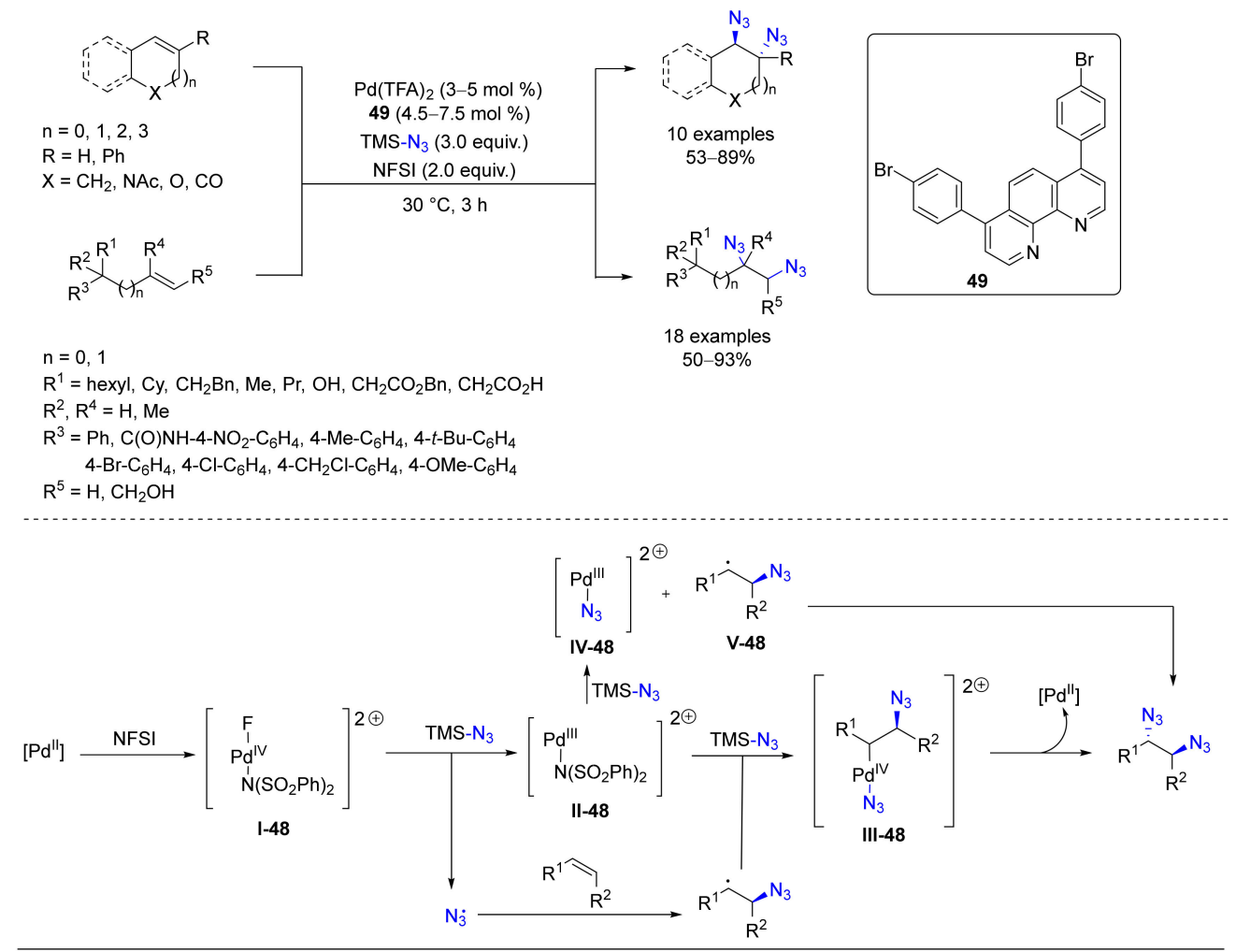

Scheme 48. Pd(II)-catalyzed diazidation of olefins.

In 2017, Lin and co-workers developed an electrochemical protocol for the manganese catalyzed diazidation of olefins, which is an environmentally friendly way to vicinal diazides [108]. The best conditions were identified using $\mathrm{MnBr}_{2} \cdot 4 \mathrm{H}_{2} \mathrm{O}$ as the catalyst, $\mathrm{NaN}_{3}$ as the azide source, $\mathrm{LiClO}_{4}$ as the electrolyte with an $\mathrm{RVC} / \mathrm{Pt}$-cell in $\mathrm{MeCN} / \mathrm{AcOH}$ (9:1) as solvent (Scheme 49). This procedure resulted in excellent chemoselectivity and was applicable to alkenes bearing a wide range of substituents. The selectivity of this process is due to $\mathrm{MnBr}_{2}$ that inhibits competitive side reactions, such as radical $\mathrm{N}_{3}$ dimerization, $\mathrm{C}-\mathrm{H}$, or electron abstraction. The azidation reaction proceeds through a radical pathway promoted by a $\mathrm{Mn}(\mathrm{II})-\mathrm{N}_{3}$ species, which is oxidized to the azidyl transfer agent $\mathrm{Mn}(\mathrm{III})-\mathrm{N}_{3}$. The $\pi$-bond homolyses of the alkene from the Mn(III)species allows the formation of the diazidated product.
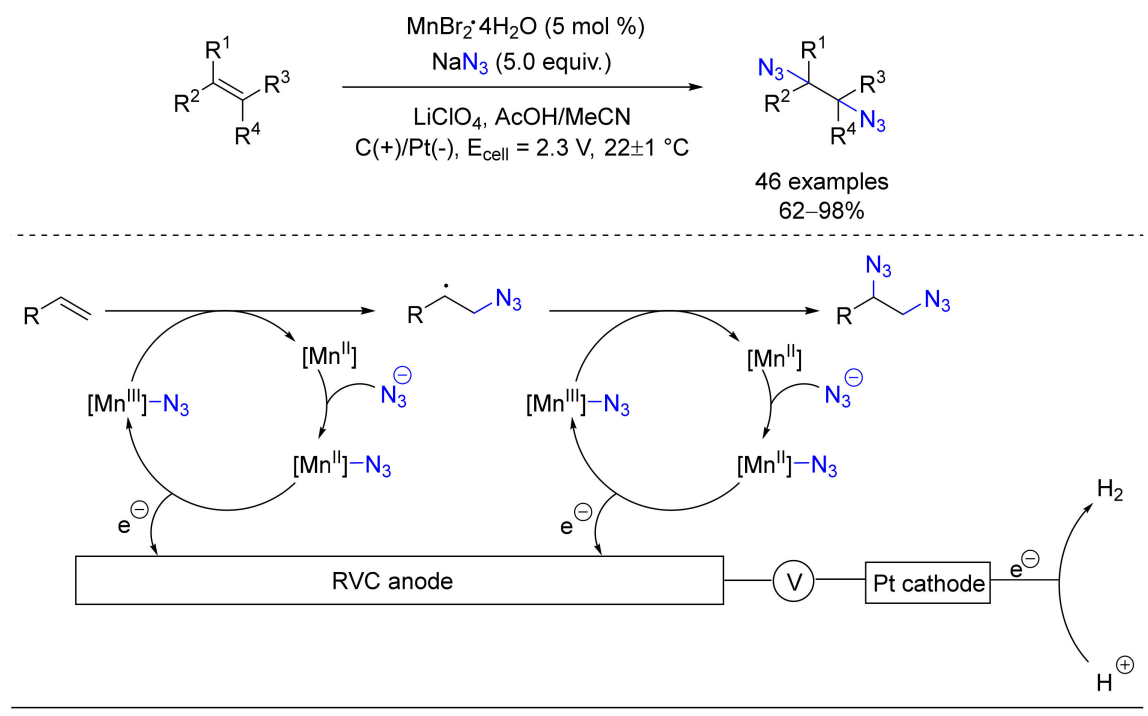

Scheme 49. Electrochemical diazidation of olefins. 


\subsection{Hydroxylation/Azidation}

In 2015, Jiao and co-workers reported a Mn-catalyzed aerobic oxidative hydroxyazidation of alkenes as a new synthetic procedure to access to $\beta$-azido alcohols, which are very important in the chemistry of carbohydrates and nucleosides [109]. The optimal conditions were found with $\mathrm{MnBr}_{2}$, which worked both as catalyst for the generation of azido radical as well as a stabilizer of the peroxyl radical intermediate and atmospheric oxygen as oxidant (Scheme 50). Further addition of $\mathrm{PPh}_{3}$ to reduce the peroxy alcohols intermediates provided substituted products from styrenes and heteroaromatic olefins. The possible reaction mechanism starts with the oxidation of $\mathrm{MnBr}_{2}$ to $\mathrm{Mn}$ (III), which in turn oxidizes TMS- $\mathrm{N}_{3}$ to the azido radical. The latter reacts with the olefin at the sterically less hindered position to produce the radical intermediate I-50. This intermediate is trapped by $\mathrm{O}_{2}$ giving the peroxy radical II-50, which is converted into the $\beta$-azido peroxy alcohol III-50 by a SET and subsequent protonation. Finally, $\mathrm{PPh}_{3}$ reduces III-50 to form the desired $\beta$-azido alcohol.

$$
\begin{gathered}
\text { a) } \mathrm{MnBr}_{2}(5 \mathrm{~mol} \%), \mathrm{H}_{2} \mathrm{O}(10.0 \text { equiv. }) \\
{^{2} \text { air, r.t. }} }
\end{gathered}
$$

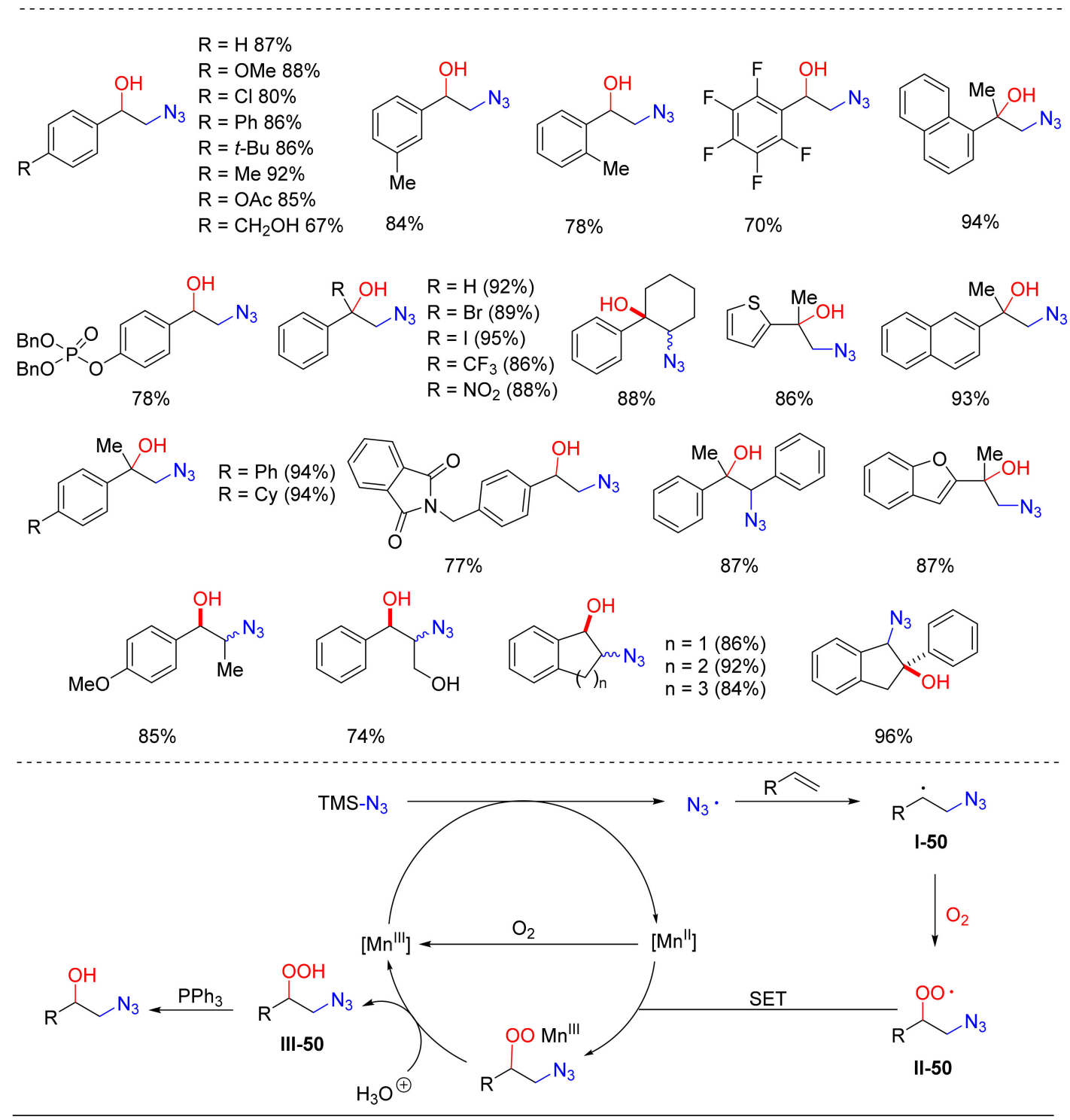

Scheme 50. Hydroxyazidation of terminal and internal styrenes. 


\subsection{Alkoxylation/Azidation}

In a frame of a work focused on the difunctionalization of alkenes involving an azidation step, in 2015, Greaney developed a new way to obtain vicinal methoxyazides (Scheme 51) [110]. Working in the presence of $\left[\mathrm{Cu}(\text { dap })_{2}\right] \mathrm{Cl}$ as the catalyst, Zhdankin reagent as azide source in methanol with visible light, the azidomethoxylation of styryl derivatives was achieved. It is worth noting that a diazidation reaction was observed when the reaction has been performed in the dark. From a mechanistic point of view, the catalytic cycle seems to proceed via benzyl radical, which undergoes different pathways according to reaction conditions. In the dark, the lifetime of this species resulted to be long enough to permit a second azidation step after the first azido radical attack, while in the presence of light, the oxidation of the benzylic radical takes place, followed by trapping with methanol.

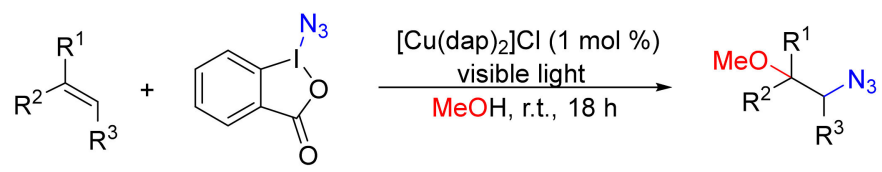

(1.0 equiv.)

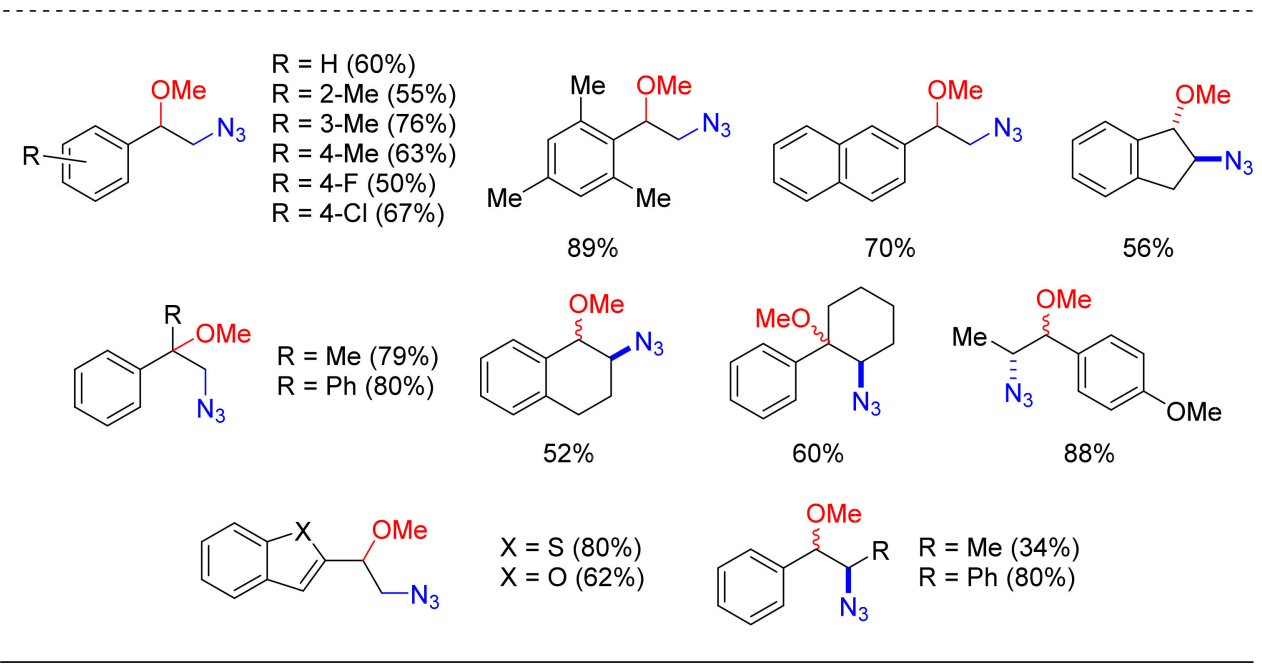

Scheme 51. $\mathrm{Cu}(\mathrm{I})$-catalyzed methoxyazidation.

In the same year, an intermolecular alkoxyazidation of the C2/C3-positions of indoles affording indolenines and oxindoles was proposed by Jiao and co-workers using catalytic $\mathrm{Cu}(\mathrm{acac})_{2}$ and azidoiodinane as azide source in alcohols as solvent and alkoxylation agent (Scheme 52) [111].<smiles>[R]c1ccc2[nH]cc([R])c2c1</smiles><smiles>N[I-]1OC(=O)c2ccccc21</smiles>

(1.5 equiv.)

$\mathrm{R}^{1}=\mathrm{Me}, \mathrm{OMe}$

$\mathrm{R}^{2}=\mathrm{Me}, \mathrm{Bu}, \mathrm{Pr}, \mathrm{Et}$

$\mathrm{R}^{3}=\mathrm{Me}, \mathrm{Et}, \mathrm{Bu}, \mathrm{CH}_{2} \mathrm{Bn}, i-\mathrm{Pr}$
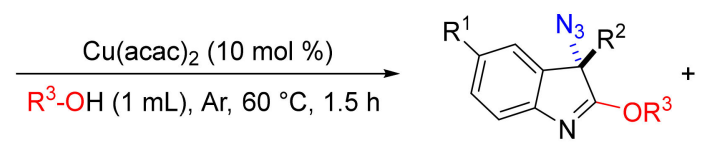<smiles>[R]c1ccc2c(c1)C([R])(N)C(=O)N2</smiles>

11 examples

$47-81 \%$

Scheme 52. Oxoazidation of indoles with 1-Azido-1,2-benziodoxol-3(1H)-one (ABX).

An intramolecular version of this procedure for the dearomatization of indoles has been proposed by the same authors starting from 3-indolyl-alcohols (Scheme 53, eq. A). In addition, tryptophols can undergo cyclization/azidation reaction using $\mathrm{Cu}(\mathrm{OAc})_{2} \cdot \mathrm{H}_{2} \mathrm{O}$ as the catalyst, $\mathrm{PhI}(\mathrm{OAc})_{2}$ as oxidant, and $\mathrm{NaN}_{3}$ as the azide source (Scheme 53, eq. B) [112]. These reaction conditions were proven to be 
suitable for the aminoazidation of tryptamine derivatives. The procedures described in eqs. A and B of Scheme 53 follow a radical mechanism based on an initial azidation at the indolyl C3-position and subsequent intramolecular nucleophilic attack at C2-position to obtain the desired product.

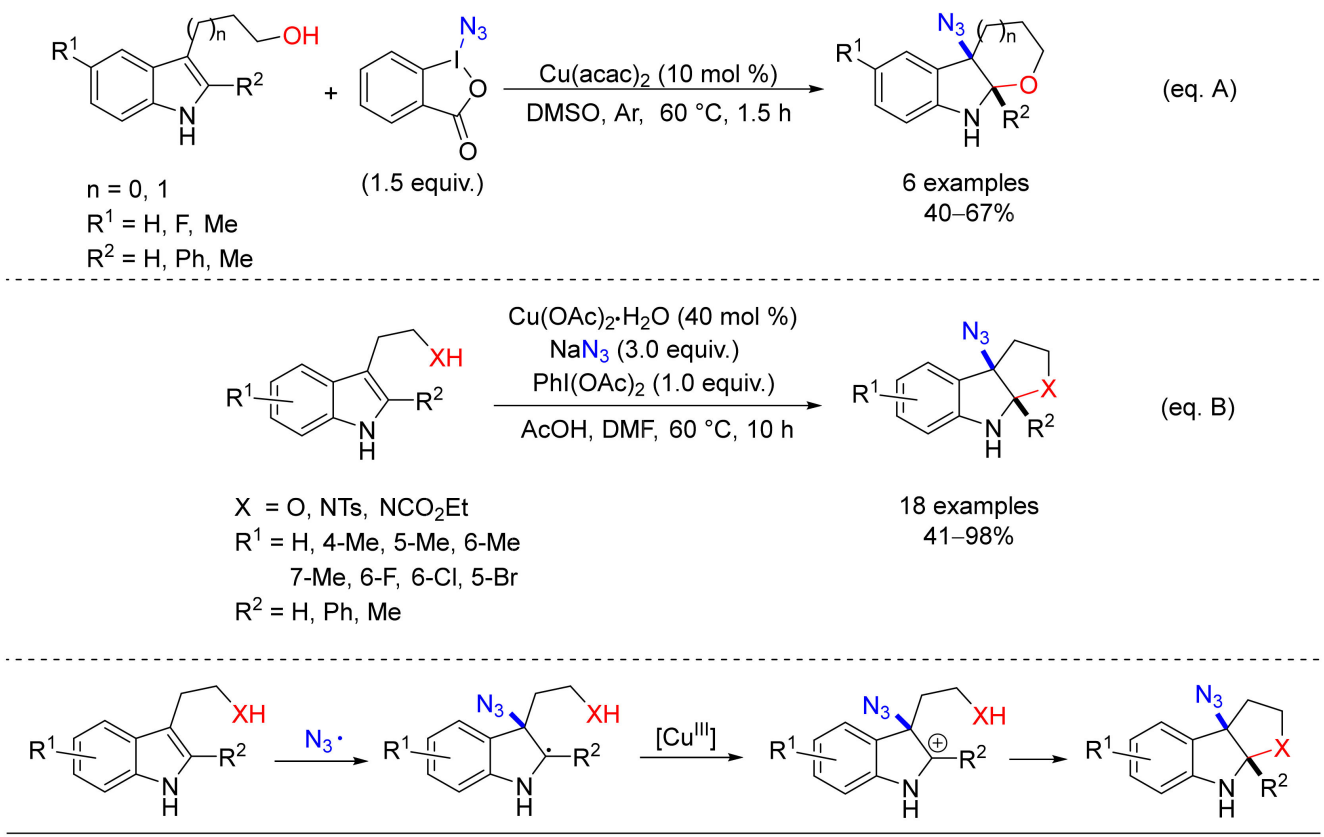

Scheme 53. Jiao and Wang's azidation/cyclization reactions.

In 2015, Buchwald and co-worker developed an enantioselective Cu-catalyzed procedure of chiral lactones by radical oxyazidation of alkene-containing carboxylic acids (Scheme 54) [113]. Using $\mathrm{Cu}(\mathrm{MeCN})_{4} \mathrm{PF}_{6}$ in the presence of $\mathrm{PhI}(\mathrm{OAc})_{2}, \mathrm{TMS}-\mathrm{N}_{3}$, and 2,2'-isopropylidenebis[(4S)-4-terbutyl-2-oxazoline] (50) at low temperature, a wide range of azidolactones containing tetrasubstituted stereogenic centers were obtained in good enantioselectivity.
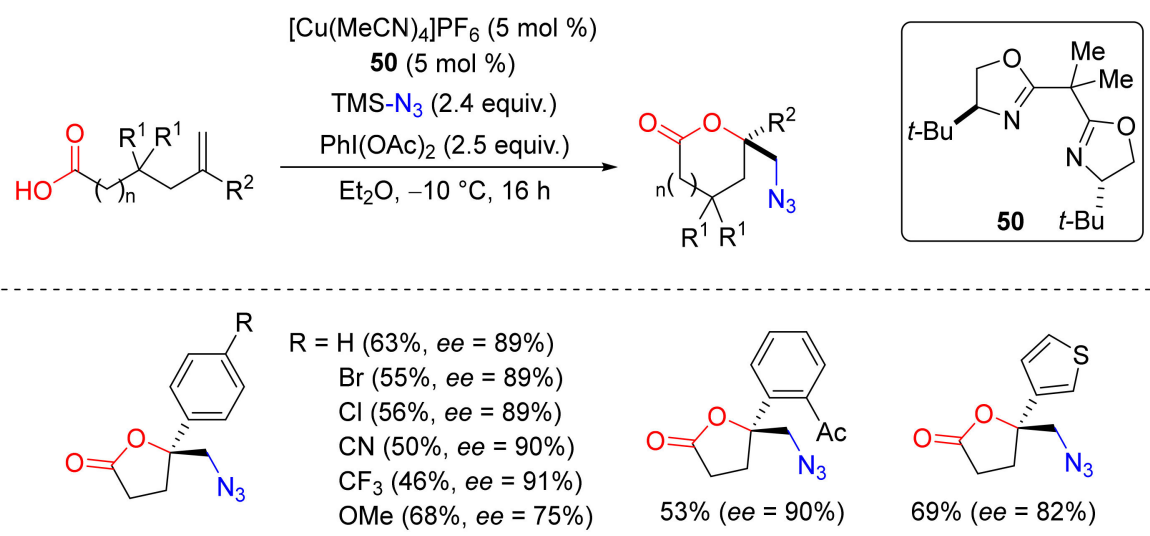

OMe $(68 \%$, ee $=75 \%)$

$53 \%(e e=90 \%)$

$69 \%(e e=82 \%)$

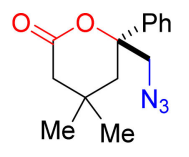

$68 \%(e e=92 \%)$

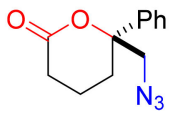

$62 \%(e e=89 \%)$

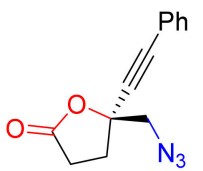

$50 \%(e e=72 \%)$

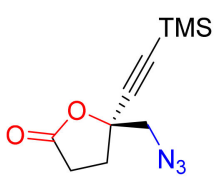

$44 \%(e e=82 \%)$

Scheme 54. Enantioselective Cu-catalyzed cyclization/azidation reactions of alkene-containing carboxylic acids. 
Two years later, Waser and co-workers also investigated the cyclization/azidation of carboxylic acids to convert alkene-containing carboxylic acids into lactones using azidoiodinanes (ABX or ADBX) as the azide source [114]. The reaction can be performed in the presence of a Cu-catalyst combined with photoredox conditions or a Pd-catalyst giving access to $(1,1)$ - or $(1,2)$-azidolactones, respectively (Scheme 55).

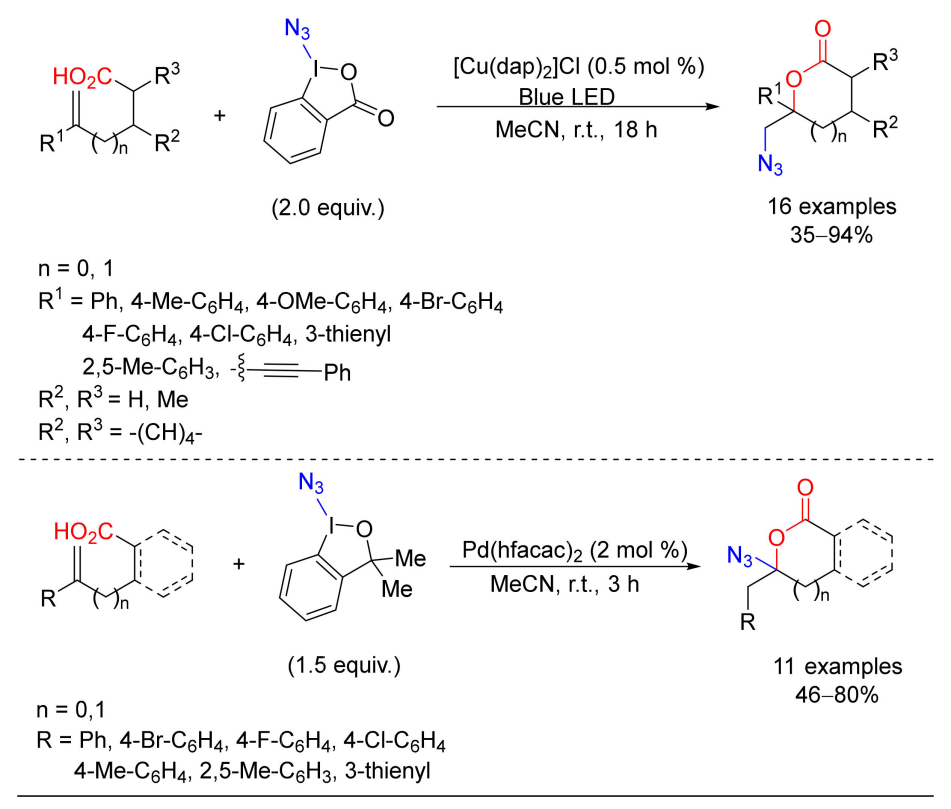

Scheme 55. Synthesis of different azidolactones.

Wang and co-workers described a reaction that, starting from alkenyl oximes, leads to 5-azidomethyl-substituted isoxazolines using $\mathrm{Cu}(\mathrm{OAc})_{2}$ as the catalyst and TMS- $\mathrm{N}_{3}$ (Scheme 56) [115].

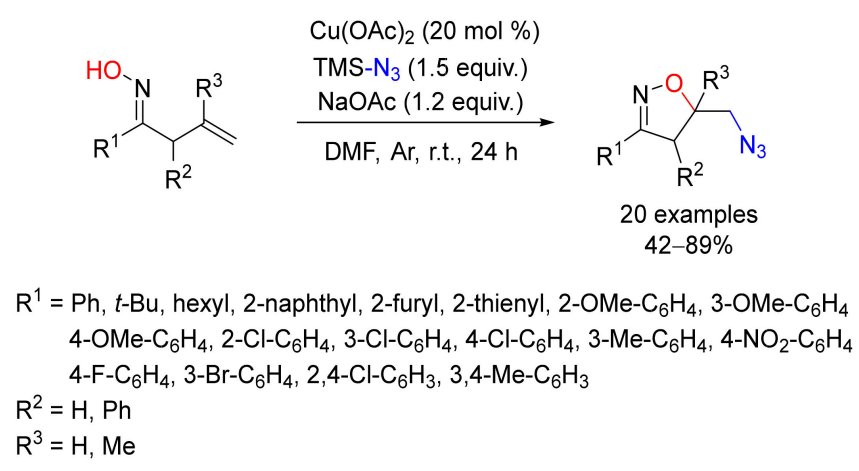

Scheme 56. Cu-catalyzed synthesis of isoxazoline.

Recently, a fruitful procedure for the synthesis of the 3-azidomethylfurans $\mathbf{5 2}$ has been reported by $\mathrm{Ag}(\mathrm{I})$-catalyzed cyclization/azidation of the 2-(1-alkynyl)-2-alken-1-ones 51 [116]. The scope and mechanism of the reaction are shown in Scheme 57. After coordination of the Ag(I)-catalyst to the carbon-carbon triple bond, the intramolecular formation of the $\mathrm{C}-\mathrm{O}$ bond generates the benzylic carbocation I-57. The subsequent nucleophilic addition of the azide anion gives the furyl-silver intermediate II-57, which evolves into the final product by protonation with regeneration of the silver catalyst.

A regio- and diastereoselective intermolecular oxyazidation of enamides was carried out in iron catalyzed conditions [117]. The reaction proceeds under mild conditions using $\mathrm{FeCl}_{2}$ as the initiator radical and azidoperiodinanes as the azide and alkoxyl moiety source. A SET from the iron catalyst to the hypervalent iodine compound generates the intermediate I-58, which undergoes a second SET and 
addition of the alkoxyl portion to the substrate $\mathbf{5 3}$ giving intermediate II-58. Finally, the addition of azido anion furnishes the product 54 (Scheme 58).

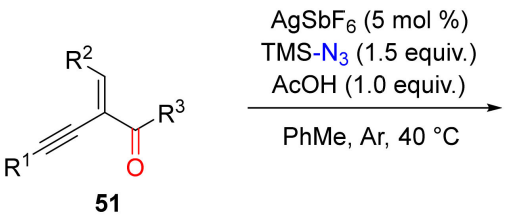

$\mathrm{R}^{1}=\mathrm{Ph}, \mathrm{Cy}, 2$-naphthyl, 2-thienyl, 4-OMe- $\mathrm{C}_{6} \mathrm{H}_{4}, 2-\mathrm{Cl}-\mathrm{C}_{6} \mathrm{H}_{4}$ 3- $\mathrm{Cl}-\mathrm{C}_{6} \mathrm{H}_{4}, 4-\mathrm{Cl}-\mathrm{C}_{6} \mathrm{H}_{4}, 4-\mathrm{Me}-\mathrm{C}_{6} \mathrm{H}_{4}, 4-\mathrm{NO}_{2}-\mathrm{C}_{6} \mathrm{H}_{4}, 4-\mathrm{Ph}-\mathrm{C}_{6} \mathrm{H}_{4}$ $2-\mathrm{F}-\mathrm{C}_{6} \mathrm{H}_{4}, 4-\mathrm{F}-\mathrm{C}_{6} \mathrm{H}_{4}, 3-\mathrm{CF}_{3}-\mathrm{C}_{6} \mathrm{H}_{4}, 4-\mathrm{CO}_{2} \mathrm{Et}^{-} \mathrm{C}_{6} \mathrm{H}_{4}, 4-\mathrm{Ac}_{-} \mathrm{C}_{6} \mathrm{H}_{4}$ $\mathrm{R}^{2}=\mathrm{Ph}, 4-\mathrm{Cl}-\mathrm{C}_{6} \mathrm{H}_{4}$

$\mathrm{R}^{3}=\mathrm{Me}, \mathrm{Ph}, 2-\mathrm{Cl}-\mathrm{C}_{6} \mathrm{H}_{4}, 3-\mathrm{Cl}-\mathrm{C}_{6} \mathrm{H}_{4}, 4-\mathrm{Cl}-\mathrm{C}_{6} \mathrm{H}_{4}, 4-\mathrm{Me}-\mathrm{C}_{6} \mathrm{H}_{4}$

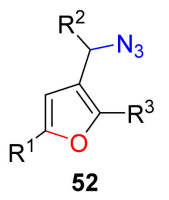

23 examples $54-99 \%$

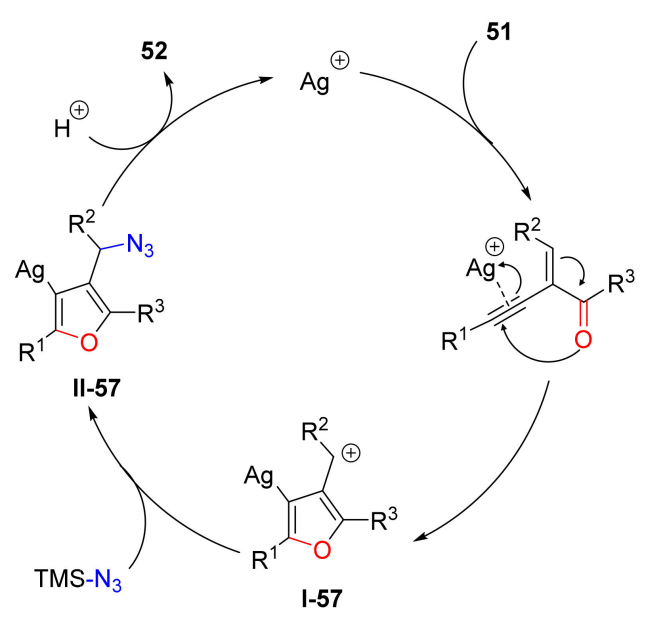

Scheme 57. Ag(I)-catalyzed reaction for the synthesis of 3-azidomethylfurans.<smiles>[R]C1[X][14CH]=CN([R6])C1[R]</smiles>

53<smiles>[R][R]1ccc2c(c1)c(=O)on2N</smiles>

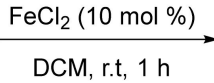<smiles>[R]c1cccc(I)c1C(=O)OC1[X]C([R])C([R])N([R6])[C@@H]1N</smiles>

54

16 examples $25-77 \%$

$\mathrm{R}^{2}=\mathrm{H}, \mathrm{C}(\mathrm{O})$

$\mathrm{R}^{1}, \mathrm{R}^{2}=-(\mathrm{CH})_{4^{-}}$

$\mathrm{R}^{3}=\mathrm{H}, 3-\mathrm{Me}, 3-\mathrm{OMe}, 3-\mathrm{F}, 3-\mathrm{Cl}, 4-\mathrm{F}, 4-\mathrm{Cl}$

$\mathrm{X}=\mathrm{CH}_{2}, \mathrm{O}, \mathrm{S}$

$\mathrm{PG}=\mathrm{Bn}, \mathrm{Boc}, \mathrm{PMB}, \mathrm{CO}_{2} \mathrm{Ph}, \mathrm{CH}_{2} \mathrm{CO}_{2} \mathrm{Et}$

$\left(\mathrm{CH}_{2}\right)_{3} \mathrm{Br}$, 经

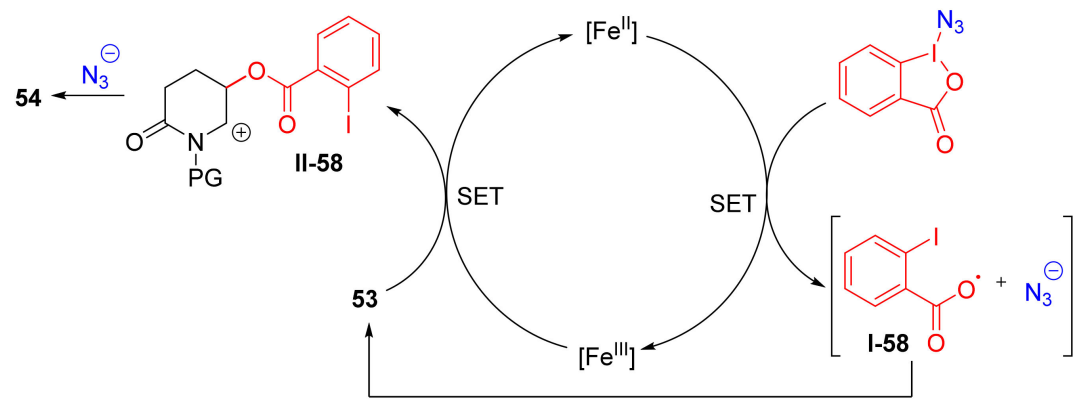

Scheme 58. Iron catalyzed alkoxyazidation of enamides with hypervalent iodine sources. 


\subsection{Haloalkylation/Azidation}

In 2014, Liu reported the first trifluoromethylazidation of olefins using the 3,3-dimethyl-1-(trifluoromethyl)-1,2-benziodoxole (Togni reagent II) as $\mathrm{CF}_{3}$ source and TMS- $\mathrm{N}_{3}$ in the presence of a Cu-catalyst [118]. Different compounds were obtained working with aliphatic cyclic alkenes and aromatic compounds bearing both electron-donating and electron-withdrawing groups (Scheme 59). The same conditions are fruitful to transform alkynes into 1,2-azido-trifluoromethyl alkenes that are easily converted into trifluoromethyl-substituted azirines and aziridines [119].

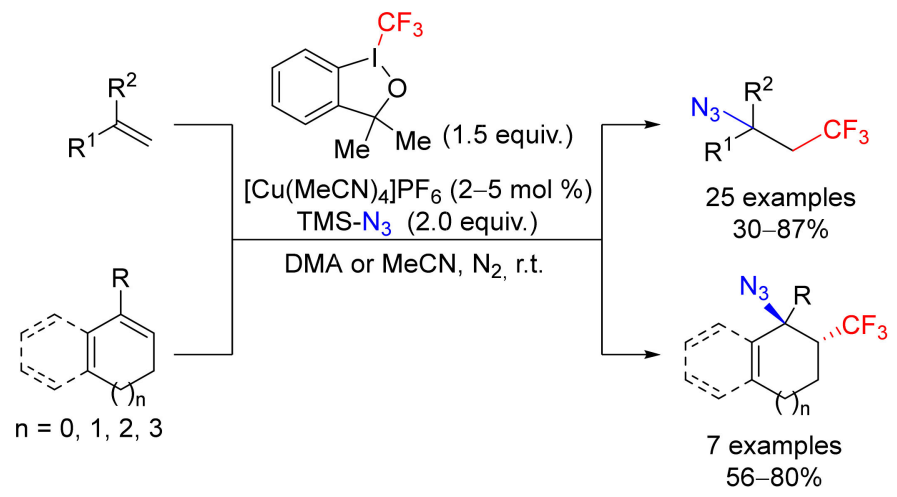

Scheme 59. Trifluoromethylazidation of alkenes with Togni reagent I.

A similar copper catalyzed three-component azidotrifluoromethylation of olefins was proposed by Yang and co-workers [120]. The use of $\mathrm{CuBr}$ as the catalyst and Togni reagent II as the $\mathrm{CF}_{3}$ source allows the formation of the products in mild conditions.

A copper catalyzed concurrent addition of trifluoromethyl and azide moieties to alkene and remote $\alpha-\mathrm{C}-\mathrm{H}$ position of carbonyl groups of the aliphatic keto-olefins 55 allows the formation of $\mathrm{CF}_{3}$-containing $\alpha$-azido ketones 56 [121]. The optimal conditions were identified using $\mathrm{CuI}$ as the catalyst, 1-trifluoromethyl-1,2-benziodoxol-3- $(1 H)$-one (Togni reagent II) and TMS-N $\mathrm{N}_{3}$ in DCE as the solvent (Scheme 60). The products could be converted into trifluoromethyl $\gamma$-lactams and spirobenzofuranone lactams in a one-pot process based on the addition of triethylamine. CuI has a dual role in the mechanism activating the Togni reagent and catalyzing the azidation step. After attack by the trifluoromethyl radical to the olefin, a siteselective $\mathrm{Cu}(\mathrm{II})$-promoted 1,5-H radical shift occurs due to the presence of $\mathrm{Cu}(\mathrm{II})$. The so-obtained $\mathrm{C}$-radical $\mathbf{I}-60$ is transformed by the azide radical into the $\mathrm{Cu}(\mathrm{III})$-intermediate II-60, which evolves to the product by reductive elimination. However, a possible azidation of $\mathbf{I}-\mathbf{6 0}$ by uncatalyzed nucleophilic attack of the azide anion on the carbocationic species III-60 cannot be ruled out.

In 2014, Masson and Magnier reported two examples of photoredox-catalyzed azido-trifluomethylation of alkenes. In the first one, $\alpha$-azido $\beta$-trifluoromethyl amines were obtained in good yields by treatment of enecarbamates with $\left[\mathrm{Ru}(\mathrm{bpy})_{3}\left(\mathrm{PF}_{6}\right)_{2}\right]$ as the photocatalyst and Togni reagent II and $\mathrm{NaN}_{3}$ as the $\mathrm{CF}_{3}$ and $\mathrm{N}_{3}$ sources, respectively (Scheme 61) [122]. The same catalyst used in the presence of the Umemoto's reagent (61) and TMS- $\mathrm{N}_{3}$ permits the trifluoromethylation/azidation of alkenes [123]. The reaction mechanism starts with the irradiation with visible light of ruthenium catalyst to generate the strong reductant activated species ${ }^{*} \mathrm{Ru}^{\mathrm{II}}(\mathrm{bpy})_{3}$. This species by SET generates the $\mathrm{CF}_{3}$ radical and the following intermediates: I-61 and II-61 by addition to substrate 57 or 59, respectively. Another SET transfer converts $\mathrm{Ru}^{\mathrm{III}}(\mathrm{bpy})_{3}$ previously generated from the original ruthenium complex, leading to the formation of intermediates III-61 and IV-61, which furnish the final products 58 or $\mathbf{6 0}$ by nucleophilic azido addition. 
<smiles>[R]C(=C)CC([R2])([R2])CCC([R])=O</smiles>

55<smiles>O=C1OC(C(F)(F)F)c2ccccc21</smiles>

(1.5 equiv.)

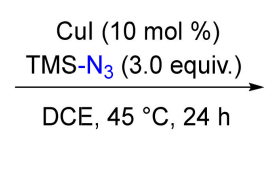

DCE, $45^{\circ} \mathrm{C}, 24 \mathrm{~h}$<smiles>[R]C(=O)C(N)CC([R])([R])CCC([R])([R])F</smiles>

56

17 examples $56-93 \%$

$\mathrm{R}^{1}=\mathrm{Ph}, 4-\mathrm{Me}-\mathrm{C}_{6} \mathrm{H}_{4}, 3-\mathrm{Me}^{-\mathrm{C}_{6}} \mathrm{H}_{4}, 2-\mathrm{Me}^{-} \mathrm{C}_{6} \mathrm{H}_{4}$ 4-OMe- $\mathrm{C}_{6} \mathrm{H}_{4}, 4-\mathrm{Br}-\mathrm{C}_{6} \mathrm{H}_{4}, 4-\mathrm{Cl}-\mathrm{C}_{6} \mathrm{H}_{4}, 2-\mathrm{OH}-\mathrm{C}_{6} \mathrm{H}_{4}$ 2-thienyl, Me, NMePh, PMPO

$\mathrm{R}^{2}=\mathrm{CO}_{2} \mathrm{Me}, \mathrm{CN}, \mathrm{CO}_{2} \mathrm{Et}, \mathrm{CH}_{2} \mathrm{OBz}$ $\mathrm{R}^{3}=\mathrm{H}, \mathrm{Me}$

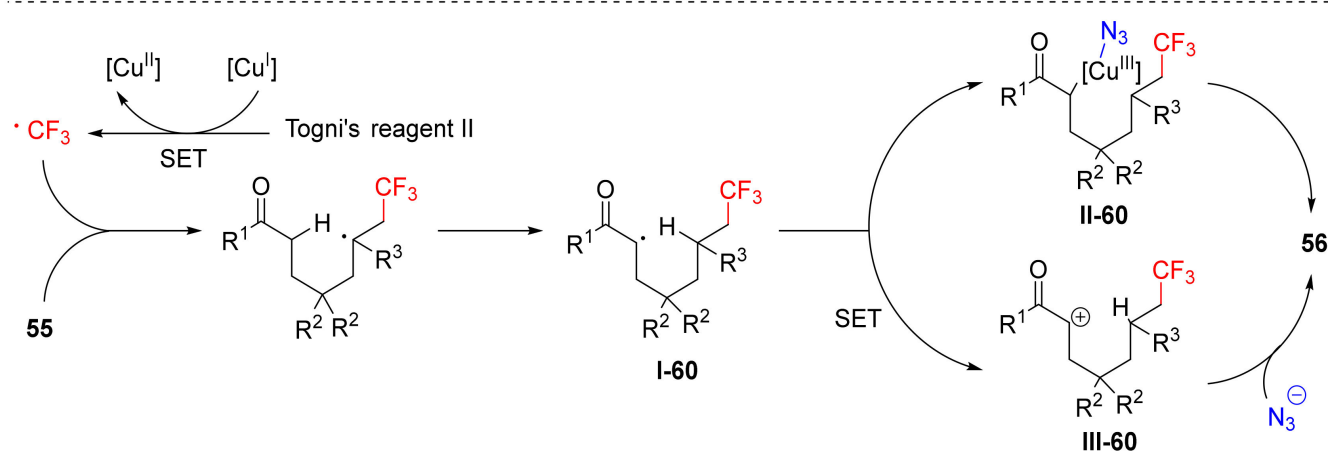

Scheme 60. Azidation/trifluoromethylation in presence of Togni reagent II.

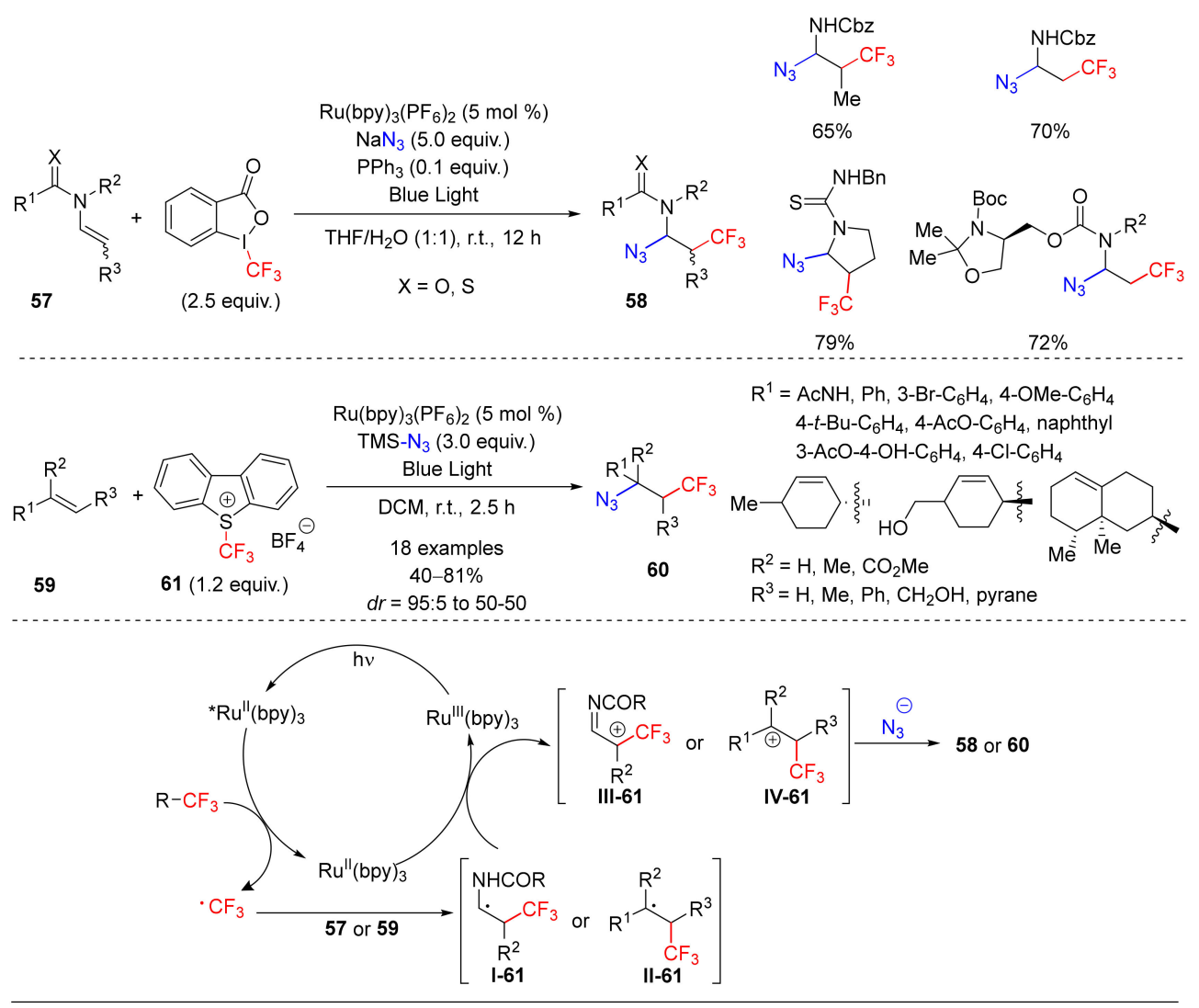

Scheme 61. Ruthenium catalyzed photoredox azidotrifluoromethylation of alkenes.

A more general ruthenium catalyzed fluoroalkylation/azidation of alkenes has been reported by Jiao's group using readily available fluoroalkyl iodides (Scheme 62) [124]. The phase transfer catalyst $\mathrm{BnEt}_{3} \mathrm{NBr}$ was added to favor the solubility of $\mathrm{NaN}_{3}$ in the co-solvent system. The reaction plausibly proceeds through a mechanism in which $\mathrm{Ru}(\mathrm{II})$-catalyst is initially promoted into the excited species 
I-62 by hv irradiation. The reductive quenching of $\mathbf{I}-\mathbf{6 2}$ by $\mathrm{NaN}_{3}$ leads to the formation of an azido radical with generation of a $\mathrm{Ru}(\mathrm{I})$-complex. This latter promotes the formation of a perfluoroalkylated radical, which reacts with the compound $\mathbf{6 2}$ to furnish the intermediate II-62, finally giving the product 63 by interaction with the azido radical.

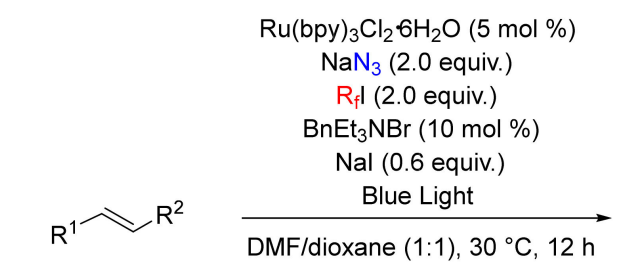

62

$$
\begin{aligned}
& \mathrm{R}^{1}=4-\mathrm{Ph}-\mathrm{C}_{6} \mathrm{H}_{4}, \mathrm{Ph}, 4-\mathrm{Br}_{-} \mathrm{C}_{6} \mathrm{H}_{4}, 4-\mathrm{Me}-\mathrm{C}_{6} \mathrm{H}_{4} \\
& \text { 4-t-Bu- } \mathrm{C}_{6} \mathrm{H}_{4}, 4-\mathrm{CN}-\mathrm{C}_{6} \mathrm{H}_{4} \text {, naphthyl } \\
& \text { 3-Me- } \mathrm{C}_{6} \mathrm{H}_{4}, 3,4-\mathrm{Me}-\mathrm{C}_{6} \mathrm{H}_{3}, 4-\mathrm{Cl}-\mathrm{C}_{6} \mathrm{H}_{4} \\
& \mathrm{CH}_{2} \mathrm{Bn} \text {, hexyl, octyl, } \mathrm{Np} \\
& \mathrm{R}^{2}=\mathrm{H} \text {, alkaloid } \\
& \mathrm{R}_{\mathrm{f}}=\mathrm{CF}_{3}, \mathrm{C}_{4} \mathrm{~F}_{9}, \mathrm{C}_{6} \mathrm{~F}_{13}, \mathrm{C}_{8} \mathrm{H}_{17}, \mathrm{C}_{2} \mathrm{~F}_{4} \mathrm{Cl}
\end{aligned}
$$

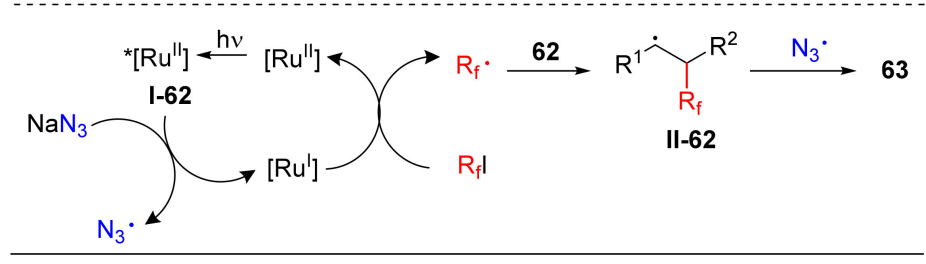

Scheme 62. Photoredox azidofluoroalkylation of alkenes via ruthenium catalysis.

An iron catalyzed perfluoroalkylation/azidation reaction of olefins was investigated in 1992 by Huang and co-worker [125]. $\mathrm{FeSO}_{4} \cdot 7 \mathrm{H}_{2} \mathrm{O}$ was used as the catalyst with perfluoroalkanesulfinates and $\mathrm{NaN}_{3}$ (Scheme 63). In the plausible mechanism, the Fenton reagent $\left(\mathrm{Fe}^{\mathrm{II}}-\mathrm{H}_{2} \mathrm{O}_{2}\right)$ has the role of radical initiator. The $\mathrm{Fe}(\mathrm{OH})_{2}$ species generated in the first step permits the electron transfer on the intermediates I-63 giving carbocation species II- 63 that are converted into the products 64 by attack of the azide anion.

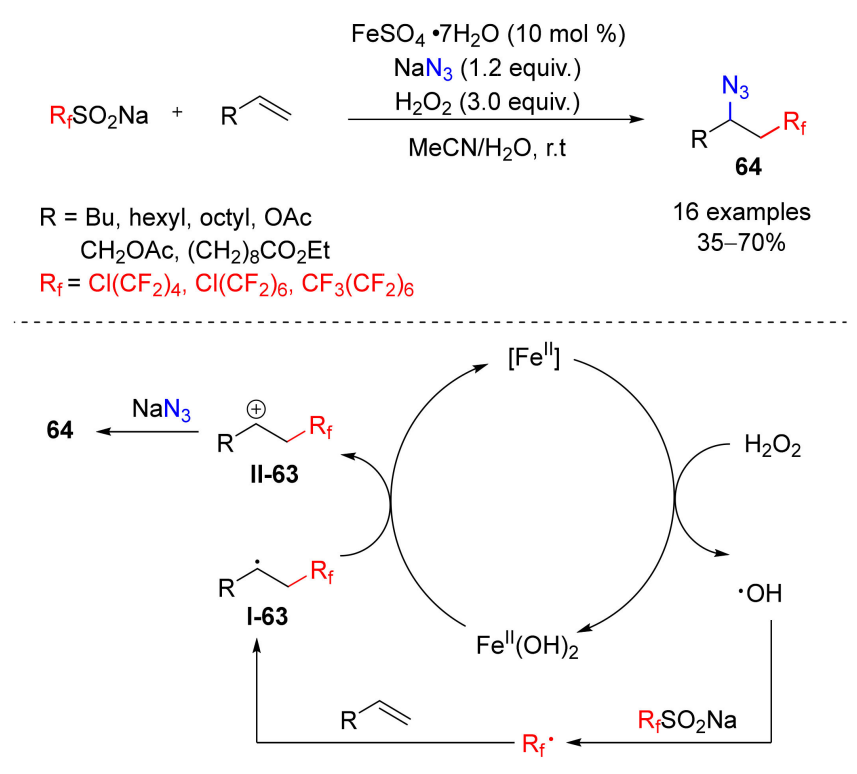

Scheme 63. Fenton reagent catalyzed radical carboazidation of alkenes. 
Analogous conditions, performed in the presence of 2-(pyridin-2-yl)-4,5-dimethyl-4,5dihydrooxazole (67), were applied by $\mathrm{Xu}$ and co-workers for the trifluoromethylazidation of the olefins 65 to obtain precursors of the corresponding amino products (Scheme 64) [126]. Authors proposed a mechanism based on the formation of the diazido-iron salt I-64, which undergoes addition of alkyl trifluoromethyl substrate to afford the intermediate II-64 and the radical species $\mathrm{CF}_{3}$. The latter attacks the olefin giving the complex III-64, which evolves to the intermediate IV-64 with release of the final product 66 .

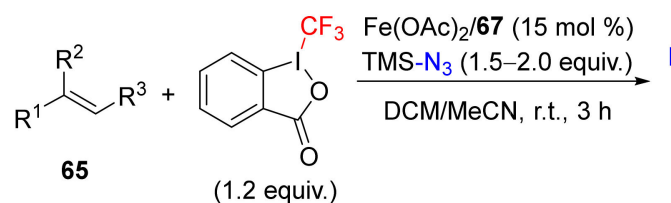

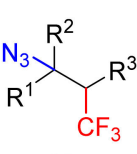

66

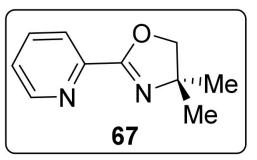

33 examples $51-93 \%$

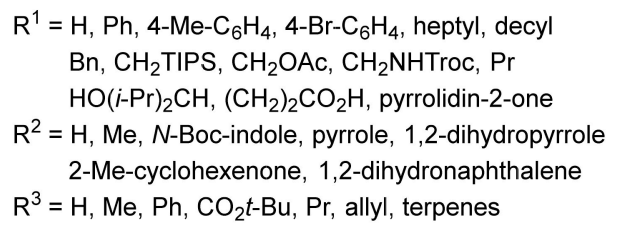

Scheme 64. Enantioselective azidotrifluoromethylation of olefins via iron catalysis.

An efficient and general iron catalyzed fluoroalkylation/azidation of carbon-carbon multiple bonds has been reported by Bao and co-workers [127]. The use of fluoroalkyl iodides with catalytic $\mathrm{Fe}(\mathrm{OTf})_{2}$, TMS- $\mathrm{N}_{3}$, and (TBPB) in DME at room temperature permits the carboazidation of alkenes, dienes, or alkynes systems in moderate to high yields (Scheme 65). The great number of the synthesized products, including several fluoroalkylated derivatives, is an index of the versatility of this methodology.

Recently, Bao and Zhang proposed a reaction mechanism for the carboazidation reaction involving di-t-butyl peroxide (DTBP) supported by DFT studies [128]. As shown in Scheme 66, a SET between the Fe(II) species and DTBP leads to the formation of intermediate I-66, which is the precursor of the methyl radical. The interaction of the latter with the alkyl halogen gives an alkyl radical, which reacts with the olefin leading to iron-complex II-66. A second SET promotes the evolution of the intermediate II-66 into the final compound. 


$$
\begin{aligned}
& \mathrm{Fe}(\mathrm{OTf})_{2}(3-5 \mathrm{~mol} \%) \\
& \text { TMS- } \mathrm{N}_{3} \text { (1.4-2.0 equiv.) }
\end{aligned}
$$

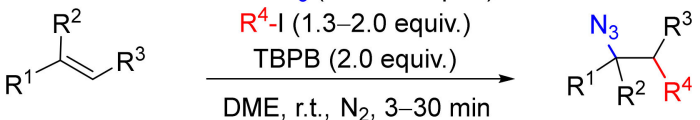

$$
\begin{aligned}
& 75 \text { examples }
\end{aligned}
$$

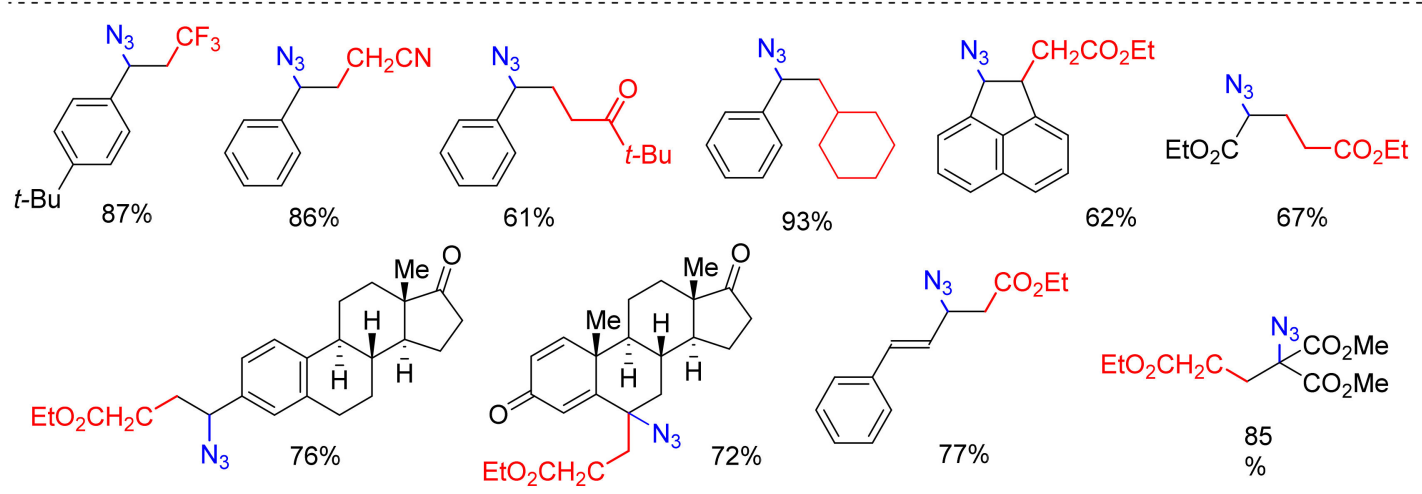

$$
{ }_{67 \%}
$$

Scheme 65. Fe(II)-catalyzed carboazidation of alkenes and dienes.

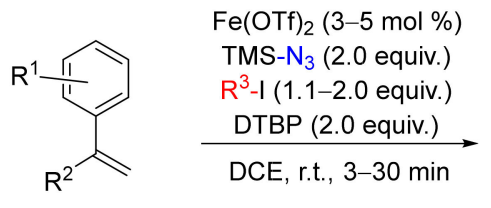

$\mathrm{R}^{1}=\mathrm{H}, \mathrm{Ph}, 4-\mathrm{t}-\mathrm{Bu}, 4-\mathrm{Me}$, 4-OMe, 4-Cl, 4-Br, 4-F, 3,4-F $4-\mathrm{CO}_{2} \mathrm{H}, 4-\mathrm{CO}_{2} \mathrm{Me}, 4-\mathrm{OAc}, 4-\mathrm{Ph}, 3-\mathrm{Me}, 3,4-\mathrm{Cl}$ 3-Cl, 2,5-Me, 3,5- $\mathrm{CF}_{3}$, pentafluoro, anthranyl

$\mathrm{R}^{2}=\mathrm{H}, \mathrm{Me}, \mathrm{Ph}, \mathrm{CO}_{2} \mathrm{Me}$, cinnamyl, $\left(\mathrm{CH}_{2}\right)_{2} \mathrm{Ph}, \mathrm{Bz}$ $\left(\mathrm{CH}_{2}\right)_{6} \mathrm{Br},\left(\mathrm{CH}_{2}\right)_{9} \mathrm{OBn},\left(\mathrm{CH}_{2}\right)_{9} \mathrm{OTBDPS},\left(\mathrm{CH}_{2}\right)_{9} \mathrm{OH}$ $\left(\mathrm{CH}_{2}\right)_{9} \mathrm{OTs},\left(\mathrm{CH}_{2}\right)_{6} \mathrm{PhThN},\left(\mathrm{CH}_{2}\right)_{7} \mathrm{CO}_{2} \mathrm{H}$

$\mathrm{R}^{3}=\mathrm{CF}_{3}, \mathrm{CF}_{2} \mathrm{CF}_{3}, \mathrm{CH}_{2} \mathrm{CN}, \mathrm{CH}_{2} \mathrm{CO}_{2} \mathrm{Et}$ $\mathrm{CF}_{2} \mathrm{CO}_{2} \mathrm{Et}, \mathrm{CHFCO}_{2} \mathrm{Et},\left(\mathrm{CF}_{2}\right)_{2} \mathrm{Cl}$ $\mathrm{C}_{4} \mathrm{~F}_{9}, 2-\mathrm{Cy}-\mathrm{C}_{6} \mathrm{~F}_{11}, \mathrm{CH}_{2} \mathrm{CF}_{3}, \mathrm{CH}_{2} \mathrm{CO}_{2} t-\mathrm{Bu}$ $\mathrm{CO}_{2} \mathrm{Et}, \mathrm{C}_{10} \mathrm{~F}_{21}, i-\mathrm{C}_{3} \mathrm{~F}_{7}, \mathrm{C}_{8} \mathrm{~F}_{17}, \mathrm{C}_{6} \mathrm{~F}_{13}$

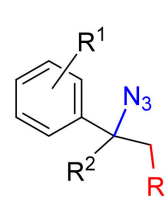

70 examples 46-93\%

Scheme 66. Iron catalyzed carboazidation with di-t-butyl peroxide (DTPB).

Analogous conditions were proposed by $\mathrm{Chu}$ and co-workers as a tool for the azidochloroalkylation of alkenes [129]. TMS- $\mathrm{N}_{3}$ and dichloromethane (DCM) are the azide and the chlorine sources, respectively (Scheme 67). Radical carbon- and/or azido species are generated in situ by DTBP. The iron catalyst has the double function to favor both the radical formation and the attack of the azido radical. A suitable choice of the solvent is essential for the outcome of the reaction, because the use of a mixture of $\mathrm{DCM} / \mathrm{t}-\mathrm{BuOH}$ promotes the formation of the diazidation product. 


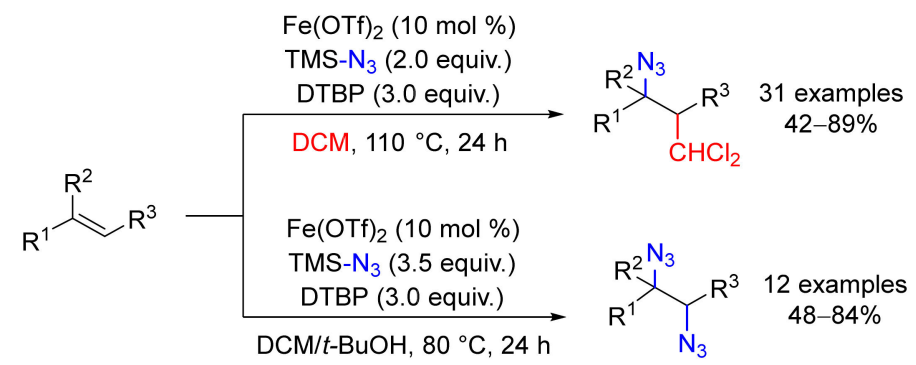

Scheme 67. Iron catalysis of alkenes: Carboazidation vs. diazidation process.

$\mathrm{Zn}(\mathrm{OTf})_{2}$ was proven to be an efficient catalyst to promote the bromoazidation of alkenes using $\mathrm{N}$-bromosuccinimide (NBS) and TMS- $\mathrm{N}_{3}$ as the bromine and azide sources, respectively (Scheme 68) [130]. These conditions allowed to obtain stereoselectively anti vicinal bromoazides starting from various alkenes including $\alpha, \beta$-unsaturated aryl compounds.
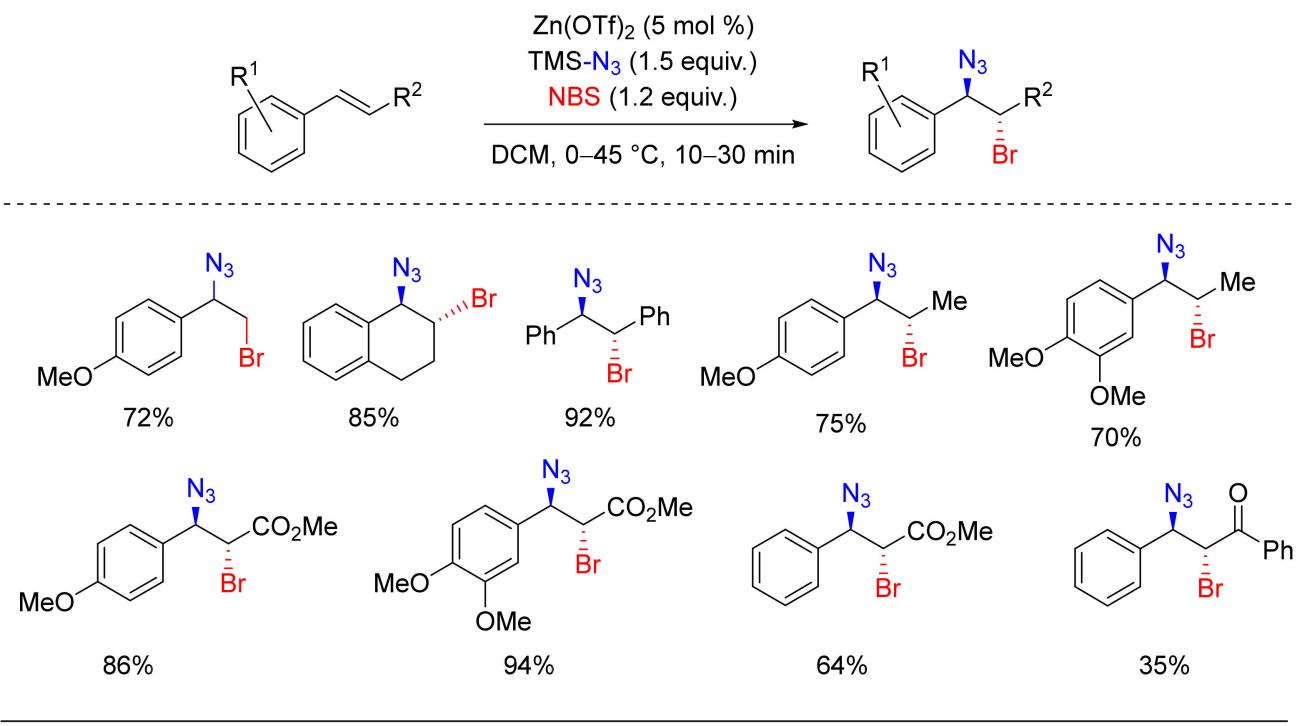

Scheme 68. Zn-catalyzed bromoazidation of alkenes.

\subsection{Alkylation or Arylation/Azidation}

The carboazidation of alkenes allows to access azide products with rapid increase in the complexity of the structure.

In 2017, Yang's group discovered a Fe-catalyzed decarbonylative carboazidation reaction for the functionalization of the styrenes 68 with aldehydes as reagents (Scheme 69) [131]. The driving force of the reaction is the releasing of $\mathrm{CO}$ from the intermediate I-69, generated from oxidation of the aldehyde by Fe(III) and DTBP, to give the intermediate II-69. This latter is, in turn, oxidized to the intermediate III-69, which undergoes nucleophilic attack by the azide anion providing the final product 69 . Alternatively, intermediate II-69 can be attacked by azido radical obtained by oxidation of TMS-N $\mathrm{N}_{3}$.

One year later, the same group proposed a variant of this reaction on the styrenes $\mathbf{7 0}$ using alkanes instead of aldehydes [132]. As reported in Scheme 70, the reaction mechanism to achieve the benzyl azides $\mathbf{7 1}$ has strong analogies with that previously described in Scheme 69. 


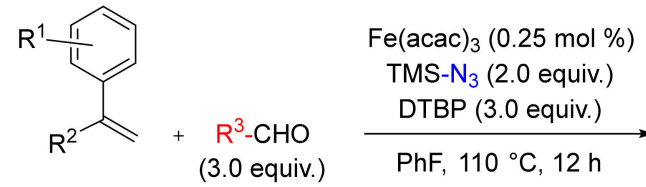

68

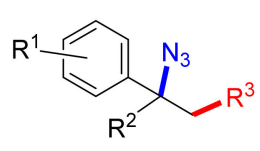

69

23 examples $55-84 \%$

$\mathrm{R}^{1}=4-\mathrm{OMe}, 4-t-\mathrm{Bu}, 4-\mathrm{Me}, 4-\mathrm{CF}_{3}, 4-\mathrm{CH}_{2} \mathrm{Cl}$

2-Cl, 3-Cl, 4-Cl, 4-Br, 3-Br, 4-F, H

$\mathrm{R}^{2}=\mathrm{H}, \mathrm{Ph}, \mathrm{Me}$

$\mathrm{R}^{3}=i$-Pr, 2-pentyl, cyclopentyl, cyclohexyl cyclohexenyl, Bn, t-Bu, s-Bu, isopentyl, 3-heptyl

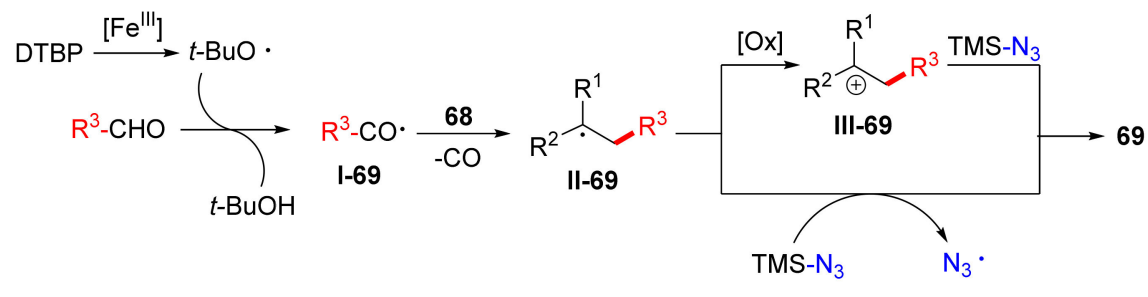

Scheme 69. Decarbonylative iron catalyzed carboazidation of styrenes.

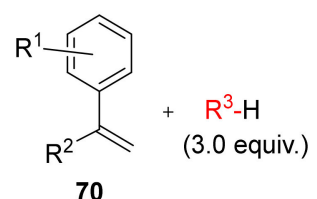

70

$\mathrm{R}^{1}=4-\mathrm{OMe}, 4-t-\mathrm{Bu}, 4-\mathrm{Me}, 4-\mathrm{CF}_{3}, 4-\mathrm{CH}_{2} \mathrm{Cl}, 4-\mathrm{F}$

2-Cl, 3- $\mathrm{Cl}, 4-\mathrm{Cl}, 3-\mathrm{Br}, 4-\mathrm{Br}, \mathrm{H}$, anthranyl

$\mathrm{R}^{2}=\mathrm{H}, \mathrm{Ph}, \mathrm{Me}, \mathrm{CO}_{2} \mathrm{Et}$

$\mathrm{R}^{3}=\mathrm{Cy}$, cyclopentyl, cycloheptyl, cyclooctyl, hexyl, $\mathrm{CHCl}_{2}$

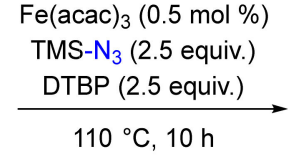

$110^{\circ} \mathrm{C}, 10 \mathrm{~h}$

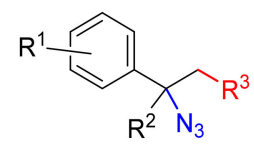

71

33 examples $55-92 \%$

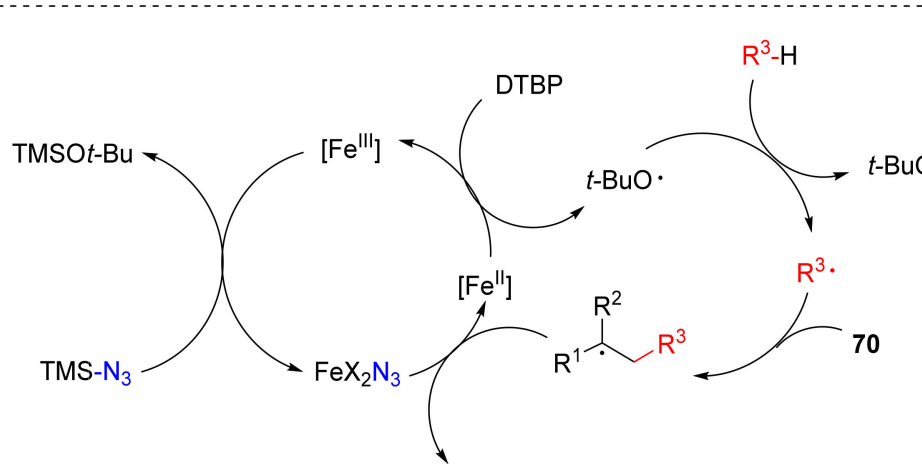

71

Scheme 70. Alkenes iron catalyzed carboazidation of styrenes.

In the field of azidation reactions, very few works exploit the iridium catalysis. One example based on photoredox catalysis has been recently reported by Lu's group [133]. The reaction occurs by a carboazidation process between alkenes and Michael acceptors in the presence of an iridium catalyst, TMS- $\mathrm{N}_{3}$, and a visible-light source (Scheme 71 ). The reaction was investigated both in inter- and intramolecular version and the corresponding products were isolated with moderate or good yields.

A radical carbocyclization/azidation strategy based on the use of non-toxic silver salt for the conversion of the arylacrylamides $\mathbf{7 2}$ into the oxindoles $\mathbf{7 3}$ was investigated by Yang's group (Scheme 72) [134]. Authors suppose two possible reaction routes, both starting with the generation of 
the $\mathrm{AgN}_{3}$ salt by reaction of TMS-N $\mathrm{N}_{3}$ and the silver catalyst. At this point, the silver azide species could generate the azido radical $\mathrm{N}_{3}{ }^{\bullet}$, which adds the substrate furnishing the intermediate II-72. Radical II-72 evolves to intermediate III-72 by $\mathrm{C}-\mathrm{H}$ activation of the aryl group and the $\mathrm{C}-\mathrm{C}$ bond formation on the alkene, with delocalization of the radical on the aromatic system. Finally, radical III-72 is quenched by SET to give the product and $\mathrm{AgNO}_{3}$ as a precursor of $\mathrm{Ag}(0)$ and $\mathrm{HNO}_{3}$. Alternatively, the $\mathrm{AgN}_{3}$ species could form the complex I-72 by addition to the activated double bond, which is later oxidized to the intermediate II-72 by intervention of the zirconium salt.

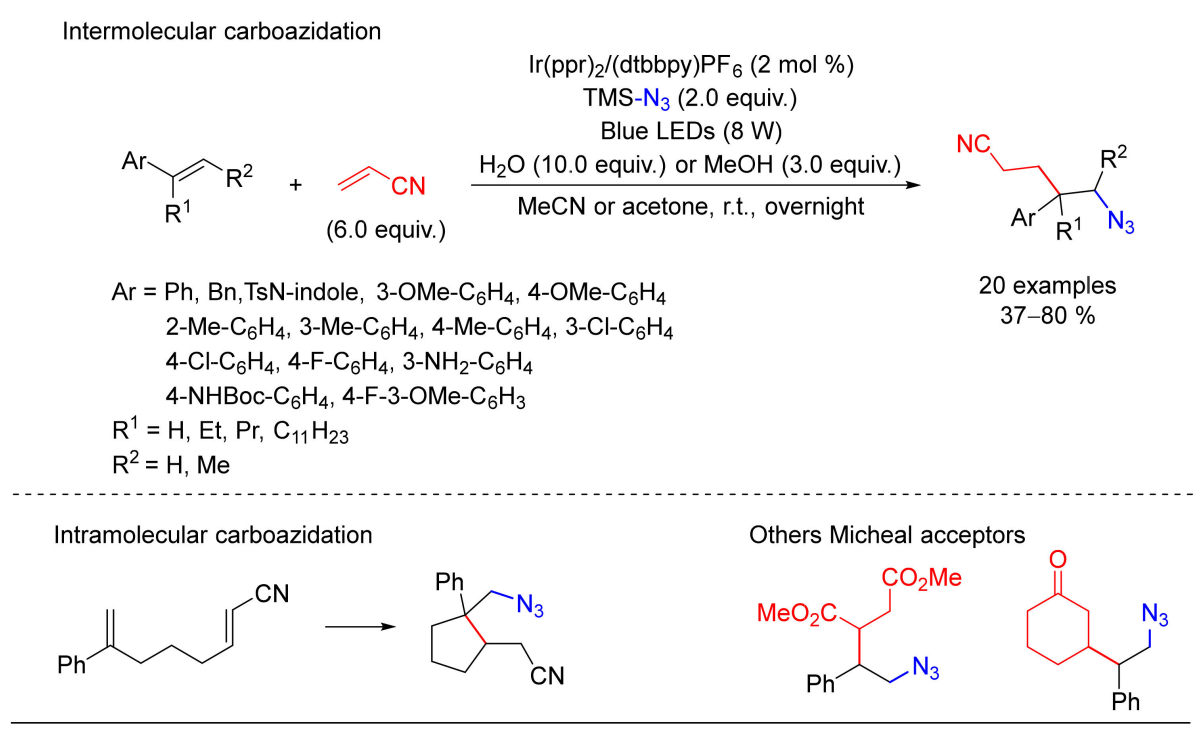

Scheme 71. Photochemical carboazidation of alkenes via Ir(I)-complex and visible-light source.

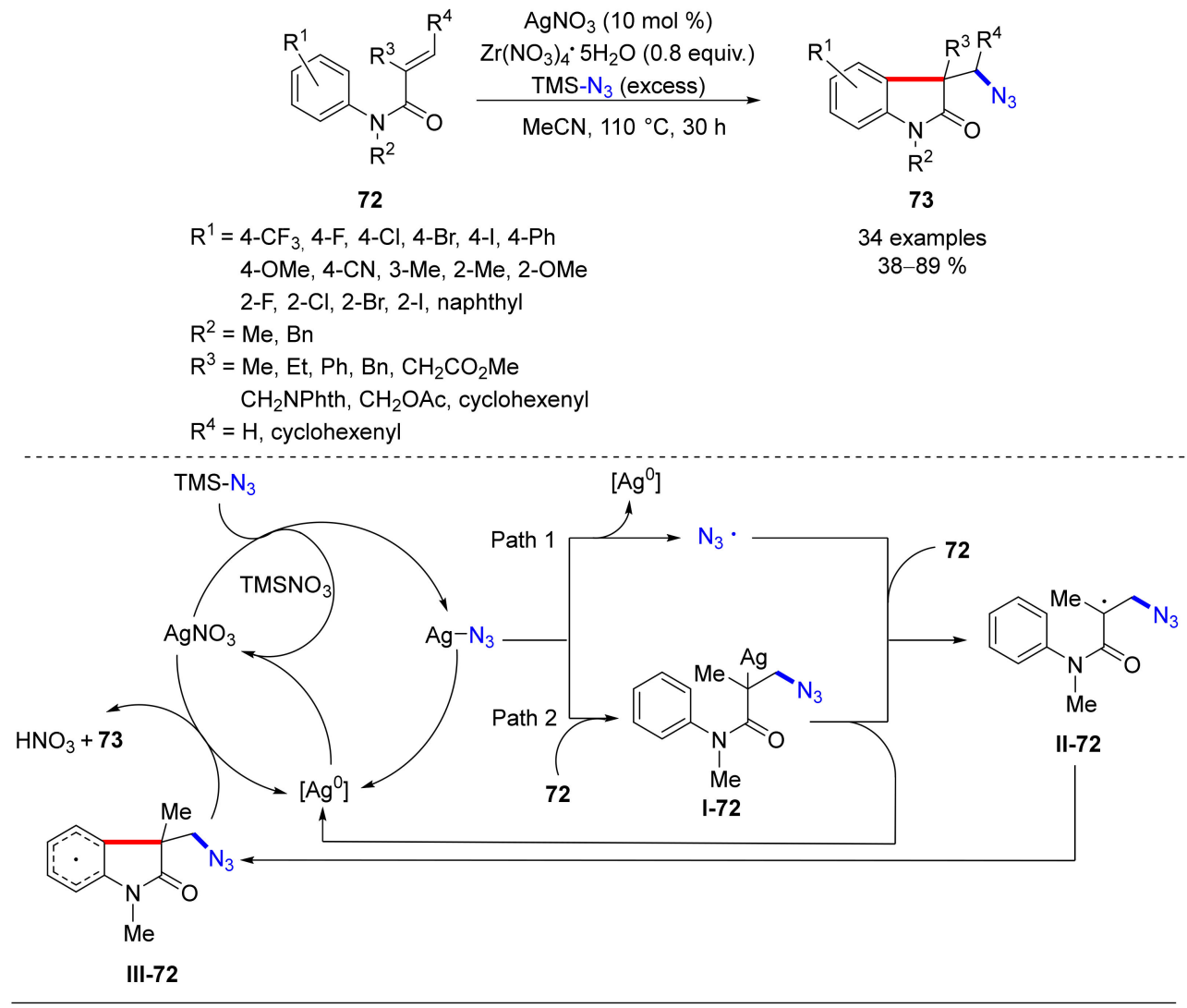

Scheme 72. Radical-silver catalyzed procedure of arylacrylamides. 
The carboazidation process starting from the substrates $\mathbf{7 4}$ is possible working with catalytic $\mathrm{AgNO}_{3}, \mathrm{TMS} \mathrm{N}_{3}$, and $\mathrm{Ce}\left(\mathrm{SO}_{4}\right)_{2}$ in acetonitrile as the solvent (Scheme 73) [135]. As in the mechanism previously described in Scheme 72, the products 75 arise from the evolution of the intermediate I-73, generated by reaction of the alkene with the azido radical in turn formed by oxidation of TMS- $\mathrm{N}_{3}$ by $\mathrm{Ce}\left(\mathrm{SO}_{4}\right)_{2}$.

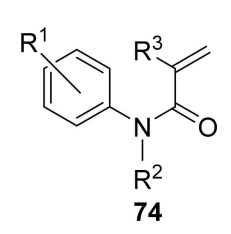

$\mathrm{R}^{1}=\mathrm{H}, 4-\mathrm{Br}$, 4-Me, 4- $t-\mathrm{Bu}, 4-\mathrm{NO}_{2}, 4-\mathrm{CF}_{3}$ 4-CN, 4- $\mathrm{CO}_{2} \mathrm{Me}, 4-\mathrm{OCF}_{3}, 4-\mathrm{Cl}, 4-\mathrm{F}$ 4-I, 2-F, 2,5-F, 2-Br, 2-Me

$\mathrm{R}^{2}=\mathrm{Me}, \mathrm{Et}, \mathrm{Bn}$

$\mathrm{R}^{3}=\mathrm{Me}, \mathrm{Bn}, \mathrm{Ph}$
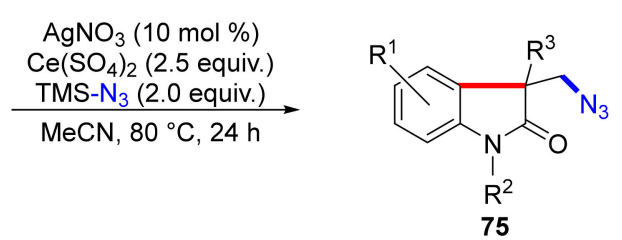

21 examples $54-93 \%$

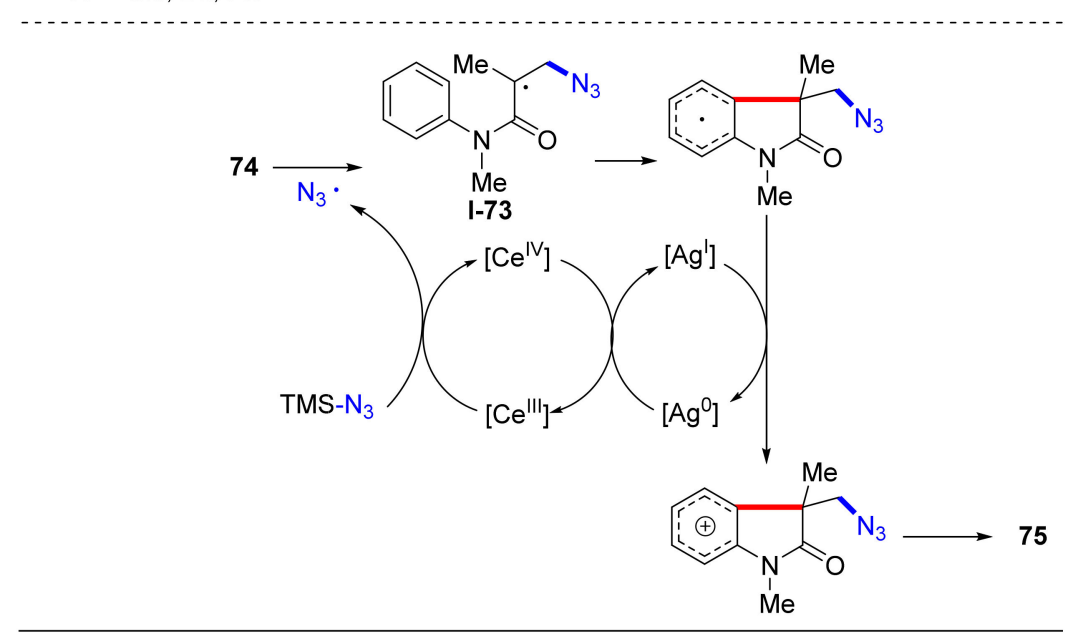

Scheme 73. Silver promoted radical carbocyclization for the preparation of oxindoles.

\subsection{Cyanation/Azidation}

Compounds with azido and cyano moieties are useful tools for the synthesis of amino acids. For this purpose, in 2014, Wang and co-workers developed a copper catalyzed Markovnikov-type azidocyanation of olefins (Scheme 74) [136]. TMS- $\mathrm{N}_{3}$ and TMS-CN were used as the azide and nitrile sources, respectively. $\mathrm{PhI}(\mathrm{OAc})_{2}$ has the dual role to generate the azide radical and to reoxidize $\mathrm{Cu}(\mathrm{I})$ to $\mathrm{Cu}(\mathrm{II})$. The plausible mechanism started with the reaction between the azide radical and the alkene, followed by the generation of a carbocation species, which is trapped by the cyanide anion to furnish the targeted azidocyano compound. 


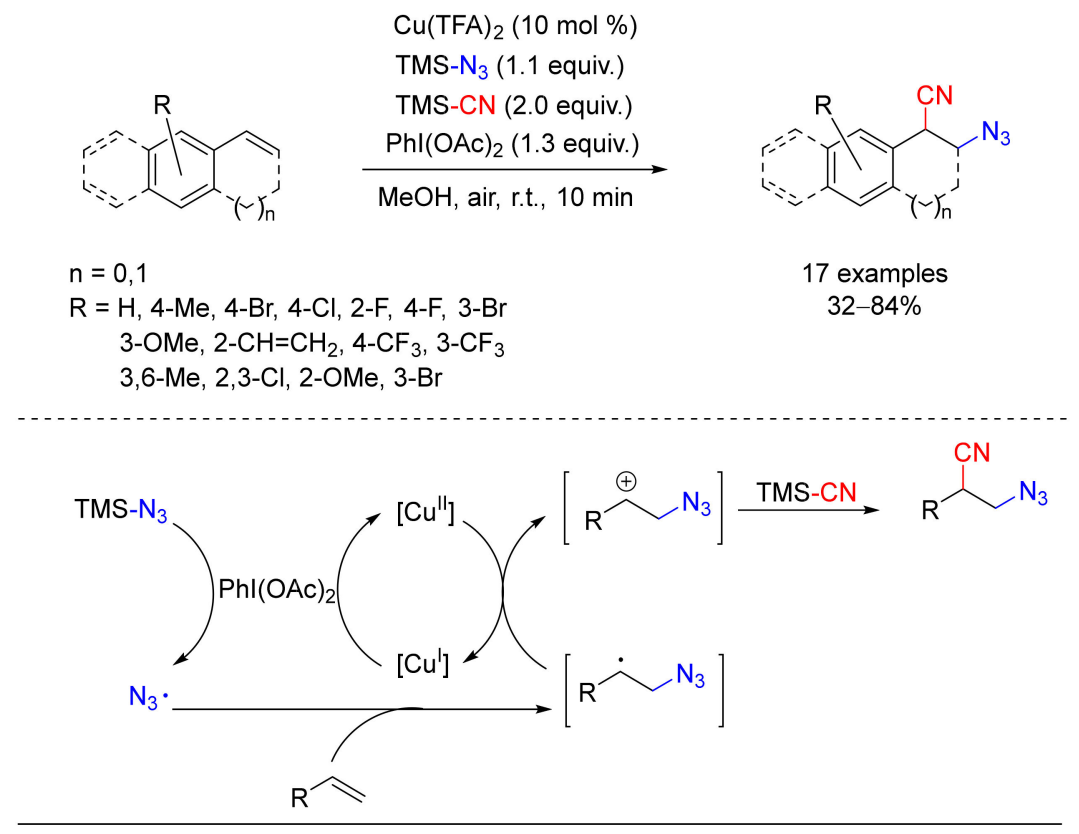

Scheme 74. Copper catalyzed azidocyanation of alkenes.

\section{Other Preparation of Allylic Azides}

An efficient synthesis of allyl azides starting from alkenes under Pd(II)-catalysis in oxidative conditions was developed by Jiang and co-workers [137]. Heating a mixture of $\mathrm{Pd}(\mathrm{OAc})_{2}$ with $\mathrm{NaN}_{3}$ under oxygen atmosphere in DMSO as the solvent, terminal alkenes were converted into allyl azides (Scheme 75). By addition of a copper catalyst in the reaction medium, triazole derivatives arising from 1.3-dipolar cycloaddition were achieved.

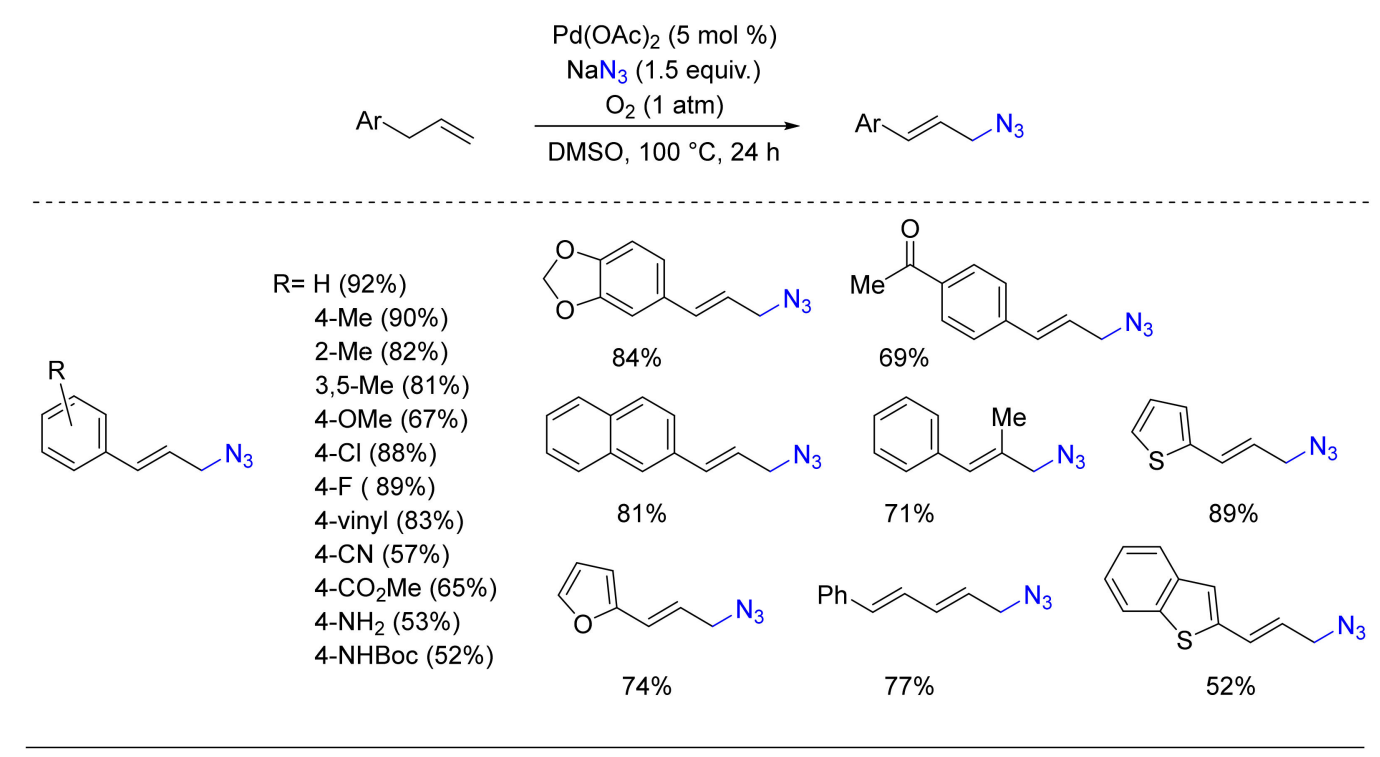

Scheme 75. Conversion of terminal alkenes into allyl azides in $\mathrm{Pd}(\mathrm{II})$-catalyzed oxidative conditions.

The $\operatorname{Pd}(0)$-catalyzed carboazidation of the allenes 77 with aryl iodides 76 was proven to be a fruitful procedure to access $\alpha$-azidomethyl styrenes 78 and 79 (Scheme 76) [138]. Aryl moieties bearing electron-withdrawing groups gave higher yields than compounds with electron-donating ones. The same conditions were applied at intramolecular level furnishing the benzopyrane derivative $\mathbf{8 0}$ in high yield. The Pd(II)-intermediate, generated by oxidative addition of the aryl iodide to the catalyst, 
interacts with the allene providing the $\pi$-allyl complex I-76. After the nucleophilic attack of azide anion, the desired azido-substituted product was formed, and the catalyst was regenerated.

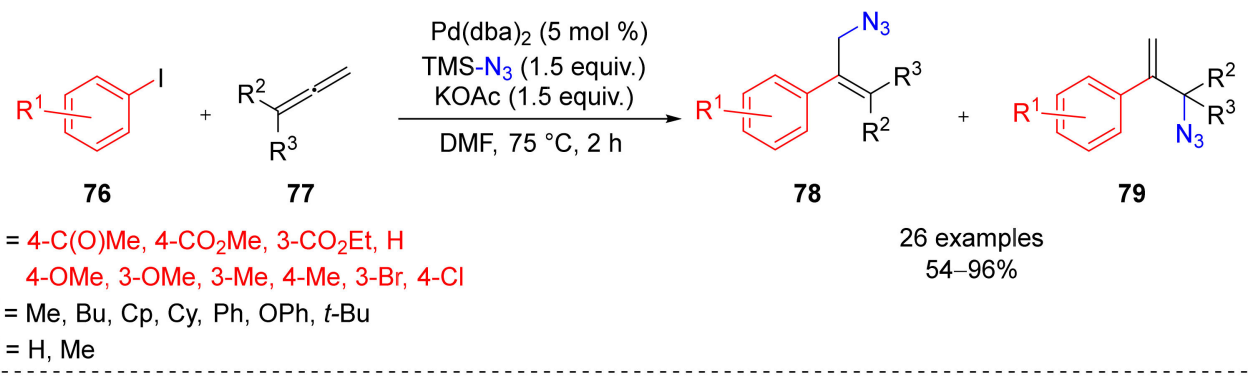

$$
\mathrm{R}^{3}=\mathrm{H}, \mathrm{Me}
$$

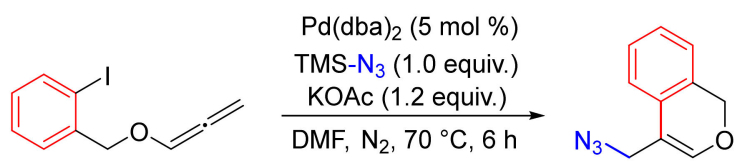

$80(89 \%)$

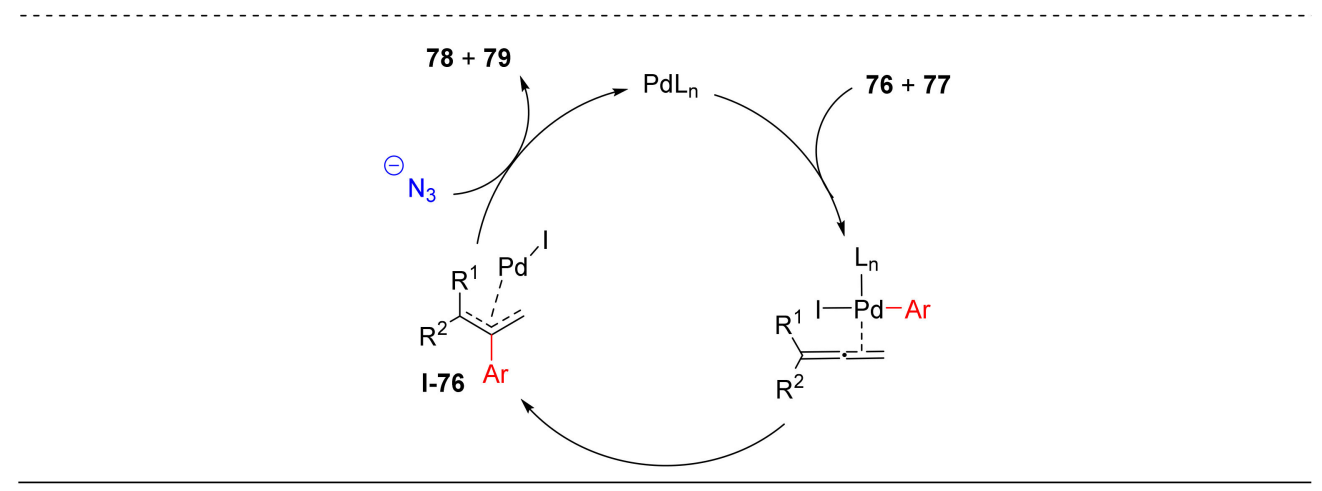

Scheme 76. $\operatorname{Pd}(0)$-catalyzed carboazidation of allenes.

Another similar intramolecular procedure for the construction of heterocyclic compounds was reported by Vicker and co-workers [139]. The treatment of 2-allenyl-substituted aryl iodides with $\mathrm{Pd}\left(\mathrm{PPh}_{3}\right)_{4}$ as the catalyst and $\mathrm{NaN}_{3}$ provided the azide-containing products suitable for subsequent 1,3-dipolar cycloaddition reactions (Scheme 77).

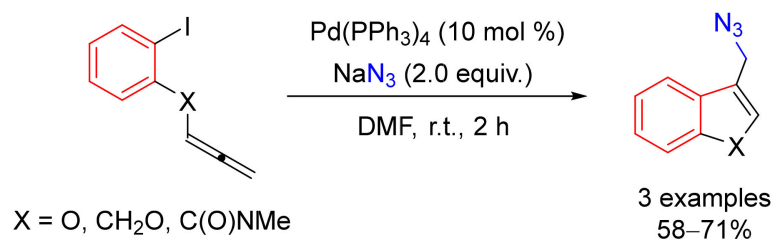

Scheme 77. $\mathrm{Pd}(0)$-catalyzed Viker's azidation reactions.

An innovative work carried out by Munoz and co-workers in 2014 focused on a gold and silver catalyzed azidation of the allenes 81 [140]. The methodology, based on the use of $(\mathrm{PhO})_{3} \mathrm{PAuCl}$ and AgOTf as the catalysts, exploits the in situ generation of $\mathrm{HN}_{3}$ from TMS- $\mathrm{N}_{3}$ and $\mathrm{CF}_{3} \mathrm{CO}_{2} \mathrm{H}$ (Scheme 78). The electronic effects of substituents $\mathrm{R}^{1}$ and $\mathrm{R}^{2}$ seem to be crucial for the control of regioselectivity towards the less substituted carbon of the allene system. However, as known, allylic azides tend to equilibrate by $[3,3]$-sigmatropic rearrangement at room temperature, justifying the formation of compounds 83 from 82 [141,142]. 


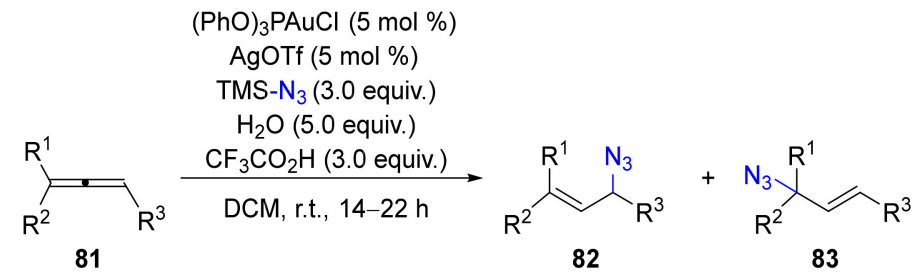

$\mathrm{R}^{1}=\mathrm{Cy}, \mathrm{Bn}, \mathrm{Me}$, hexyl, octyl, Ph $\mathrm{CH}_{2} \mathrm{~N}$-phthalamide, $(\mathrm{Boc})_{2} \mathrm{NCH}_{2}$ $\mathrm{CH}_{2} \mathrm{CH}\left(\mathrm{CO}_{2} \mathrm{Me}\right)_{2}$

$$
\begin{gathered}
16 \text { examples } \\
38-80 \% \\
\text { ratio: } 100 / 0 \text { to } 44 / 56
\end{gathered}
$$

$\mathrm{R}^{2}=\mathrm{H}, \mathrm{Me}$

$\mathrm{R}^{3}=\mathrm{H}, i-\mathrm{Pr}, \mathrm{Pr}$, octyl

Scheme 78. Gold(I)-catalyzed azidation of allenes.

Two years later, Toste and co-workers reported the enantioselective gold catalyzed hydroazidation of allenes for the synthesis of allylic azides [143]. For the positive outcome of the reaction, acyclic diaminocarbene $(\mathrm{ADC}) \mathrm{Au}(\mathrm{I})$-complexes are required. Interestingly, the enantioinduction obtained with the same catalyst enantiomer is reversed when the reaction is carried out in the presence of amines instead of azide. This feature allows access, directly or indirectly, to both enantiomers of the corresponding allylic amines.

A regio- and stereoselective approach for the conversion of allenamides into allylic azides by iron(II)-catalysis has been recently reported [144]. This approach, which requires $\mathrm{TMS}^{-\mathrm{N}_{3}}$ as the azide source, affords $(E)$-allylic azides and features good functional-group compatibility.

\section{Hydroazidation Reactions}

The hydroazidation of alkenes to give alkyl azides can be accomplished by cobalt catalysis $[145,146]$. Depending on the ligand structure, the active cobalt complex can be synthesized or generated in situ. The optimized conditions involve the presence of tosyl azide $\left(\mathrm{TsN}_{3}\right)$ as the azide source, $\mathrm{Co}\left(\mathrm{BF}_{4}\right)_{2} \cdot 6 \mathrm{H}_{2} \mathrm{O}$, potassium (E)-2-[(3,5-di-terbutyl-2-hydroxybenzylidene)amino]-2,2- diphenylacetate (84) as the ligand, terbutyl hydroperoxide $(t-\mathrm{BuOOH})$, a silane, in $\mathrm{EtOH}$ as the solvent at room temperature (Scheme 79 ). The reaction proceeds through Markovnikov selectivity with formation of alkanes as side products. 1,1,3,3-Tetramethyldisiloxane (TMDSO) furnished high selectivity (20:1) towards the azide product, whereas the shortest reaction times were observed with $\mathrm{PhSiH}_{3}$.
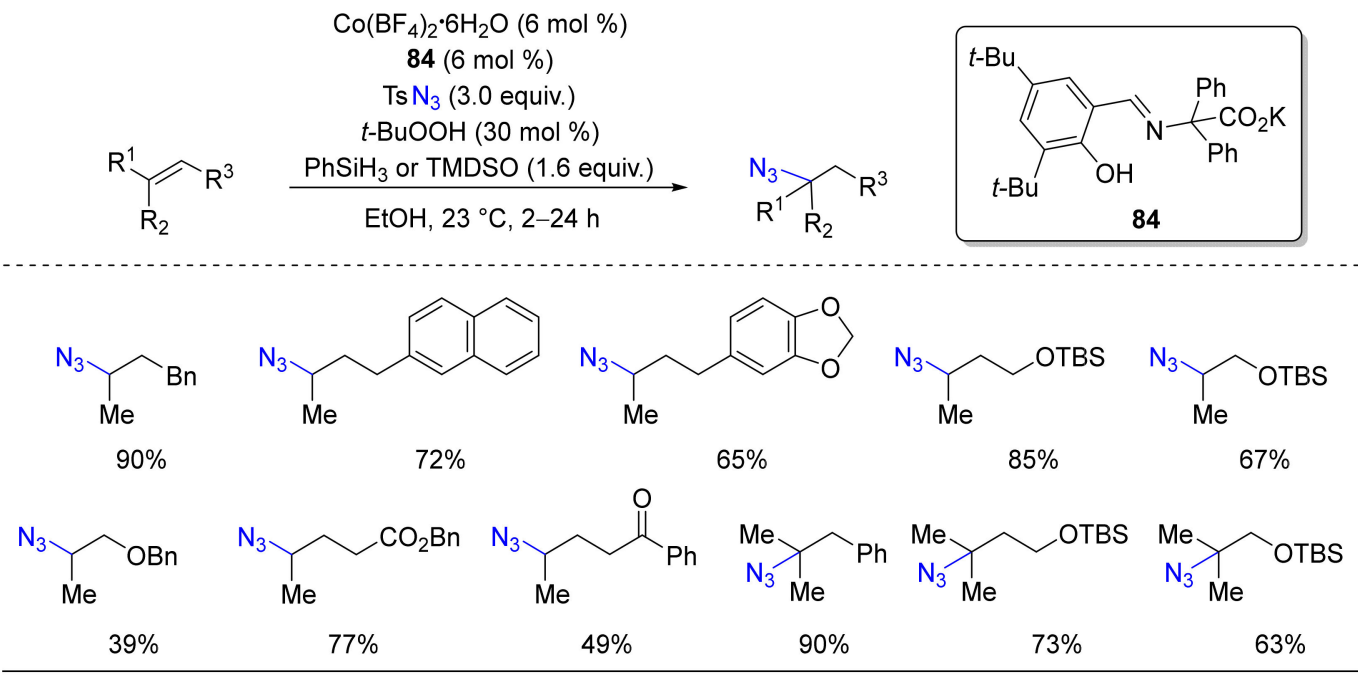

Scheme 79. Co-catalyzed azidation of alkenes. 
Recently, Wang and Yu proposed an innovative anti-Markovnikov hydroazidation of unactivated alkenes exploiting an Ir(III) complex for a visible light photoredox protocol (Scheme 80) [147]. The employment of TMS- $\mathrm{N}_{3}$ as azide source, combined with the use of dimethylamino pyridine (DMAP) and water, permitted to functionalize a wide range of terminal alkenes showing a good tolerance for nitrogen- and oxygenated functional groups. Mechanistically, the reaction starts with the irradiation of the iridium catalyst with Blue LED to generate the active species $\operatorname{Ir}(\mathrm{III})^{*}$, which consequently promotes the formation of the azido radical and of the species $\operatorname{Ir}(\mathrm{II})$. The azido radical then reacts with the substrates to give the radical intermediates I-80, later reduced by the $\operatorname{Ir}(\mathrm{II})$ to the anion species II-80. Finally, these latter are protonated to give the final products by the $\mathrm{DMAPH}^{+}$cation, formed by protonation of DMAP in the equilibrium with the in situ formed TMSOH.

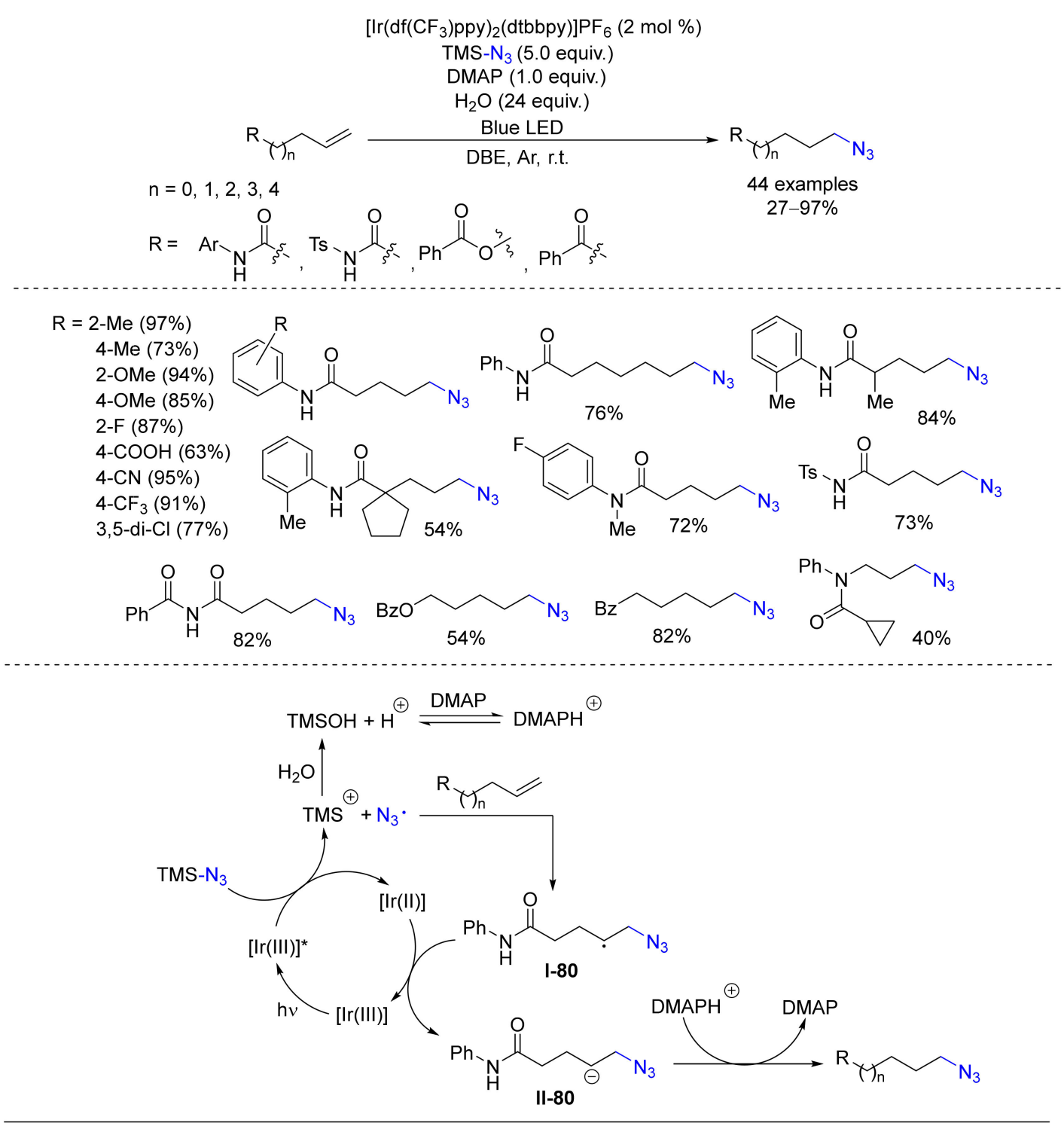

Scheme 80. $\operatorname{Ir}(\mathrm{III})$ catalyzed terminal alkenes hydroazidation.

Hydroazidation of alkynes is one of the most useful methods for the preparation of vinyl azides. A significant example of this reactivity catalyzed by silver salts was reported by Jiao and co-workers in the perspective of the alkynes 85 transformation into nitriles [148]. As described in Scheme 81, the $\alpha$-azidostyrenes 86 were achieved working in the presence of $\mathrm{Ag}_{2} \mathrm{CO}_{3}$ as the catalyst and TMS- $\mathrm{N}_{3}$ in DMSO, which was the crucial solvent for the success of the reaction. The mechanism proposed by 
authors involved the formation of $\pi$-complex I-81 that evolves to the trans-alkenyl intermediate II-81 after azide addition. The product, formed by protonation of II-81, can be transformed into the nitrile after intervention of hydrazoic acid $\left(\mathrm{HN}_{3}\right)$.

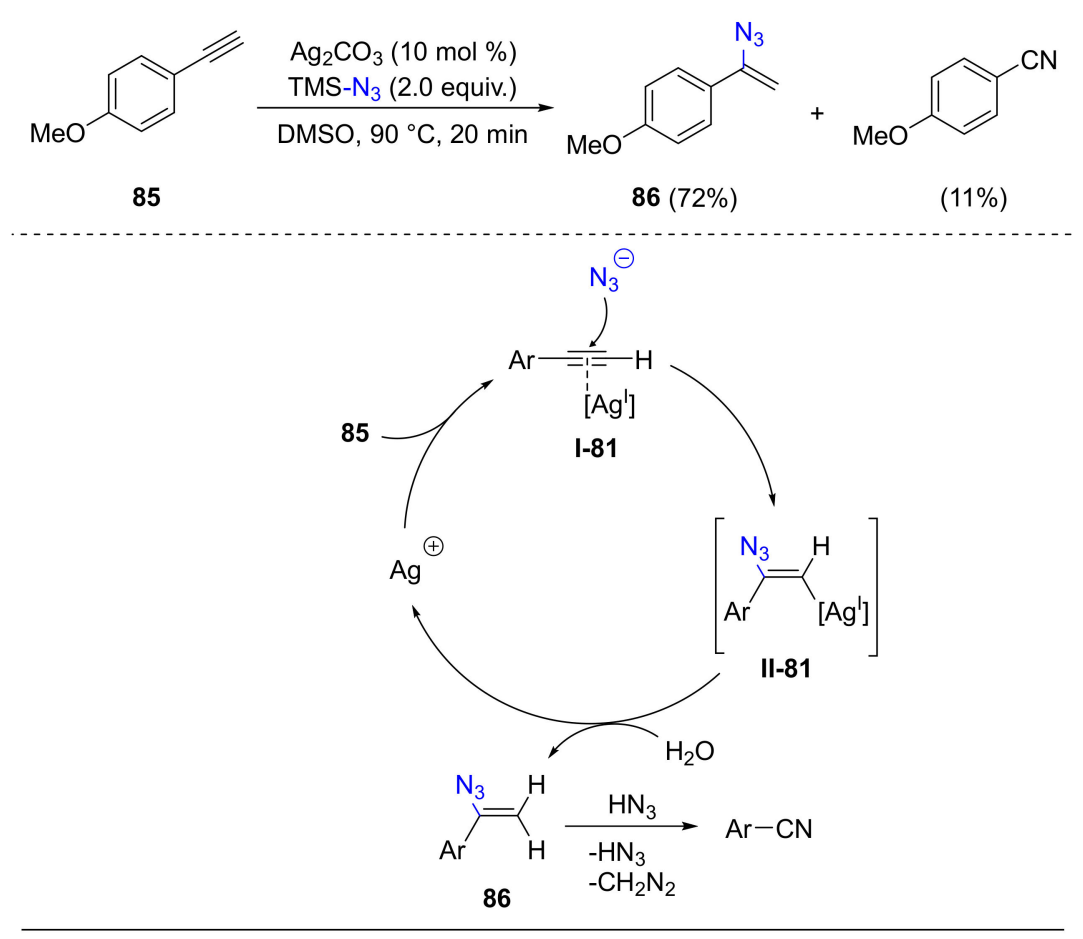

Scheme 81. Azidation of terminal alkynes for the formation of nitriles.

In 2014, Bi and co-workers applied the same strategy for the preparation of vinyl azides by hydroazidation of terminal alkynes [149]. Compared to the previous methodology, the addition of a suitable amount of water was proven to be the key part of the procedure to obtain the vinylazido compounds in good yields (Scheme 82). The outcome of the reaction is not dependent on the electronic properties and the steric hindrance of the substituents.

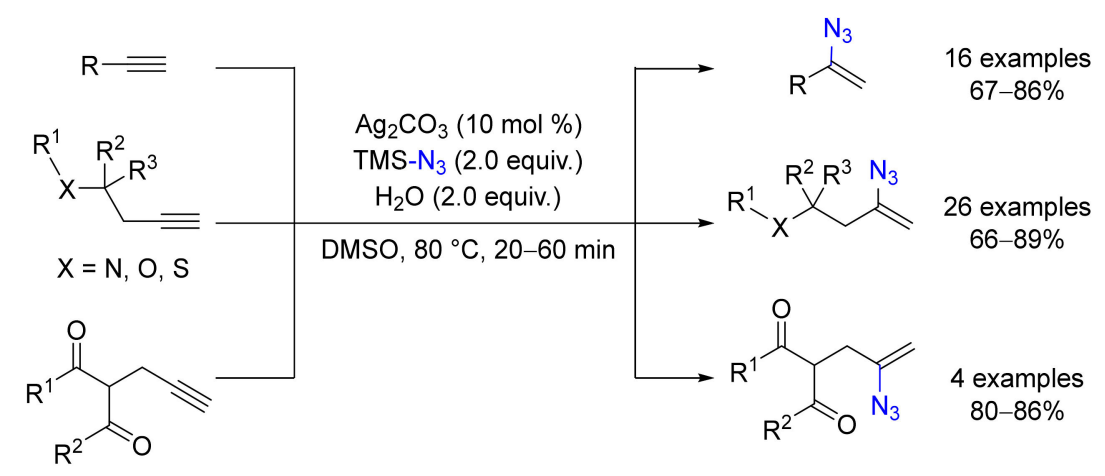

Scheme 82. Azidation of alkynes for the synthesis of azidovinyl-compounds.

In the same year, the group of Bi investigated a chemo- and regioselective hydroazidation of the ethynyl carbinols 87 [150]. Using their standard conditions, authors achieved 2-azidoallyl alcohols 88 as useful intermediates suitable for other synthetic transformations (Scheme 83). The first step of the reaction involves the formation of the silver acetylide species I-83, which is converted into the vinyl-silver intermediate II-83 by addition of $\mathrm{HN}_{3}$, generated in situ by silver catalyzed hydrolysis of TMS- $\mathrm{N}_{3}$. The products 88 are finally formed by protonation of intermediate II- $\mathbf{8 3}$ in wet DMSO. 


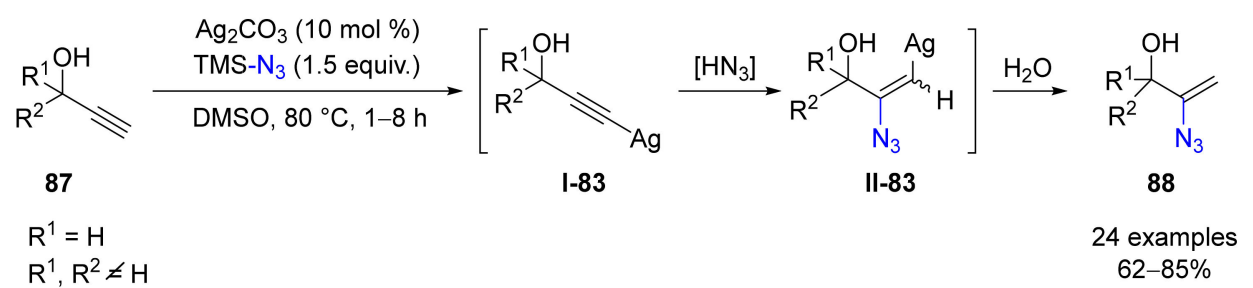

Scheme 83. Ethynyl carbinols as useful precursors for 2-azidoallyl alcohols.

Very recently, Chandrasekhar and co-workers developed a domino transformation of the alkynylated cyclohexadienones $\mathbf{8 9}$ to obtain the cis-fused bicyclic azido alcohols 90 [151]. The reaction occurs in mild conditions in the presence of $\mathrm{Mn}(\mathrm{OAc})_{3} \cdot 2 \mathrm{H}_{2} \mathrm{O}$, TMS- $\mathrm{N}_{3}$ and $\mathrm{O}_{2}$ with acetonitrile as solvent at room temperature (Scheme 84 ). The presence of aryl substituents on the alkyne moiety is essential for the success of the reaction because the process involves a radical mechanism. Initially, $\mathrm{Mn}$ (III) oxidizes TMS- $\mathrm{N}_{3}$ to the azido radical, which reacts with the alkyne to generate the alkenyl radical I-84. This intermediate is converted into the bicyclic intermediate II-84 by radical conjugate addition. This latter traps $\mathrm{O}_{2}$ to give the peroxy radical III-84, which affords the hydroperoxide intermediate IV-84 through a SET process and is finally converted, through two SET processes, into intermediate $\mathbf{V - 8 4}$ with release of water and successively in the products $\mathbf{9 0}$.

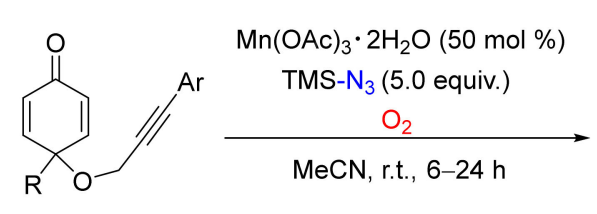

89

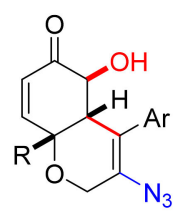

90

4 examples $30-80 \%$

$\mathrm{R}=\mathrm{Me}, \mathrm{Et}, i-\mathrm{Pr}, \mathrm{Ph}, \mathrm{CH}_{2} \mathrm{CH}_{2} \mathrm{OTBS}$

$\mathrm{Ar}=\mathrm{H}, \mathrm{Ph}, 1$-naphthyl, 3-Me- $\mathrm{C}_{6} \mathrm{H}_{4}, 4-\mathrm{OMe}-\mathrm{C}_{6} \mathrm{H}_{4}, 4-\mathrm{Cl}-\mathrm{C}_{6} \mathrm{H}_{4}$ 4- $\mathrm{NO}_{2}-\mathrm{C}_{6} \mathrm{H}_{4}, 4-\mathrm{CN}-\mathrm{C}_{6} \mathrm{H}_{4}, 4-\mathrm{CF}_{3}-\mathrm{C}_{6} \mathrm{H}_{4}$, 9-phenanthrene

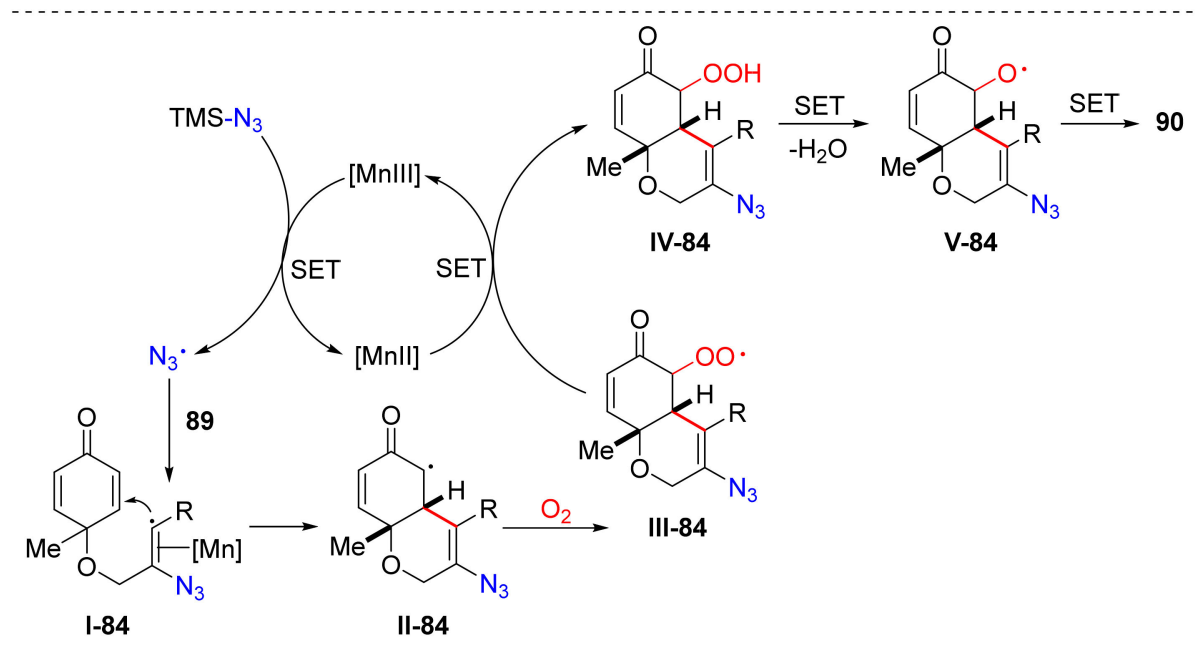

Scheme 84. Procedure for the synthesis of bicyclic azido alcohols.

\section{Azidation Involving Ring-Opening}

In 2009, Krause's group exploited the use of Au-salts to perform a ring-opening allylation/azidation of the 2,5-dihydrofuran compounds 91 affording the 2,6-dien-1-ols 92 (Scheme 85) [152]. The allylation proceeds regioselectively in the C2-position, whereas the azidation takes place selectively in the C4-position. The reaction mechanism proposed by authors involves the initial coordination of the 
metal center to the oxygen atom, with opening of the ring and delocalization of the positive charge (intermediate I-85). The subsequent addition of the azide anion can follow two possible pathways: The first one gives the intermediate II-85, which rapidly undergoes a [3,3]-sigmatropic rearrangement to furnish the thermodynamically more stable intermediate III-85. Alternatively, the direct attack of azide anion on the more substituted carbon of the zwitterionic intermediate I-85 cannot be ruled out.

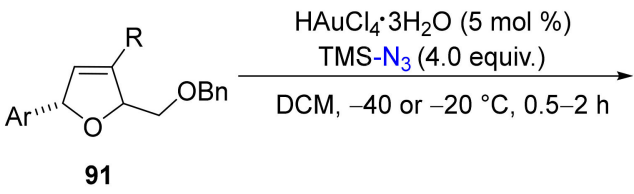

91

$\mathrm{Ar}=\mathrm{Ph}, 4-\mathrm{OMe}-\mathrm{C}_{6} \mathrm{H}_{4}, 4-\mathrm{CO}_{2} \mathrm{Me}-\mathrm{C}_{6} \mathrm{H}_{4}, 4-\mathrm{Br}-\mathrm{C}_{6} \mathrm{H}_{4}$
$\mathrm{R}=\mathrm{H}, \mathrm{Me}$

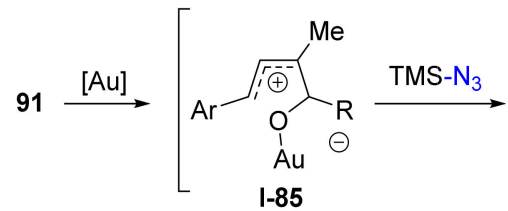

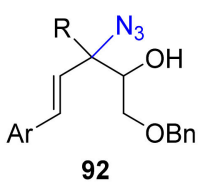

$12-85 \%$

$d r=50: 50$ to $70: 30$

Scheme 85. Gold catalyzed ring-opening azidation.

2-Aryltetrahydrofuran derivatives underwent ring-opening processes associated to azidation of the benzylic position when treated with catalytic $\mathrm{FeCl}_{3}$ in the presence of TMS- $\mathrm{N}_{3}$ (Scheme 86) [153]. These conditions were proven to be effective on substrates bearing electron-donating and electron-withdrawing groups on the aromatic ring, giving 4-azidated primary alcohols and carboxylic acids, whereas 2-alkylated tetrahydrofurans never produced the azidation products.

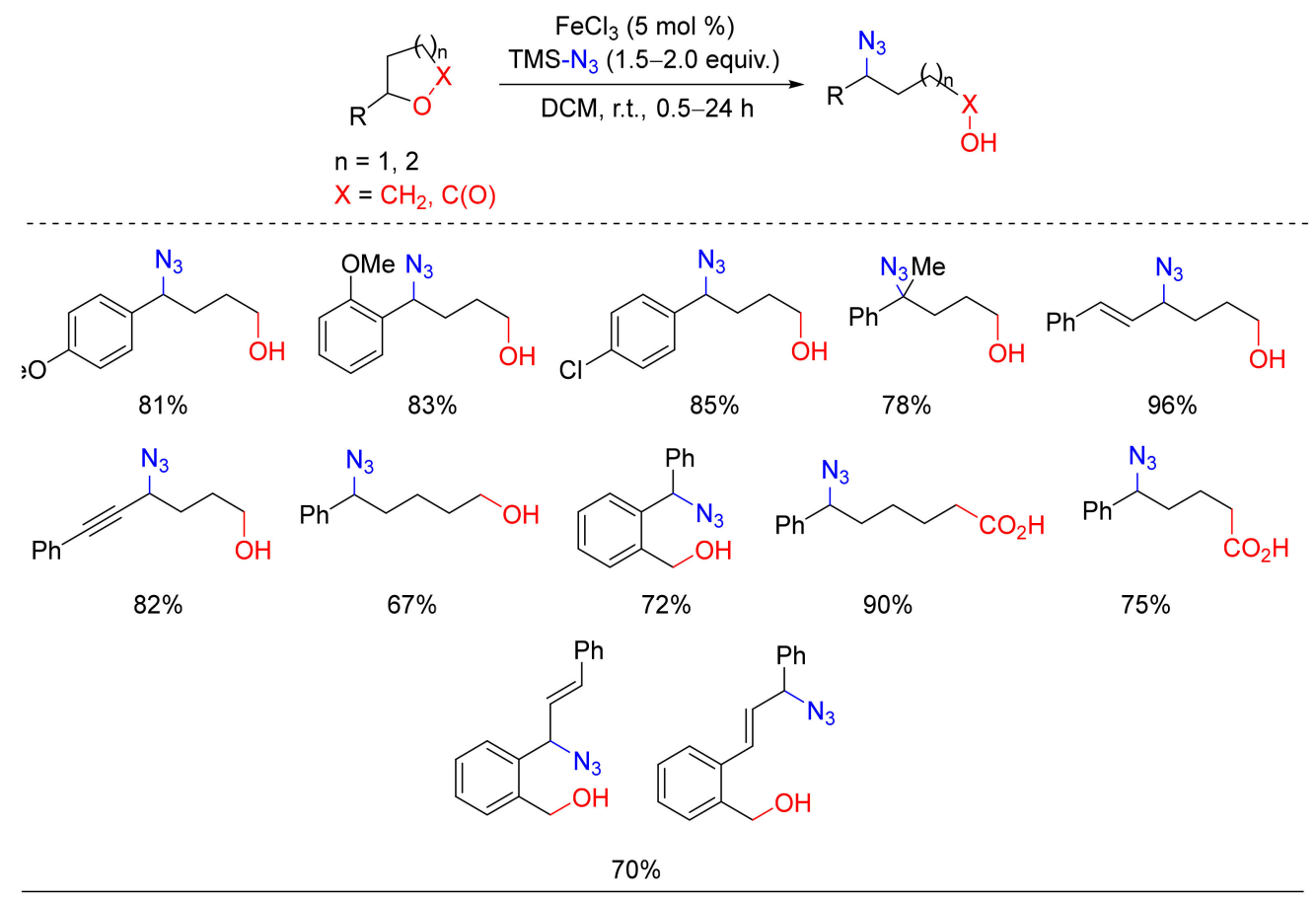

Scheme 86. Iron catalyzed ring-opening with azidation of the benzylic position.

An oxidative azidation of cyclobutanols as highly regioselective synthetic procedure to obtain primary, secondary, and tertiary alkyl azides was reported in 2015 by Zhu and co-workers [154]. 
As shown in Scheme 87 , working with $\mathrm{Mn}(\mathrm{OAc})_{3} \cdot 2 \mathrm{H}_{2} \mathrm{O}, 2,2^{\prime}$-bipy, TMS- $\mathrm{N}_{3}$, and a benziodoxol (BI-OH) as the oxidant, a wide range of substituents, including electron-rich substrate, various halides, and strong electron-withdrawing groups, was compatible with this process. This method also allowed access to benzocyclic azides with seven to ten membered rings with a ring expansion strategy. The possible mechanism starts with the reaction between $\mathrm{Mn}(\mathrm{OAc})_{3}, \mathrm{TMS}-\mathrm{N}_{3}$, and $\mathrm{BI}-\mathrm{OH}$, which could generate a $\mathrm{Mn}(\mathrm{V})-\mathrm{N}_{3}$ species I-87. This intermediate, after the interaction with the substrate, gave II-87, which, through a simultaneous SET, led to the formation of a Mn(IV) intermediate III-87 and the alkyl radical IV-87. In this way, IV-87 reacted with the III-87 providing the product and catalytic species able to restart the cycle.
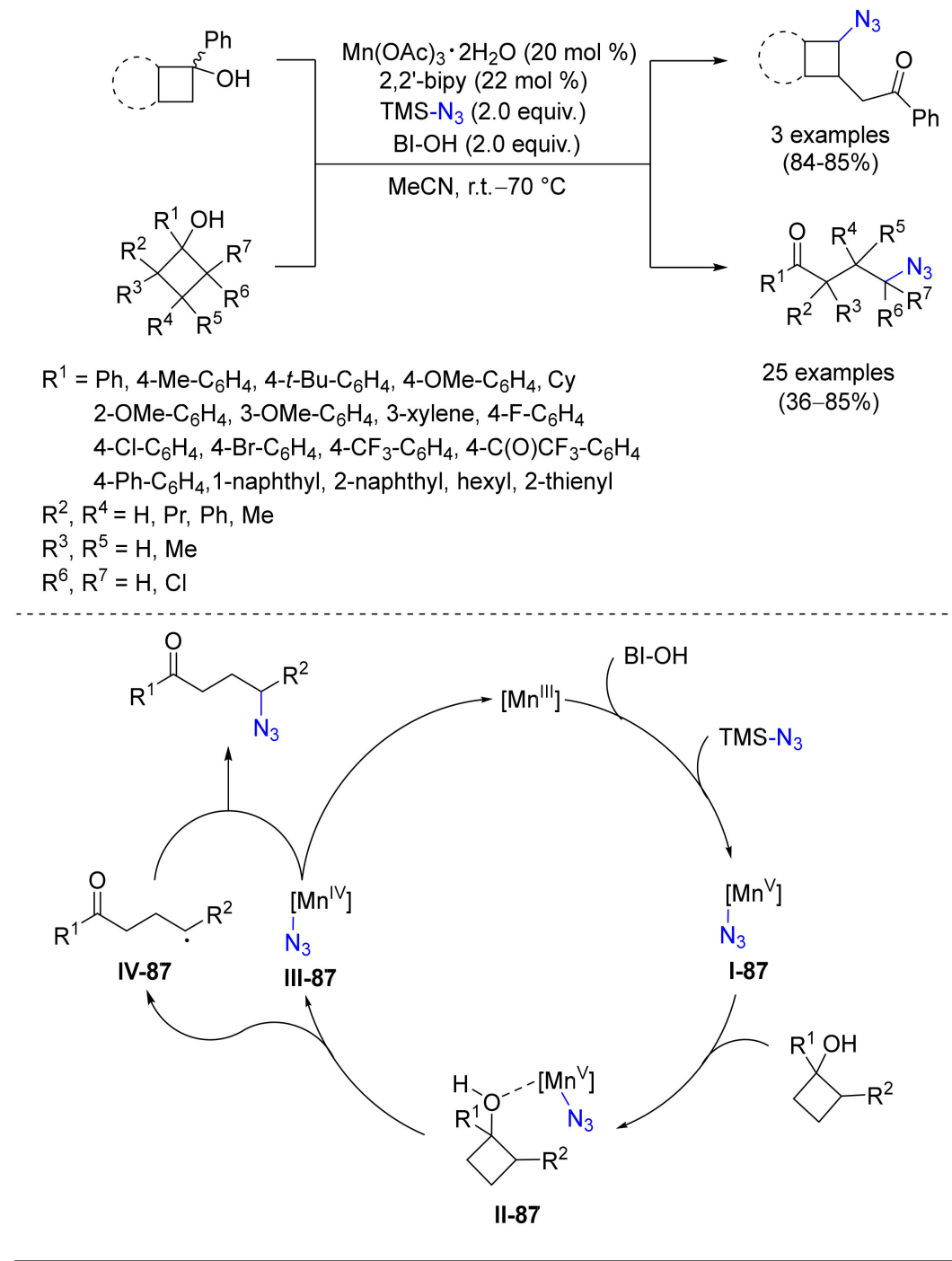

Scheme 87. Oxidative azidation of cyclobutanols.

\section{Conclusions}

This review is an overview of the procedures based on the use of transition metal catalysts to achieve azido products. Following the trend of growth in the importance that the use of transition metals has had, and is still having, in general, in organic synthesis, the reactions catalyzed by transition metals have made it possible to widely expand the opportunities to access azide compounds. The added value arising from the easy accessibility of these compounds is given by their possible further transformation to nitrogen-containing products. 
The utility of this type of reaction is mainly reflected in the possibility (i) to introduce the azide group on substrates bearing unconventional leaving groups, (ii) to perform direct azidation reactions on $\mathrm{C}-\mathrm{H}$ bonds, and (iii) to introduce the azide group simultaneously with another functional group through difunctionalization reactions on not-activated olefins.

The benefit of using these reaction conditions is most evident in the direct azidation of non-activated carbon-carbon multiple bonds. Synthetic approaches based on the intervention of directing groups are also frequent in azidation reactions. The chelating effect of nitrogenous substituents facilitates selective azidation of aromatic $\mathrm{C}-\mathrm{H}$ bonds in the ortho position under very mild conditions. On the other hand, harsher reaction conditions are required for the azidation of aliphatic $\mathrm{C}-\mathrm{H}$ bonds. $\mathrm{NaN}_{3}$, TMS- $\mathrm{N}_{3}$, and hypervalent iodine compounds were proven to be the most used azide sources, but the discovery of new azidation reagents to avoid their potential explosive nature and/or the formation of waste materials is highly desirable. The mechanism by which the reactions proceed depends on the type of metal catalyst, even if in most cases, an oxidative single electron transfer (SET) is involved.

The use of innovative and economically accessible transition metal catalysts, such as iron complexes, seems promising also in this type of reactions. The ongoing effort to optimize the structures of these catalysts can only bring benefits also in the preparation of azide derivatives.

In the future, despite various options available to ensure different solutions for preparing organic azides, the attention should be placed on the development of other reaction conditions, mainly suitable to provide difunctionalization reactions as well as to expand azidations on aliphatic $\mathrm{C}-\mathrm{H}$ bonds. On the other hand, the wide plethora of transition metal catalysts and ligands available permits to explore other possibilities. First of all, the regio- and/or stereodivergent control of the azide synthesis on substrates bearing similar functional groups is an intriguing perspective. Furthermore, great interest will be focused on the use of cheaper and more ecofriendly transition metal sources, according to the principles of the Green Chemistry.

Author Contributions: G.B., R.S. and C.L. wrote the manuscript; R.S. and C.L. drew schemes and revised the mechanisms; G.B. and F.F. revised the text; G.B. proofread the whole manuscript. All authors have read and agreed to the published version of the manuscript.

Funding: This research was funded by Insubria University.

Conflicts of Interest: The authors declare no conflict of interest.

\section{References}

1. Abramovitch, R.A.; Banthorpe, D.V.; Biffin, M.E.C.; Gurst, J.E.; Kyba, E.P.; Lwowski, W.; Miller, J.; Paul, D.B.; Pryde, C.A.; Reiser, A.; et al. The Chemistry of the Azido Group; Patai, S., Ed.; Wiley: New York, NY, USA, 1971.

2. Bräse, S.; Gil, C.; Knepper, K.; Zimmermann, V. Organic Azides: An Exploding Diversity of a Unique Class of Compounds. Angew. Chem. Int. Ed. 2005, 44, 5188-5240. [CrossRef] [PubMed]

3. Gololobov, Y.G.; Kasukhin, L.K. Recent advances in the staudinger reaction. Tetrahedron 1992, 48, 1353-1406. [CrossRef]

4. Chen, B.; Mapp, A.K. A Phosphorimidate Rearrangement for the Facile and Selective Preparation of Allylic Amines. J. Am. Chem. Soc. 2004, 126, 5364-5365. [CrossRef]

5. Wang, H.; Yu, Y.; Hong, X.; Tan, Q.; Xu, B. Rhodium-catalyzed Direct ortho C-N Bond Formation of Aromatic Azo Compounds with Azides. J. Org. Chem. 2014, 79, 3279-3288. [CrossRef] [PubMed]

6. Bellow, J.A.; Yousif, M.; Cabelof, A.C.; Lord, R.L.; Groysman, S. Reactivity Modes of an Iron Bis(alkoxide) Complex with Aryl Azides: Catalytic Nitrene Coupling vs. Formation of Iron(III) Imido Dimers. Organometallics 2015, 34, 2917-2923. [CrossRef]

7. Azides and Nitrenes—Reactivity and Utility; Scriven, E.F.V. (Ed.) Academic Press: New York, NY, USA, 1984.

8. Müller, P.; Fruit, C. Enantioselective Catalytic Aziridinations and Asymmetric Nitrene Insertions into CH Bonds. Chem. Rev. 2003, 103, 2905-2920. [CrossRef]

9. DeGennaro, L.; Trinchera, P.; Luisi, R. Recent Advances in the Stereoselective Synthesis of Aziridines. Chem. Rev. 2014, 114, 7881-7929. [CrossRef] 
10. Zheng, Z.-J.; Wang, D.; Xu, Z.; Xu, L.-W. Synthesis of bi- and bis-1,2,3-triazoles by copper-catalyzed Huisgen cycloaddition: A family of valuable products by click chemistry. Beilstein J. Org. Chem. 2015, 11, 2557-2576. [CrossRef]

11. Schulze, B.; Schubert, U.S. Beyond click chemistry-supramolecular interactions of 1,2,3-triazoles. Chem. Soc. Rev. 2014, 43, 2522-2571. [CrossRef]

12. Broggini, G.; de Marchi, I.; Martinelli, M.; Paladino, G.; Pilati, T.; Terraneo, A. Effective Synthesis of Enantiopure [1,2,3]Triazolo[1,5- $a]$ - and Pyrazolo[1,5- $a]$-pyrrolo[2,1-c] [1,4]benzodiazepines by Diastereoselective Intramolecular Azide and Nitrilimine Cycloadditions. Synthesis 2005, 2005, 2246-2252. [CrossRef]

13. Xie, Y.-Y.; Wang, Y.-C.; He, Y.; Hu, D.-C.; Wang, H.-S.; Pan, Y.-M. Catalyst-free synthesis of fused 1,2,3-triazole and isoindoline derivatives via an intramolecular azide-alkene cascade reaction. Green Chem. 2017, 19, 656-659. [CrossRef]

14. Broggini, G.; Garanti, L.; Molteni, G.; Zecchi, G. A new entry to [1,2,4]triazolo[1,5-a][1,4]benzodiazepin6-onesvia intramolecular nitrilimine cycloaddition to the cyano group. Tetrahedron 1998, 54, 14859-14868. [CrossRef]

15. Habeeb, A.G.; Rao, P.P.N.; Knaus, E.E. Design and Synthesis of Celecoxib and Rofecoxib Analogues as Selective Cyclooxygenase-2 (COX-2) Inhibitors: Replacement of Sulfonamide and Methylsulfonyl Pharmacophores by an Azido Bioisostere. J. Med. Chem. 2001, 44, 3039-3042. [CrossRef] [PubMed]

16. Geurink, P.P.; van der Linden, W.A.; Mirabella, A.C.; Gallastegui, N.; de Bruin, G.; Blom, A.E.M.; Voges, M.J.; Mock, E.D.; Florea, B.I.; van der Marel, G.A.; et al. Incorporation of Non-natural Amino Acids Improves Cell Permeability and Potency of Specific Inhibitors of Proteasome Trypsin-like Sites. J. Med. Chem. 2013, 56, 1262-1275. [CrossRef]

17. Saxon, E.; Luchansky, S.J.; Hang, H.C.; Yu, C.; Lee, S.C.; Bertozzi, C.R. Investigating Cellular Metabolism of Synthetic Azidosugars with the Staudinger Ligation. J. Am. Chem. Soc. 2002, 124, 14893-14902. [CrossRef]

18. Lin, T.-S.; Prusoff, W.H. Synthesis and biological activity of several amino analogs of thymidine. J. Med. Chem. 1978, 21, 109-112. [CrossRef]

19. Pathak, T. Azidonucleosides: Synthesis, Reactions, and Biological Properties. Chem. Rev. 2002, 102, $1623-1668$. [CrossRef]

20. Fletcher, M.D.; Campbell, M.M. Partially Modified Retro-Inverso Peptides: Development, Synthesis, and Conformational Behavior. Chem. Rev. 1998, 98, 763-796. [CrossRef]

21. Patai, S.; Rappoport, Z. Chemistry of Halides, Pseudo-Halides and Azides, Part 1; Patai, S., Ed.; Wiley: Chichester, UK, 1995.

22. Patai, S.; Rappoport, Z. Chemistry of Halides, Pseudo-Halides and Azides, Part 2; Patai, S., Ed.; Wiley: Chichester, UK, 1995.

23. Biffin, J.M.E.C.; Miller, D.B. Paul in. In The Chemistry of the Azido Group; Patai, S., Ed.; Wiley: New York, NY, USA, 1971; pp. 147-176.

24. Noelting, E.; Grandmougin, E.; Michel, O. Ueber die Bildung von Stickstoffwasserstoffsäure (Azoimid) aus aromatischen Azoimiden. Ber. Dtsch. Chem. Ges. 1892, 25, 3328-3342. [CrossRef]

25. Noelting, E.; Michel, O. Direkte Ueberführung von Aminen in Diazoimide mittels Stickstoffwasserstoffsäure. Ber. Dtsch. Chem. Ges. 1893, 26, 86-87. [CrossRef]

26. Noelting, E.; Michel, O. Ueber die Einwirkung von Diazoverbindungen auf Hydrazine. Ber. Dtsch. Chem. Ges. 1893, 26, 88-92. [CrossRef]

27. Kauer, J.C.; Carboni, R.A. Aromatic azapentalenes. III. 1,3a,6,6a-Tetraazapentalenes. J. Am. Chem. Soc. 1967, 89, 2633-2637. [CrossRef]

28. Chehade, K.A.H.; Spielmann, H.P. Facile and Efficient Synthesis of 4-Azidotetrafluoroaniline: A New Photoaffinity Reagent. J. Org. Chem. 2000, 65, 4949-4953. [CrossRef] [PubMed]

29. Miller, D.R.; Swenson, D.C.; Gillan, E.G. Synthesis and Structure of 2,5,8-Triazido-s-Heptazine: An Energetic and Luminescent Precursor to Nitrogen-Rich Carbon Nitrides. J. Am. Chem. Soc. 2004, 126, 5372-5373. [CrossRef]

30. Lowe-Ma, C.K.; Nissan, R.A.; Wilson, W.S. Tetrazolo[1,5-a]pyridines and furazano[4,5-b]pyridine 1-oxides. J. Org. Chem. 1990, 55, 3755-3761. [CrossRef]

31. Righi, G.; D'Achille, C.; Pescatore, G.; Bonini, C. New stereoselective synthesis of the peptidic aminopeptidase inhibitors bestatin, phebestin and probestin. Tetrahedron Lett. 2003, 44, 6999-7002. [CrossRef] 
32. Halland, N.; Braunton, A.; Bachmann, S.; Marigo, M.; Jørgensen, K.A. Direct Organocatalytic Asymmetric $\alpha$-Chlorination of Aldehydes. J. Am. Chem. Soc. 2004, 126, 4790-4791. [CrossRef]

33. Tashiro, M.; Tsuge, A.; Sawada, T.; Makishima, T.; Horie, S.; Arimura, T.; Mataka, S.; Yamato, T. Metacyclophanes and related compounds. 26. Tetrahydroxy[2.n.2.n]metacyclophanes. Preparation, reactions, and spectra. J. Org. Chem. 1990, 55, 2404-2409. [CrossRef]

34. Goswami, M.G.; de Bruin, B. Metal-Catalysed Azidation of Organic Molecules. Eur. J. Org. Chem. 2017, 2017, 1152-1176. [CrossRef]

35. Liu, Y.; Ebadi, A.G.; Youseftabar-Miri, L.; Hassanpour, A.; Vessally, E. Methods for direct C(sp $\left.{ }^{2}\right)-H$ bonds azidation. RSC Adv. 2019, 9, 25199-25215. [CrossRef]

36. Huang, X.; Groves, J.T. Taming Azide Radicals for Catalytic C-H Azidation. ACS Catal. 2015, 6, 751-759. [CrossRef]

37. Chen, Z.; Rong, M.-Y.; Nie, J.; Zhu, X.-F.; Shi, B.-F.; Ma, J.-A. Catalytic alkylation of unactivated C( $\left.\operatorname{sp}^{3}\right)-H$ bonds for $\mathrm{C}\left(\mathrm{sp}^{3}\right)-\mathrm{C}\left(\mathrm{sp}^{3}\right)$ bond formation. Chem. Soc. Rev. 2019, 48, 4921-4942. [CrossRef] [PubMed]

38. Santoro, S.; Ferlin, F.; Ackermann, L.; Vaccaro, L. C-H functionalization reactions under flow conditions. Chem. Soc. Rev. 2019, 48, 2767-2782. [CrossRef]

39. Gandeepan, P.; Müller, T.; Zell, D.; Cera, G.; Warratz, S.; Ackermann, L. 3d Transition Metals for C-H Activation. Chem. Rev. 2018, 119, 2192-2452. [CrossRef]

40. Borpatra, P.J.; Deka, B.; Deb, M.L.; Baruah, P.K. Recent advances in intramolecular C-O/C-N/C-S bond formation via C-H functionalization. Org. Chem. Front. 2019, 6, 3445-3489. [CrossRef]

41. Broggini, G.; Borelli, T.; Giofré, S.; Mazza, A. Intramolecular Oxidative Palladium-Catalyzed Amination Involving Double C-H Functionalization of Unactivated Olefins. Synthesis 2017, 49, 2803-2818. [CrossRef]

42. Ping, L.; Chung, D.S.; Bouffard, J.; Lee, S.-G. Transition metal-catalyzed site- and regio-divergent C-H bond functionalization. Chem. Soc. Rev. 2017, 46, 4299-4328. [CrossRef]

43. Théveau, L.; Schneider, C.; Fruit, C.; Hoarau, C. Orthogonal Palladium-Catalyzed Direct C-H Bond Arylation of Heteroaromatics with Aryl Halides. ChemCatChem 2016, 8, 3183-3194. [CrossRef]

44. Beccalli, E.M.; Broggini, G.; Martinelli, M.; Sottocornola, S. C-C, C-O, C-N Bond Formation on sp ${ }^{2}$ Carbon by Pd(II)-Catalyzed Reactions Involving Oxidant Agents. Chem. Rev. 2007, 107, 5318-5365. [CrossRef] [PubMed]

45. Cho, S.H.; Kim, J.Y.; Kwak, J.; Chang, S. Recent advances in the transition metal-catalyzed twofold oxidative C-H bond activation strategy for C-C and C-N bond formation. Chem. Soc. Rev. 2011, 40, 5068-5083. [CrossRef]

46. Godula, K.; Sames, D. C-H Bond Functionalization in Complex Organic Synthesis. Science 2006, 312, 67-72. [CrossRef] [PubMed]

47. Murahashi, S.-I.; Tanigawa, Y.; Imada, Y.; Taniguchi, Y. Palladium(0) catalyzed azidation and amination of allyl acetates. Selective synthesis of allyl azides and primary allylamines. Tetrahedron Lett. 1986, 27, 227-230. [CrossRef]

48. Murahashi, S.-I.; Taniguchi, Y.; Imada, Y.; Tanigawa, Y. Palladium(0)-Catalyzed Azidation of Allyl Esters. Selective Synthesis of Allyl Azides, Primary Allylamines, and Related Compounds. J. Org. Chem. 1989, 54, 3292-3303. [CrossRef]

49. Aufranc, P.; Ollivier, J.; Stolle, A.; Bremer, C.; Es-Sayed, M.; de Meijere, A.; Salaün, J. Regioselective Palladium (0) Azidation and Amination of 1-Alkenylcyclopropyl Esters: A New Route to 2,3-Methanoamino Acids. Tetrahedron Lett. 1993, 34, 4193-4196. [CrossRef]

50. Safi, M.; Fahrang, R.; Sinou, D. Palladium(0)-Catalyzed Azidation of Allyl Esters with Trimethylsilyl Azide. Tetrahedron Lett. 1990, 31, 527-530. [CrossRef]

51. Trost, B.M.; Pulley, S.R. Asymmetric Total Synthesis of (+)-Pancratistatin. J. Am. Chem. Soc. 1995, 117, 10143-10144. [CrossRef]

52. Rueping, M.; Vila, C.; Uria, U. Direct Catalytic Azidation of Allylic Alcohols. Org. Lett. 2012, 14, $768-771$. [CrossRef]

53. Kim, S.; Chan, L.Y.; Kim, S.; Chung, W.T.; Long, C. Fe(OTf) 3 -Catalyzed Reaction of Benzylic Acetates with Organosilicon Compounds. Synlett 2011, 3, 415-419. [CrossRef]

54. Salunke, S.B.; Babu, N.S.; Chen, C.-T. Iron(iii) chloride as an efficient catalyst for stereoselective synthesis of glycosyl azides and a cocatalyst with $\mathrm{Cu}(0)$ for the subsequent click chemistry. Chem. Commun. 2011, 47, 10440-10442. [CrossRef] 
55. Sawama, Y.; Nagata, S.; Yabe, Y.; Morita, K.; Monguchi, Y.; Sajiki, H. Iron-Catalyzed Chemoselective Azidation of Benzylic Silyl Ethers. Chem. Eur. J. 2012, 18, 16608-16611. [CrossRef]

56. Sawama, Y.; Goto, R.; Nagata, S.; Shishido, Y.; Monguchi, Y.; Sajiki, H. Chemoselective and Direct Functionalization of Methyl Benzyl Ethers and Unsymmetrical Dibenzyl Ethers by Using Iron Trichloride. Chem. Eur. J. 2014, 20, 2631-2636. [CrossRef]

57. Liu, C.; Wang, X.; Li, Z.; Cui, L.; Li, C. Silver-Catalyzed Decarboxylative Radical Azidation of Aliphatic Carboxylic Acids in Aqueous Solution. J. Am. Chem. Soc. 2015, 137, 9820-9823. [CrossRef] [PubMed]

58. Zhu, Y.; Li, X.; Wang, X.; Huang, X.; Shen, T.; Zhang, Y.; Sun, X.; Zou, M.; Song, S.; Jiao, N. Silver-Catalyzed Decarboxylative Azidation of Aliphatic Carboxylic Acids. Org. Lett. 2015, 17, 4702-4705. [CrossRef] [PubMed]

59. Khedar, P.; Pericherla, K.; Kumar, A. Copper Triflate: An Efficient Catalyst for Direct Conversion of Secondary Alcohols into Azides. Synlett 2014, 25, 515-518. [CrossRef]

60. Zhu, W.; Ma, D. Synthesis of aryl azides and vinyl azides via proline-promoted CuI-catalyzed coupling reaction. Chem. Commun. 2004, 7, 888-889. [CrossRef]

61. Tao, C.-Z.; Cui, X.; Li, J.; Liu, A.-X.; Liu, L.; Guo, Q.-X. Copper-catalyzed synthesis of aryl azides and 1-aryl-1,2,3-triazoles from boronic acids. Tetrahedron Lett. 2007, 48, 3525-3529. [CrossRef]

62. Li, Y.; Gao, L.-X.; Han, F.-S. Reliable and Diverse Synthesis of Aryl Azides through Copper-Catalyzed Coupling of Boronic Acids or Esters with $\mathrm{TMSN}_{3}$. Chem. Eur. J. 2010, 16, 7969-7972. [CrossRef]

63. Clerc, A.; Beneteau, V.; Pale, P.; Chassaing, S. Chan-Lam-type Azidation and One-Pot CuAAC under $\mathrm{Cu}^{\mathrm{i}-Z e o l i t e}$ Catalysis. ChemCatChem 2020, 12, 2060-2065. [CrossRef]

64. Raushel, J.; Pitram, S.M.; Fokin, V.V. Efficient Synthesis of Sulfonyl Azides from Sulfonamides. Org. Lett. 2008, 10, 3385-3388. [CrossRef]

65. Tang, C.; Jiao, N. Copper-Catalyzed C-H Azidation of Anilines under Mild Conditions. J. Am. Chem. Soc. 2012, 134, 18924-18927. [CrossRef]

66. Fang, H.; Dou, Y.; Ge, J.; Chhabra, M.; Sun, H.; Zhang, P.; Zheng, Y.; Zhu, Q. Regioselective and Direct Azidation of Anilines via $\mathrm{Cu}(\mathrm{II})$-Catalyzed C-H Functionalization in Water. J. Org. Chem. 2017, 82, 11212-11217. [CrossRef] [PubMed]

67. Fan, Y.; Wan, W.; Ma, G.; Gao, W.; Jiang, H.; Zhu, S.; Hao, J. Room-temperature Cu(II)-catalyzed aromatic $\mathrm{C}-\mathrm{H}$ azidation for the synthesis of ortho-azido anilines with excellent regioselectivity. Chem. Commun. 2014, 50, 5733-5736. [CrossRef] [PubMed]

68. Azad, C.S.; Narula, A.K. Copper-catalysed regioselective azidation of arenes by C-H activation directed by pyridine. RSC Adv. 2015, 5, 100223-100227. [CrossRef]

69. Dou, Y.; Xie, Z.; Sun, Z.; Fang, H.; Shen, C.; Zhang, P.; Zhu, Q. Copper(II)-Catalyzed Direct Azidation of $\mathrm{N}$-Acylated 8-Aminoquinolines by Remote C-H Activation. ChemCatChem 2016, 8, 3570-3574. [CrossRef]

70. Yao, B.; Liu, Y.; Zhao, L.; Wang, D.-X.; Wang, M.-X. Designing a Cu(II)-ArCu(II)-ArCu(III)-Cu(I) Catalytic Cycle: $\mathrm{Cu}(\mathrm{II})-$ Catalyzed Oxidative Arene C-H Bond Azidation with Air as an Oxidant under Ambient Conditions. J. Org. Chem. 2014, 79, 11139-11145. [CrossRef]

71. Suh, S.-E.; Chen, S.-J.; Mandal, M.; Guzei, I.A.; Cramer, C.J.; Stahl, S.S. Site-Selective Copper-Catalyzed Azidation of Benzylic C-H Bonds. J. Am. Chem. Soc. 2020, 142, 11388-11393. [CrossRef]

72. Hendrick, C.E.; Bitting, K.J.; Cho, S.; Wang, Q. Site-Selective Copper-Catalyzed Amination and Azidation of Arenes and Heteroarenes via Deprotonative Zincation. J. Am. Chem. Soc. 2017, 139, 11622-11628. [CrossRef]

73. Xie, F.; Qi, Z.; Li, X. Rhodium(III)-Catalyzed Azidation and Nitration of Arenes by C-H Activation. Angew. Chem. Int. Ed. 2013, 52, 11862-11866. [CrossRef]

74. Wang, Y.; Fang, Z.; Chen, X.; Wang, Y. Mild Dirhodium(II)-Catalyzed Chemo- and Regioselective Azidation of Arenes. Org. Lett. 2018, 20, 5732-5736. [CrossRef]

75. Wang, Y.; Fang, Z.; Chen, X.; Wang, Y. Dirhodium(II)-Catalyzed C(sp²)-H Azidation of Benzaldegydes. Chem. Eur. J. 2020, 26, 6805-6811. [CrossRef]

76. Huang, X.; Bergsten, T.M.; Groves, J.T. Manganese-Catalyzed Late-Stage Aliphatic C-H Azidation. J. Am. Chem. 2015, 137, 5300-5303. [CrossRef] [PubMed]

77. Deng, Q.-H.; Bleith, T.; Wadepohl, H.; Gade, L.H. Enantioselective Iron-Catalyzed Azidation of $\beta$-Keto Esters and Oxindoles. J. Am. Chem. Soc. 2013, 135, 5356-5359. [CrossRef]

78. Sharma, A.; Hartwig, J.F. Metal-catalysed azidation of tertiary C-H bonds suitable for late-stage functionalization. Nature 2015, 517, 600-604. [CrossRef] [PubMed] 
79. Karimov, R.R.; Sharma, A.; Hartwig, J.F. Late Stage Azidation of Complex Molecules. ACS Cent. Sci. 2016, 2, 715-724. [CrossRef] [PubMed]

80. Bian, K.-J.; Wang, C.Y.; Huang, Y.-L.; Xu, Y.L.; Wang, X.-S. Remote azidation of C( $\left(\mathrm{sp}^{3}\right)$-H bonds to synthesize $\delta$-azido sulphonamides via iron-catalyzed radical relay. Org. Biomol. Chem. 2020, 18, 5354-5357. [CrossRef]

81. Wang, Y.; Li, G.-X.; Yang, G.; He, G.; Chen, G. A visible-light-promoted radical reaction system for azidation and halogenation of tertiary aliphatic C-H bonds. Chem. Sci. 2016, 7, 2679-2683. [CrossRef]

82. Vita, M.V.; Waser, J. Azidation of $\beta$-Keto Esters and Silyl Enol Ethers with a Benziodoxole Reagent. Org. Lett. 2013, 15, 3246-3249. [CrossRef]

83. Rabet, P.T.G.; Fumagalli, G.; Boyd, S.; Greaney, M.F. Benzylic C-H Azidation Using the Zhdankin Reagent and a Copper Photoredox Catalyst. Org. Lett. 2016, 18, 1646-1649. [CrossRef]

84. Dhineshkumar, J.; Samaddar, P.; Prabhu, K.R. A copper catalyzed azidation and peroxidation of $\beta$-naphthols via an oxidative dearomatization strategy. Chem. Commun. 2016, 52, 11084-11087. [CrossRef]

85. Dhineshkumar, J.; Gadde, K.; Prabhu, K.R. Substituent-Directed Regioselective Azidation: Copper-Catalyzed C-H Azidation and Iodine-Catalyzed Dearomatizative Azidation of Indole. J. Org. Chem. 2018, 83, $228-235$. [CrossRef]

86. Hossain, A.; Vidyasagar, A.; Eichinger, C.; Lankes, C.; Phan, J.; Rehbein, J.; Reiser, O. Visible-Light-Accelerated Copper(II)-Catalyzed Regio- and Chemoselective Oxo-Azidation of Vinyl Arenes. Angew. Chem. Int. Ed. 2018, 57, 8288-8292. [CrossRef] [PubMed]

87. Sequeira, F.C.; Turnpenny, B.W.; Chemler, S.R. Copper-promoted and copper-catalyzed intermolecular alkene diamination. Angew. Chem. Int. Ed. 2010, 49, 6365-6368. [CrossRef] [PubMed]

88. Li, Y.; Liang, Y.; Dong, J.; Deng, Y.; Zhao, C.; Su, Z.; Guan, W.; Bi, X.; Liu, Q.; Fu, J. Directed Copper-Catalyzed Intermolecular Aminative Difunctionalization of Unactivated Alkenes. J. Am. Chem. Soc. 2019, 141, 18475-18485. [CrossRef] [PubMed]

89. Zhang, B.; Studer, A. Copper-Catalyzed Intermolecular Aminoazidation of Alkenes. Org. Lett. 2014, 16, 1790-1793. [CrossRef]

90. Li, Y.; Zhang, Q. N-Fluorobenzenesulfonimide: An Efficient Nitrogen Source for C-N Bond Formation. Synthesis 2015, 47, 159-174. [CrossRef]

91. Wang, L.; Wang, X.; Zhang, G.; Yang, S.; Li, Y.; Zhang, Q. Copper-catalyzed 1,3-aminoazidation of arylcyclopropanes: A facile access to 1,3-diamine derivatives. Org. Chem. Front. 2019, 6, 2934-2938. [CrossRef]

92. Lei, B.; Wang, X.; Ma, L.; Li, Y.; Li, Z. NFSI-participated intermolecular aminoazidation of alkene through iron catalysis. Org. Biomol. Chem. 2018, 16, 3109-3113. [CrossRef]

93. Shen, K.; Wang, Q. Copper-Catalyzed Alkene Aminoazidation as a Rapid Entry to 1,2-Diamines and Installation of an Azide Reporter onto Azahetereocycles. J. Am. Chem. Soc. 2017, 139, 13110-13116. [CrossRef]

94. Olding, A.; Ho, C.C. Recent Applications of the Zhdankin Reagent in Organic Synthesis. Aust. J. Chem. 2019, 72, 646-648. [CrossRef]

95. Abi-Fayssal, S.; Giungi, A.; Berhal, F.; Prestat, G. Iron-Catalyzed Intra-intermolecular Aminoazidation of Alkenes. Org. Process. Res. Dev. 2019, 24, 695-703. [CrossRef]

96. Foschi, F.; Loro, C.; Sala, R.; Oble, J.; Presti, L.L.; Beccalli, E.M.; Poli, G.; Broggini, G. Intramolecular Aminoazidation of Unactivated Terminal Alkenes by Palladium-Catalyzed Reactions with Hydrogen Peroxide as the Oxidant. Org. Lett. 2020, 22, 1402-1406. [CrossRef] [PubMed]

97. Li, X.; Qi, X.; Hou, C.; Chen, P.; Liu, G. Palladium(II)-Catalyzed Enantioselective Azidation of Unactivated Alkenes. Angew. Chem. Int. Ed. 2020, 59, 17239-17244. [CrossRef] [PubMed]

98. Su, H.; Li, W.; Xuan, Z.; Yu, W. Copper-Catalyzed Cyclization and Azidation of $\gamma, \delta$-Unsaturated Ketone O-Benzoyl Oximes. Adv. Synth. Catal. 2014, 357, 64-70. [CrossRef]

99. Zhao, Y.; Hu, Y.; Wang, H.; Li, X.; Wan, B. Transition-Metal Controlled Diastereodivergent Radical Cyclization/Azidation Cascade of 1,7-Enynes. J. Org. Chem. 2016, 81, 4412-4420. [CrossRef]

100. Ouyang, X.-H.; Song, R.-J.; Liu, Y.; Hu, M.; Li, J.-H. Copper-Catalyzed Radical [2 + $2+1]$ Annulation of Benzene-Linked 1,n-Enynes with Azide: Fused Pyrroline Compounds. Org. Lett. 2015, 17, 6038-6041. [CrossRef]

101. Lu, M.-Z.; Wang, C.-Q.; Loh, T.-P. Copper-Catalyzed Vicinal Oxyazidation and Diazidation of Styrenes under Mild Conditions: Access to Alkyl Azides. Org. Lett. 2015, 17, 6110-6113. [CrossRef] 
102. Zhou, H.; Jian, W.; Qian, B.; Ye, C.; Li, D.; Zhou, J.; Bao, H. Copper-Catalyzed Ligand-Free Diazidation of Olefins with $\mathrm{TMSN}_{3}$ in $\mathrm{CH}_{3} \mathrm{CN}$ or in $\mathrm{H}_{2} \mathrm{O}$. Org. Lett. 2017, 19, 6120-6123. [CrossRef]

103. Minisci, F.; Galli, R. Influence of the electrophilic character on the reactivity of free radicals in solution reactivity of alkoxy, hydroxy, alkyl and azido radicals in presence of olefins. Tetrahedron Lett. 1962, 3, 533-538. [CrossRef]

104. Minisci, F.; Galli, R. Reactivity of alkoxy and hydroxy radicals in presence of olefins and oxidation-reduction systems. Introduction of azido, chloro and acyloxy groups in allylic position and azido-chlorination of olefins. Tetrahedron Lett. 1963, 6, 357-360. [CrossRef]

105. Yuan, Y.-A.; Lu, D.-F.; Chen, Y.R.; Zu, H. Iron-Catalyzed Direct Diazidation for a Broad Range of Olefins. Angew. Chem. Int. Ed. 2015, 55, 534-538. [CrossRef]

106. Shen, S.-J.; Zhu, C.-L.; Lu, D.-F.; Xu, H. Iron-Catalyzed Direct Olefin Diazidation Via Peroxyester Activation Promoted by Nitrogen-Based Ligands. ACS Catal. 2018, 8, 4473-4482. [CrossRef]

107. Peng, H.; Yuan, Z.; Chen, P.; Liu, G. Palladium-Catalyzed Intermolecular Oxidative Diazidation of Alkenes. Chin. J. Chem. 2017, 35, 876-880. [CrossRef]

108. Fu, N.; Sauer, G.S.; Saha, A.; Loo, A.; Lin, S. Metal-catalyzed electrochemical diazidation of alkenes. Science 2017, 357, 575-579. [CrossRef]

109. Sun, X.; Li, X.; Song, S.; Zhu, Y.; Liang, Y.-F.; Jiao, N. Mn-Catalyzed Highly Efficient Aerobic Oxidative Hydroxyazidation of Olefins: A Direct Approach to $\beta$-Azido Alcohols. J. Am. Chem. Soc. 2015, 137, 6059-6066. [CrossRef]

110. Fumagalli, G.; Rabet, P.T.G.; Boyd, S.; Greaney, M.F. Three-Component Azidation of Styrene-Type Double Bonds: Light-Switchable Behavior of a Copper Photoredox Catalyst. Angew. Chem. Int. Ed. 2015, 54, 11481-11484. [CrossRef]

111. Yin, H.; Wang, T.; Jiao, N. Copper-Catalyzed Oxoazidation and Alkoxyazidation of Indoles. Org. Lett. 2014, 16, 2302-2305. [CrossRef]

112. Zhang, P.; Sun, W.; Li, G.; Hong, L.; Wang, R. Copper-catalyzed cascade azidation-cyclization of tryptophols and tryptamines. Chem. Commun. 2015, 51, 12293-12296. [CrossRef]

113. Zhu, R.; Buchwald, S.L. Versatile Enantioselective Synthesis of Functionalized Lactones via Copper-Catalyzed Radical Oxyfunctionalization of Alkenes. J. Am. Chem. Soc. 2015, 137, 8069-8077. [CrossRef]

114. Alazet, S.; le Vaillant, F.; Nicolai, S.; Courant, T.; Waser, J. Divergent Access to $(1,1)$ and $(1,2)$-Azidolactones from Alkenes using Hypervalent Iodine Reagents. Chem. Eur. J. 2017, 23, 9501-9504. [CrossRef]

115. Zhu, L.; Yu, H.; Xu, Z.; Jiang, X.; Lin, L.; Wang, R. Copper-Catalyzed Oxyazidation of Unactivated Alkenes: A Facile Synthesis of Isoxazolines Featuring an Azido Substituent. Org. Lett. 2014, 16, 1562-1565. [CrossRef]

116. Qian, L.-L.; Yi, R.; Min, X.-T.; Hu, Y.-C.; Wan, B.; Chen, Q.C. Rapid assembly of 3-azidomethylfurans from 2-(1-alkynyl)-2-alken-1-ones enabled by silver catalysis. Tetrahedron 2020, 76, 131327. [CrossRef]

117. Bertho, S.; Rey-Rodriguez, R.; Colas, C.; Retailleau, P.; Gillaizeau, I. Regio- and Stereoselective Iron-Catalyzed Oxyazidation of Enamides Using a Hypervalent Iodine Reagent. Chem. Eur. J. 2017, 23, 17674-17677. [CrossRef]

118. Wang, F.; Qi, X.; Liang, Z.; Chen, P.; Liu, G. Copper-Catalyzed Intermolecular Trifluoromethylazidation of Alkenes: Convenient Access to CF3-Containing Alkyl Azides. Angew. Chem. Int. Ed. 2014, 53, 1881-1886. [CrossRef]

119. Wang, F.; Zhu, N.; Chen, P.; Ye, J.; Liu, G. Copper-Catalyzed Trifluoromethylazidation of Alkynes: Efficient Access to CF3-Substituted Azirines and Aziridines. Angew. Chem. Int. Ed. 2015, 54, 9356-9360. [CrossRef]

120. Yang, M.; Wang, W.; Liu, Y.; Feng, L.; Jua, X. Copper-Catalyzed Three-Component Azidotrifluoromethylation/Difunctionalization of Alkenes. Chin. J. Chem. 2014, 32, 833-837. [CrossRef]

121. Huang, L.; Lin, J.-S.; Tan, B.; Liu, X.-Y. Alkene Trifluoromethylation-Initiated Remote $\alpha$-Azidation of Carbonyl Compounds toward Trifluoromethyl $\gamma$-Lactam and Spirobenzofuranone-Lactam. ACS Catal. 2015, 5, 2826-2831. [CrossRef]

122. Carboni, A.; Dagousset, G.; Magnier, E.; Masson, G. Photoredox-Induced Three-Component Oxy-', Amino-, and Carbotrifluoromethylation of Enecarbamates. Org. Lett. 2014, 16, 1240-1243. [CrossRef]

123. Dagousset, G.; Carboni, A.; Magnier, E.; Masson, G. Photoredox-Induced Three-Component Azido- and Aminotrifluoromethylation of Alkenes. Org. Lett. 2014, 16, 4340-4343. [CrossRef]

124. Geng, X.; Lin, F.; Wang, X.; Jiao, N. Azidofluoroalkylation of Alkenes with Simple Fluoroalkyl Iodides Enabled by Photoredox Catalysis. Org. Lett. 2017, 19, 4738-4741. [CrossRef] 
125. Lu, L.; Huang, W.-Y. The reaction of perfluoroalkanesulfinates VII. Fenton reagent-initiated addition of sodium perfluoroalkanesulfinates to alkenes. Chin. J. Chem. 2010, 10, 365-372. [CrossRef]

126. Zhu, C.-L.; Wang, C.; Qin, Q.-X.; Yruegas, S.; Martin, C.D.; Xu, H.; Yruegas, S. Iron(II)-Catalyzed Azidotrifluoromethylation of Olefins and N-Heterocycles for Expedient Vicinal Trifluoromethyl Amine Synthesis. ACS Catal. 2018, 8, 5032-5037. [CrossRef] [PubMed]

127. Xiong, H.; Ramkumar, N.; Chiou, M.-F.; Jian, W.; Li, Y.; Su, J.-H.; Zhang, X.; Bao, H. Iron-catalyzed carboazidation of alkenes and alkynes. Nat. Commun. 2019, 10, 122-128. [CrossRef] [PubMed]

128. Chiou, M.-F.; Xiong, H.; Li, Y.; Bao, H.; Zhang, X. Revealing the Iron-Catalyzed $\beta$-Methyl Scission of tert-Butoxyl Radicals via the Mechanistic Studies of Carboazidation of Alkenes. Molecules 2020, 25, 1224. [CrossRef] [PubMed]

129. Xu, L.; Chen, J.; Chu, L. Solvent-tuned Chemoselective carboazidation and diazidation of alkenes via iron catalysis. Org. Chem. Front. 2019, 6, 512-516. [CrossRef]

130. Hajra, S.; Sinha, D.; Bhowmick, M. Metal triflate catalyzed highly regio- and stereoselective 1,2-bromoazidation of alkenes using NBS and TMSN3 as the bromine and azide sources. Tetrahedron Lett. 2006, 47, 7017-7019. [CrossRef]

131. Li, W.-Y.; Wang, Q.-Q.; Yang, L. Fe-Catalyzed radical-type difunctionalization of styrenes with aliphatic aldehydes and trimethylsisyl azide via a decarbonilative alkylation-azidation cascade. Org. Biomol. Chem. 2017, 15, 9987-9991. [CrossRef]

132. Li, W.-Y.; Wu, C.-S.; Zhou, W.; Yang, L. Fe-catalyzed three-component carboazidation of alkenes with alkanes and trimethylsilyl azide. Chem. Commun. 2018, 54, 11013-11016. [CrossRef]

133. Yang, B.; Ren, X.; Shen, X.; Li, T.; Lu, Z. Visible Light-Promoted Three-Component Carboazidation of Unactivated Alkenes with TMSN3 and Acrylonitrile. Chin. J. Chem. 2018, 36, 1017-1023. [CrossRef]

134. Wei, X.-H.; Li, Y.-M.; Zhou, A.-X.; Yang, T.-T.; Yang, S.-D. Silver-Catalyzed Carboazidation of Arylacrylamides. Org. Lett. 2013, 15, 4158-4161. [CrossRef]

135. Yuan, Y.; Shen, T.; Wang, K.; Jiao, N. Ag-Promoted Azido-Carbocyclization of Activated Alkenes via C-H Bond Cleavage. Chem. Asian J. 2013, 8, 2932-2935. [CrossRef]

136. Xu, L.; Mou, X.-Q.; Chen, Z.-M.; Wang, S.-H. Copper-catalyzed intermolecular azidocyanation of aryl alkenes. Chem. Commun. 2014, 50, 10676-10679. [CrossRef] [PubMed]

137. Chen, H.; Yang, W.; Wu, W.; Jiang, H. Palladium-catalyzed regioselective azidation of allylic C-H bonds under atmospheric pressure of dioxygen. Org. Biomol. Chem. 2014, 12, 3340. [CrossRef] [PubMed]

138. Chang, H.-M.; Cheng, C.-H. Palladium-catalyzed intermolecular carboazidation of allenes with aryl iodides and trimethylsilyl azide. J. Chem. Soc. Perkin Trans. 1 2000, 22, 3799-3807. [CrossRef]

139. Gardiner, M.; Grigg, R.; Sridharan, V.; Vicker, N. Cascade and Sequential Palladium Catalysed Cyclisation-Azide Capture-1,3-Dipolar Cycloaddition Route to Complex Triazoles. Tetrahedron Lett. 1998, 39, 435-438. [CrossRef]

140. Hurtado-Rodrigo, C.; Hoehne, S.; Muñoz, M.P. A new gold-catalysed azidation of allenes. Chem. Commun. 2014, 50, 1494-1496. [CrossRef]

141. Porta, E.O.J.; Vallejos, M.M.; Bracca, A.B.J.; Labadie, G.R. Experimental and theoretical studies of the [3,3]-sigmatropic rearrangement of prenyl azides. RSC Adv. 2017, 7, 47527-47538. [CrossRef]

142. Jabbari, A. Transition States and Activation Barriers for [3,3]-Sigmatropic Shift of Allyl Azides. Org. Chem. J. 2010, 1, 6-14.

143. Khrakovsky, D.A.; Tao, C.; Johnson, M.W.; Thornbury, R.T.; Shavick, S.L.; Toste, F.D. Enantioselectivem Stereodivrgent Hydroazidation and Hydroamination of Allenes Catalyzed by Acyclic Diaminocarbene (ADC) Gold(I) Complexes. Angew. Chem. Int. Ed. 2016, 55, 6079-6083. [CrossRef]

144. Liu, Y.; Ding, N.; Tan, X.; Li, X.; Zhao, Z. Iron(II)-chloride-catalyzed regioselective azidation of allenamides with $\mathrm{TMSN}_{3}$. Chem. Commun. 2020, 56, 7507-7510. [CrossRef]

145. Waser, J.; Nambu, H.; Carreira, E.M. Cobalt-Catalyzed Hydroazidation of Olefins: Convenient Access to Alkyl Azides. J. Am. Chem. Soc. 2005, 127, 8294-8295. [CrossRef]

146. Waser, J.; Boris, G.; Nambu, H.; Carreira, E.M. Hydrazines and Azides via the Metal-Catalyzed Hydrohydrazination and Hydroazidation of Olefins. J. Am. Chem. Soc. 2006, 128, 11693-11712. [CrossRef] [PubMed]

147. Wang, J.-J.; Yu, W. Anti-Markovnikov Hydroazidation of Alkenes by Visible-Light Photoredox Catalysis. Chem. Eur. J. 2019, 25, 3510-3514. [CrossRef] [PubMed] 
148. Shen, T.; Wang, T.; Qin, C.; Jiao, N. Silver-Catalyzed Nitrogenation of Alkynes: A Direct Approach to Nitriles through C $\equiv C$ Bond Cleavage. Angew. Chem. Int. Ed. 2013, 52, 6677-6680. [CrossRef] [PubMed]

149. Liu, Z.; Liao, P.; Bi, X. General Silver-Catalyzed Hydroazidation of Terminal Alkynes by Combining TMS-N3 and H2O: Synthesis of Vinyl Azides. Org. Lett. 2014, 16, 3668-3671. [CrossRef]

150. Liu, Z.; Liu, J.; Zhang, L.; Liao, P.; Song, J.; Bi, X. Silver(I)-Catalyzed Hydroazidation of Ethynyl Carbinols: Synthesis of 2-Azidoallyl Alcohols. Angew. Chem. Int. Ed. 2014, 53, 5305-5309. [CrossRef]

151. Pal, P.; Mainkar, P.S.; Nayani, K.; Chandrasekhar, S. Mn-catalyzed radical initiated domino transformation of alkynylated cyclohexadienones with $\mathrm{TMSN}_{3}$ and $\mathrm{O}_{2}$ to bicyclic azido alcohols. Chem. Commun. 2020, 56, 3453-3456. [CrossRef]

152. Sawama, Y.; Sawama, Y.; Krause, N. Highly Regioselective Gold-Catalyzed Ring-Opening Allylation and Azidation of Dihydrofurans. Org. Lett. 2009, 11, 5034-5037. [CrossRef]

153. Sawama, Y.; Shibata, K.; Sawama, Y.; Takubo, M.; Monguchi, Y.; Krause, N.; Sajiki, H. Iron-Catalyzed Ring-Opening Azidation and Allylation of O-Heterocycles. Org. Lett. 2013, 15, 5282-5285. [CrossRef]

154. Ren, R.; Zhao, H.; Huan, L.; Zhu, C. Manganese-Catalyzed Oxidative Azidation of Cyclobutanols: Regiospecific Synthesis of Alkyl Azides by C-C Bond Cleavage. Angew. Chem. Int. Ed. 2015, 54, 12692-12696. [CrossRef]

(C) 2020 by the authors. Licensee MDPI, Basel, Switzerland. This article is an open access article distributed under the terms and conditions of the Creative Commons Attribution (CC BY) license (http://creativecommons.org/licenses/by/4.0/). 